\title{
Validation of version-4.61 methane and nitrous oxide observed by MIPAS
}

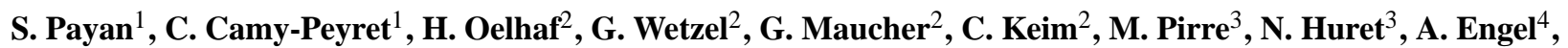 \\ M. C. Volk ${ }^{4}$, H. Kuellmann ${ }^{5}$, J. Kuttippurath ${ }^{5, *}$, U. Cortesi ${ }^{6}$, G. Bianchini ${ }^{6}$, F. Mencaraglia ${ }^{6}$, P. Raspollini ${ }^{6}$, \\ G. Redaelli $^{7}$, C. Vigouroux ${ }^{8}$, M. De Mazière ${ }^{8}$, S. Mikuteit ${ }^{2}$, T. Blumenstock ${ }^{2}$, V. Velazco ${ }^{5}$, J. Notholt ${ }^{5}$, E. Mahieu ${ }^{9}$, \\ P. Duchatelet ${ }^{9}$, D. Smale ${ }^{10}$, S. Wood $^{10}$, N. Jones ${ }^{11}$, C. Piccolo ${ }^{12}$, V. Payne ${ }^{13}$, A. Bracher ${ }^{5}$, N. Glatthor ${ }^{2}$, G. Stiller ${ }^{2}$, \\ K. Grunow ${ }^{14}$, P. Jeseck ${ }^{1}$, Y. Te ${ }^{1}$, and A. Butz ${ }^{15}$ \\ ${ }^{1}$ Laboratoire de Physique Moléculaire pour l'Atmosphère et l'Astrophysique, Université Pierre et \\ Marie Curie-Paris 6, Paris, France \\ ${ }^{2}$ Institut für Meteorologie und Klimaforschung, Forschungszentrum Karlsruhe, Karlsruhe, Germany \\ ${ }^{3}$ Laboratoire de Physique et Chimie de l'Environnement/CNRS, Orléans, France \\ ${ }^{4}$ Institut für Atmosphäre und Umwelt, J. W. Goethe Universität Frankfurt, Frankfurt, Germany \\ ${ }^{5}$ Institute of Environmental Physics/Institute of Remote Sensing, University of Bremen, Bremen, Germany \\ ${ }^{6}$ Istituto di Fisica Applicata "Nello Carrara", Sesto Fiorentino, Italy \\ ${ }^{7}$ Università di L'Aquila, Dipartimento di Fisica, L'Aquila, Italy \\ ${ }^{8}$ Belgian Institute for Space Aeronomy, Brussels, Belgium \\ ${ }^{9}$ Institut d'Astrophysique et de Géophysique, University of Liège (ULg), Liège, Belgium \\ ${ }^{10}$ National Institute for Water and Atmospheric Research (NIWA), Lauder, Otago, New Zeeland \\ ${ }^{11}$ University of Wollongong, Wollongong, Australia \\ ${ }^{12}$ Atmospheric, Oceanic and Planetary Physics, Department of Physics, Oxford University, Oxford, UK \\ ${ }^{13}$ Atmospheric and Environmental Research, Inc, Lexington, Massachusetts, USA \\ ${ }^{14}$ Meteorologisches Institut der FU Berlin, Berlin, Germany \\ ${ }^{15}$ Institut für Umweltphysik, University of Heidelberg, Germany \\ *now at: Laboratoire de Météorologie Dynamique, Ecole Polytechnique, Palaiseau, France
}

Received: 18 June 2007 - Published in Atmos. Chem. Phys. Discuss.: 17 December 2007

Revised: 13 October 2008 - Accepted: 27 October 2008 - Published: 19 January 2009

\begin{abstract}
The ENVISAT validation programme for the atmospheric instruments MIPAS, SCIAMACHY and GOMOS is based on a number of balloon-borne, aircraft, satellite and ground-based correlative measurements. In particular the activities of validation scientists were coordinated by ESA within the ENVISAT Stratospheric Aircraft and Balloon Campaign or ESABC. As part of a series of similar papers on other species [this issue] and in parallel to the contribution of the individual validation teams, the present paper provides a synthesis of comparisons performed between MIPAS $\mathrm{CH}_{4}$ and $\mathrm{N}_{2} \mathrm{O}$ profiles produced by the current ESA operational software (Instrument Processing Facility version
\end{abstract}

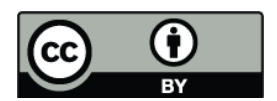

Correspondence to: S. Payan (sebastien.payan@upmc.fr)
4.61 or IPF v4.61, full resolution MIPAS data covering the period 9 July 2002 to 26 March 2004) and correlative measurements obtained from balloon and aircraft experiments as well as from satellite sensors or from ground-based instruments. In the middle stratosphere, no significant bias is observed between MIPAS and correlative measurements, and MIPAS is providing a very consistent and global picture of the distribution of $\mathrm{CH}_{4}$ and $\mathrm{N}_{2} \mathrm{O}$ in this region. In average, the MIPAS $\mathrm{CH}_{4}$ values show a small positive bias in the lower stratosphere of about 5\%. A similar situation is observed for $\mathrm{N}_{2} \mathrm{O}$ with a positive bias of $4 \%$. In the lower stratosphere/upper troposphere (UT/LS) the individual used MIPAS data version 4.61 still exhibits some unphysical oscillations in individual $\mathrm{CH}_{4}$ and $\mathrm{N}_{2} \mathrm{O}$ profiles caused by the processing algorithm (with almost no regularization). Taking

Published by Copernicus Publications on behalf of the European Geosciences Union. 
these problems into account, the MIPAS $\mathrm{CH}_{4}$ and $\mathrm{N}_{2} \mathrm{O}$ profiles are behaving as expected from the internal error estimation of IPF v4.61 and the estimated errors of the correlative measurements.

\section{Introduction}

On 1 March 2002, the Michelson Interferometer for Passive Atmospheric Sounding, MIPAS (Fischer and Oelhaf, 1996; ESA, 2000; Fischer et al., 2007), was launched on the Sun-synchronous polar-orbiting European ENVIronmental SATellite (ENVISAT). MIPAS is a Fourier transform spectrometer providing limb spectra of atmospheric infrared emission between $685 \mathrm{~cm}^{-1}(14.60 \mu \mathrm{m})$ and $2410 \mathrm{~cm}^{-1}$ $(4.15 \mu \mathrm{m})$ at a spectral unapodised resolution of $0.035 \mathrm{~cm}^{-1}$ (15 cm maximum optical path difference).

As recommended by ESA, validation results (presented and discussed during the second Atmospheric Chemistry Validation of ENVISAT workshop in May 2004 at ESRIN, Frascati, and during the first MIPAS Validation Meeting in November 2005 in Karlsruhe) had to be compared with products generated by the latest version of the operational processing software. For the MIPAS $\mathrm{CH}_{4}$ and $\mathrm{N}_{2} \mathrm{O}$ profiles discussed here, the corresponding products were generated by the Instrument Processor Facility or IPF v4.61.

A summary of MIPAS measurements, data processing, algorithm, and error budget is briefly described in Sect. 2, whereas validation experiments and analysis methods are presented in Sect. 3.

The correlative measurements for MIPAS $\mathrm{CH}_{4}$ and $\mathrm{N}_{2} \mathrm{O}$ profiles considered here (see Table 1) have been obtained by balloon experiments (Sect. 4) and by aircraft experiments (Sect. 5) participating in the ENVISAT Stratospheric Aircraft and Balloon Campaign (ESABC) coordinated by P. Wursteisen (2003).

An interesting complementary dataset allowing better statistics (but with reduced height resolution) is provided in Sect. 6 by ground-based profiles of $\mathrm{CH}_{4}$ and $\mathrm{N}_{2} \mathrm{O}$ derived by inversion of atmospheric solar absorption spectra recorded using Fourier transform infrared spectroscopy (FTIR).

A dataset with more global coverage and allowing better statistics is provided by HALOE satellite observations (Sect. 7).

Since methane and nitrous oxide are passive tracers in the lower stratosphere, the availability of simultaneous profiles of these 2 species affords the possibility of internal consistency checks by examining the corresponding $\mathrm{CH}_{4} / \mathrm{N}_{2} \mathrm{O}$ correlation plots (Sect. 8), which will be discussed in Sect. 8 for correlative balloon datasets.

Finally, in Sect. 9, with the caveat that the amount of data available for comparisons has its own limitations, some conclusions and recommendations are given.

\section{Summary of MIPAS measurements, data processing, algorithm, and error budget}

\subsection{Measurements}

The wide mid-infrared spectral region covered by MIPAS enables simultaneous observation of various trace gases. ENVISAT orbits the Earth once every $\sim 100 \mathrm{~min}$, resulting in $\sim 14$ polar orbits per day. During the original standard observation mode, which generally was the nominal one until 26 March 2004, the field-of-view is $30 \mathrm{~km}$ in the horizontal and about $3 \mathrm{~km}$ in the vertical at the tangent points. One limb scan of the standard observation mode covers the altitude range of 6-68 km in 17 steps with tangent altitude distance of $3 \mathrm{~km}$ for the 13 lower tangent altitudes, followed by tangent point around $47 \mathrm{~km}, 52 \mathrm{~km}, 60 \mathrm{~km}$ and $68 \mathrm{~km}$. These measurements cover the whole latitude band from pole to pole with 14.3 orbits per day and about 73 limb scans along one orbit.

Generation of calibrated, so-called level-1B radiance spectra is described by Nett et al. (2002) and Kleinert et al. (2007). Several data analysis schemes have been developed for near-real time and off-line retrieval of profiles of atmospheric trace species from calibrated MIPAS spectra provided by the European Space Agency (ESA) (von Clarmann et al., 2003).

During the period from mid-May until mid-October 2003 MIPAS operated quasi-continuously, with the exception of the periods 19-20 May, 25 May-4 June and 5-7 September, where no data are available. Validation of the reduced spectral resolution MIPAS data collected after 26 March 2004 is not covered in the present paper.

The $\mathrm{CH}_{4}$ and $\mathrm{N}_{2} \mathrm{O}$ distributions presented in this paper were reduced by the off-line processor under ESA responsibility (Raspollini et al., 2006).

\subsection{Error budget}

The MIPAS L2 products contain estimates of random error derived from the propagation of the radiometric noise through the retrieval. The noise itself varies with time, steadily rising between ice-decontamination periods (needed because of ice deposition on optics or detectors), but its contribution to the L2 random error also depends on the atmospheric temperature, which controls the total radiance received. Hence, for all species, the random error varies latitudinally/seasonally with atmospheric temperature, with a superimposed time dependence on ice-decontamination periods.

The main source of the random error of the ESA L2 Offline MIPAS profiles is the noise error due to the mapping of the radiometric noise on the retrieved profiles. This predicted random error is proportional to the NESR (Noise Equivalent Spectral Radiance) and inversely proportional to the Planck 
Table 1. Satellite and ground based contribution to the validation of $\mathrm{MIPAS}_{\mathrm{CH}}$ and $\mathrm{N}_{2} \mathrm{O}$ profiles.

\begin{tabular}{|c|c|c|c|c|c|}
\hline & Instrument & Flight date/campaign period & $\mathrm{CH}_{4}$ & $\mathrm{~N}_{2} \mathrm{O}$ & Latitude coverage \\
\hline \multirow{11}{*}{ 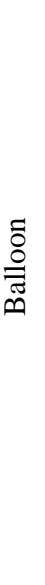 } & IBEX & 28-29 Jul 2002 & & $\sqrt{ }$ & Mid-latitude \\
\hline & TRIPLE & 24 Sep 2002 & $\sqrt{ }$ & $\sqrt{ }$ & Mid-latitude \\
\hline & & 24 Sep 2002 & $\sqrt{ }$ & $\sqrt{ }$ & Mid-latitude \\
\hline & MIPAS-B & 20/21 Mar 2003 & $\sqrt{ }$ & $\sqrt{ }$ & High latitude \\
\hline & & 3 Jul 2003 & $\sqrt{ }$ & $\sqrt{ }$ & High latitude \\
\hline & SPIRALE & 2 Oct 2002 & $\sqrt{ }$ & $\sqrt{ }$ & Mid-latitude \\
\hline & SPIKALE & 21 Jan 2003 & $\sqrt{ }$ & $\sqrt{ }$ & High latitude \\
\hline & & 4 Mar 2003 & $\sqrt{ }$ & $\sqrt{ }$ & High latitude \\
\hline & & 23 Mar 2003 & $\sqrt{ }$ & $\sqrt{ }$ & High latitude \\
\hline & LPMA & 9 Oct 2003 & $\sqrt{ }$ & $\sqrt{ }$ & Mid-latitude \\
\hline & & 24 Mar 2004 & $\sqrt{ }$ & $\sqrt{ }$ & High latitude \\
\hline \multirow{4}{*}{ 莺 } & MIPAS-STR & 22 Jul 2002 & $\sqrt{ }$ & $\sqrt{ }$ & Mid-latitude \\
\hline & & 28 Feb to 16 Mar 2003 & $\sqrt{ }$ & $\sqrt{ }$ & High latitude \\
\hline & ASUR & 14 flights from Oct 2002 to Mar 2003 & & $\sqrt{ }$ & Low, mid and high latitudes \\
\hline & SAFIRE-A & 24 Oct 2002 & & $\sqrt{ }$ & Mid-latitudes \\
\hline \multirow{2}{*}{ 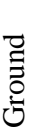 } & NDSC-FTIR & From $2002-07-06$ to $2004-03-26$ & $\sqrt{ }$ & $\sqrt{ }$ & High latitudes \\
\hline & NDSC-FTIR & From $2002-07-06$ to $2004-03-26$. & $\sqrt{ }$ & $\sqrt{ }$ & Mid and high latitudes \\
\hline 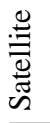 & HALOE & From 22 Jul to 24 Mar 2004 & $\sqrt{ }$ & & Mid and high latitudes \\
\hline
\end{tabular}

function (therefore atmospheric temperature), but it does not directly depend on the VMR of the gases.

In the ESA retrieval processing, first, temperature and tangent pressure are retrieved simultaneously, before the 6 "key species" $\left(\mathrm{H}_{2} \mathrm{O}, \mathrm{O}_{3}, \mathrm{HNO}_{3}, \mathrm{CH}_{4}, \mathrm{~N}_{2} \mathrm{O}, \mathrm{HNO}_{3}\right.$, and $\left.\mathrm{NO}_{2}\right)$ VMR profiles are retrieved individually in sequence. The effects of temperature and pressure errors on the VMR retrievals are taken into account in the predicted error estimation (see Piccolo and Dudhia, 2007, for details).

The MIPAS noise error is available as covariance matrices included as part of the MIPAS level 2 products. The systematic errors are described in Dudhia et al. (2002) and can be find in the Oxford web page (www.atm.ox.ac.uk/group/ mipas/err) where errors are divided into purely systematic errors with random variability and in purely systematic errors, with one exception: the altitude shift has been taken as a systematic error with random variability.

The total error is the root sum square of systematic error and random error components. The random errors take into account the propagation of instrument noise through the re- trieval. The definition of systematic error here includes everything which is not propagation of the random instrument noise through the retrieval. However, using these errors in a statistically correct manner for comparisons with other measurements is not straightforward. Each systematic error has its own length/time scale: on shorter scales it contributes to the bias and on longer scales contributes to the standard deviation of the comparison. Fortunately, two of the larger systematic errors (propagation of error due to pressure and temperature retrieval, and spectroscopic database errors) can be treated properly. The $\mathrm{p} / \mathrm{T}$ propagation error is uncorrelated between any two MIPAS profiles (since it is just the propagation of the random component of the $\mathrm{p} / \mathrm{T}$ retrieval error through the VMR retrieval). Spectroscopic database errors are constant but of unknown sign, so will always contribute to the bias of any comparison. Of the other significant errors, the calibration-related errors should, in principle, be uncorrelated between calibration cycles. However analysis of the residuals suggests that these errors are almost constant and could be included in the bias. Figure 1 presents for $\mathrm{CH}_{4}$ and 

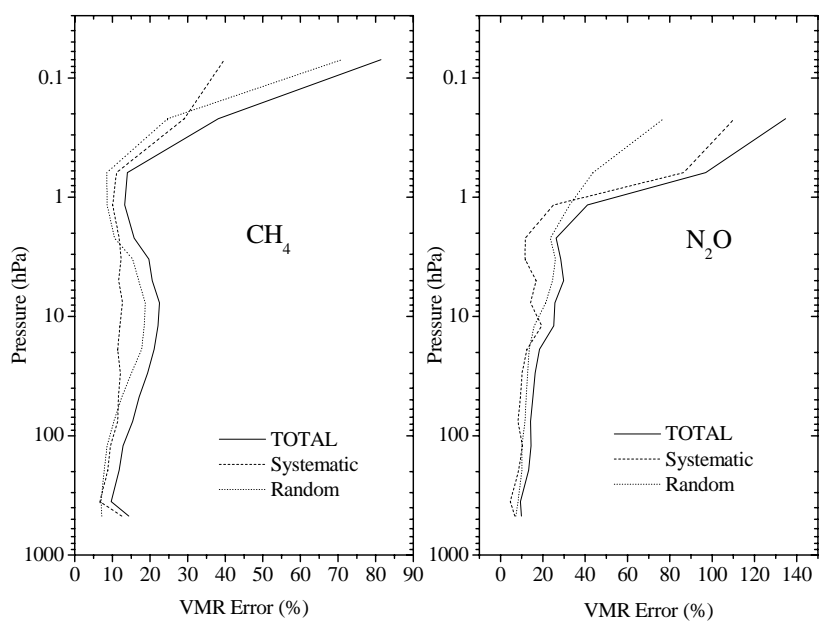

Fig. 1. Random, systematic and total errors for the nominal sets of microwindows used in off-line processing in normal MIPAS operations for $\mathrm{CH}_{4}$ (left panel) and $\mathrm{N}_{2} \mathrm{O}$ (right panel), and for a global composite of results for the five reference atmospheres, with twice the weight given to results from the polar winter case.

for $\mathrm{N}_{2} \mathrm{O}$ the vertical distribution of random, systematic and total errors for a global composite of the five reference atmospheres, with twice the weight given to results from the polar winter case (see Piccolo and Dudhia, 2007, for details).

\section{Validation experiments and analysis methods}

The correlative measurements for MIPAS $\mathrm{CH}_{4}$ and $\mathrm{N}_{2} \mathrm{O}$ profiles considered here (see Table 1) have been obtained from a large number of in situ and remote sensing instruments carried out from ground, balloon, aircraft and satellite platforms participating in the ENVISAT Stratospheric Aircraft and Balloon Campaign (ESABC) coordinated by (Wursteisen, 2003) (see Table 1 for dates).

The coincidence criteria recommended for the intercomparison were set to $300 \mathrm{~km}$ and $3 \mathrm{~h}$. However, some individual research groups involved in the validation work presented here have used more relaxed criteria whenever justified on the basis of previous experiences. A representation of $\mathrm{CH}_{4}$ and $\mathrm{N}_{2} \mathrm{O}$ volume mixing ratio (VMR) vertical profiles versus pressure rather than altitude has been adopted. Another requirement to be considered for intercomparison of polar winter measurements has been a recommended maximum potential vorticity (PV) difference of: $\Delta \mathrm{PV} / \mathrm{PV}<15 \%$.

In addition, a reduction of vertical smoothing differences using averaging kernels and common a priori state are used when needed, i.e. when vertical resolution of MIPAS and correlative measurements are significantly different. When smoothing is applied for a given correlative experiment considered in this paper, information is given in the text. The methodology of Rodgers and Connor (2003) was used to convert (depending which is the highest vertical resolution instrument) the MIPAS or/and correlative experiment profiles on a common vertical (pressure) grid.

The use of trajectory calculations to increase the number of coincidences (with the same baseline collocation criteria adopted for direct coincidences) has been used.

\section{Comparison with validation balloon campaign data}

The balloon experiments for which $\mathrm{CH}_{4}$ and/or $\mathrm{N}_{2} \mathrm{O}$ profiles (as well as the corresponding MIPAS data) were available, include FTIR remote sensing instruments operating in limb thermal emission such as IBEX (Bianchini et al., 2003) in the far-infrared and MIPAS-B (Friedl-Vallon et al., 2004) or in solar occultation such as LPMA (Camy-Peyret et al., 1995) as well as in situ samplers such as the Bonbon cryosampler (Engel et al., 1998) and in situ diode laser spectrometers such as SPIRALE (Moreau et al., 2005). They are discussed in sequence, a priority being given to the balloon experiments of the 2002 campaigns for which IPF v4.61 MIPAS $\mathrm{CH}_{4}$ and $\mathrm{N}_{2} \mathrm{O}$ profiles are available.

\subsection{IBEX}

The IBEX (Infrared Balloon Experiment, Istituto di Fisica Applicata "Nello Carrara", IFAC CNR, Firenze, Italy) (Bianchini, 2003) is a far-infrared Fourier transform spectrometer, which was flown during the first campaign of ESABC from Sicily (Trapani-Milo; $38^{\circ} \mathrm{N}, 12^{\circ} \mathrm{E}$ ) over the Mediterranean to Spain on 28-29 July 2002. Because there was no coincidence between the period when IBEX was at float and an overpass of ENVISAT, the data used for comparison was taken from MIPAS limb scans performed over the Mediterranean within a \pm 1 day window covering the IBEX measurements.

The comparison with MIPAS v4.61 data is based on trajectory calculations performed by using the Global Trajectory Model of Università di L'Aquila, since no direct coincidence satisfying the standard criteria of $300 \mathrm{~km}, 3 \mathrm{~h}$ was available for the IBEX balloon flight. Figure 2 shows the mean relative difference (red crosses) for matching pairs of MIPAS and IBEX data (with forward and back-trajectories up to 4 days), along with the combined precision (blue line) and combined total (green line) errors. The data plotted in Fig. 2 show a reasonable agreement in the mid stratosphere with some dispersion of the balloon data. The MIPAS values in the very lower stratosphere present a positive bias with respect to IBEX values.

\subsection{MIPAS-B}

ENVISAT validation flights were carried out with the cryogenic Fourier transform infrared spectrometer MIPAS-B, the balloon-borne version of MIPAS, from Aire-sur-l'Adour (France, $44^{\circ} \mathrm{N}$ ) on 24 September 2002, from Kiruna (Sweden, $68^{\circ} \mathrm{N}$ ) on 20/21 March 2003, and again from Kiruna 


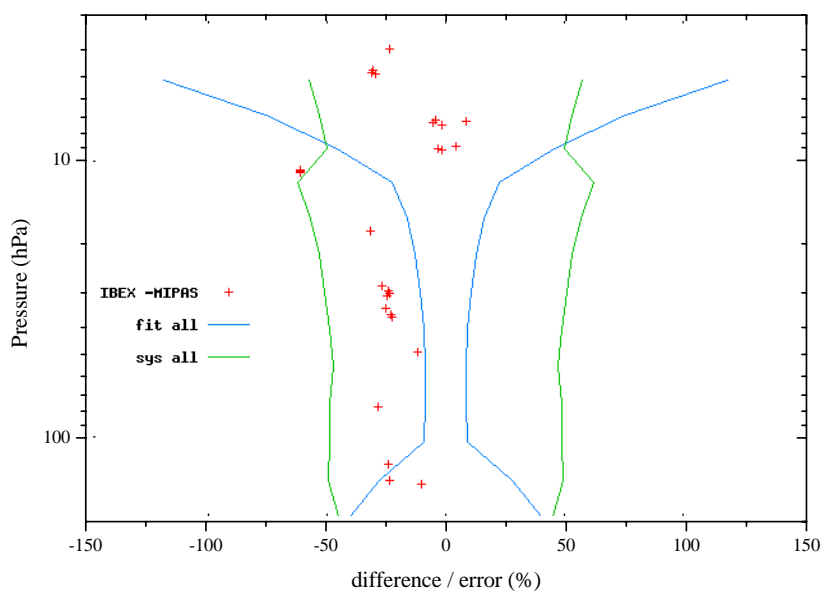

Fig. 2. Mean relative difference (red crosses) for matching pairs of MIPAS and IBEX data (with forward and back-trajectories up to 4 days), along with the combined precision (blue line) and combined total (green line) errors.

on 3 July 2003. MIPAS-B measures all atmospheric parameters that MIPAS (MIPAS-E in this section for making the distinction) is covering. Essential for the balloon instrument is the sophisticated line of sight stabilization system, which is based on an inertial navigation system and supplemented with an additional star reference system. Averaging several spectra during one single elevation angle leads to a reduction of the noise equivalent spectral radiance (NESR) and therefore to an improvement of the signal to noise ratio. The MIPAS-B data processing including instrument characterization is described in Friedl-Vallon et al. (2004) and references therein. Retrieval calculations of atmospheric target parameters were performed with a least squares fitting algorithm (using analytical derivatives) of spectra simulated by the Karlsruhe Optimized and Precise Radiative transfer Algorithm (KOPRA; Stiller et al., 2002; Höpfner et al., 2002). The resulting vertical resolution lies typically between 2 and $3 \mathrm{~km}$ and is therefore comparable to the vertical resolution of MIPAS-E. Retrieval calculations were performed in selected microwindows within the $v_{1}$ and $2 v_{2}$ bands of $\mathrm{N}_{2} \mathrm{O}$ and the $\mathrm{v}_{4}$ band of $\mathrm{CH}_{4}$. An overview on the MIPAS-B data analysis is given in Wetzel et al. (2006) and references therein.

The measurements of three MIPAS-B flights have been used in this paper: (a) Flight 11 (F11), 24 September 2002, Aire-sur-l'Adour, sequence S and N3; (b) Flight 13 (F13), 20/21 March 2003, Kiruna, sequence N3a and D15c; (c) Flight 14 (F14), 3 July 2003, Kiruna, sequence 3.

For F11 one finds two MIPAS-E comparisons (record 14 and record 15 from orbit 2975) to MIPAS-B sequence S. At low altitudes $(15 \mathrm{~km}, 120 \mathrm{hPa})$, the horizontal distance between both sensors is quite large for record 15 (ca. $460 \mathrm{~km}$ ). For F13 MIPAS-E, orbits 5508 and 5515 were used for the comparison and concerning F14 the MIPAS-E data from orbit 7004 have been compared to MIPAS-B. An

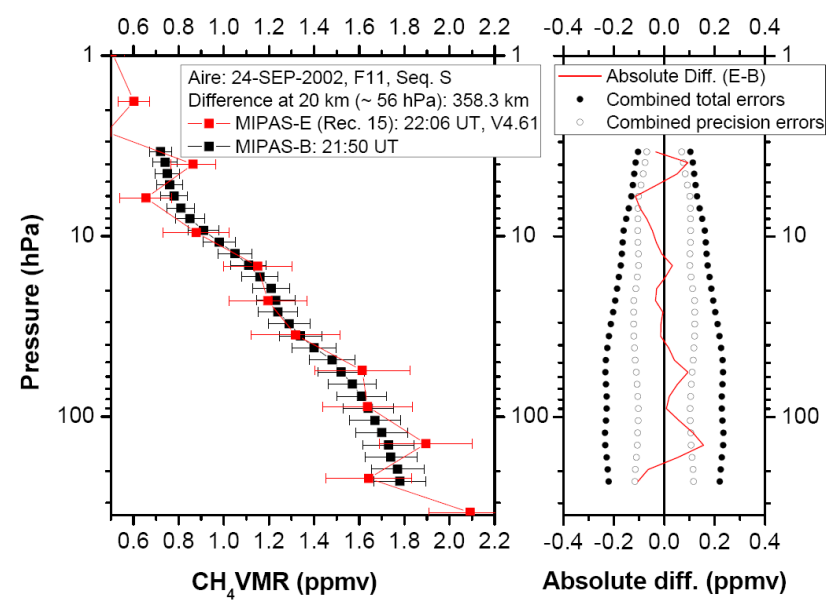

Fig. 3a. Comparison of MIPAS $\mathrm{CH}_{4}$ v4.61 profile with MIPASB on 24 September 2002 with MIPAS-B minus MIPAS-E v4.61 differences and combined error bars on the left.

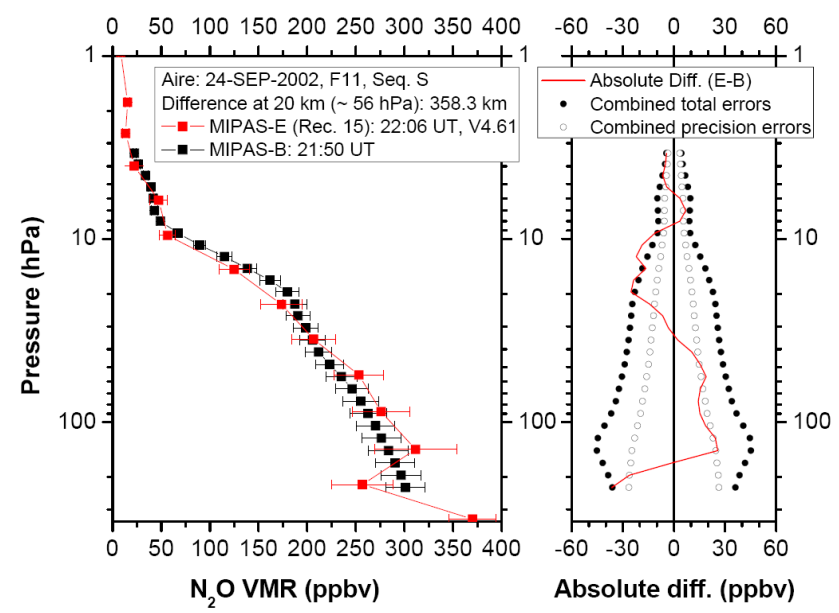

Fig. 3b. Comparison of MIPAS $\mathrm{N}_{2} \mathrm{O}$ v4.61 profile with MIPASB on 24 September 2002 with MIPAS-B minus MIPAS-E v4.61 differences and combined error bars on the left.

extremely good space and time coincidence was achieved during the MIPAS-B flight of 24 September 2002 from Airesur-l'Adour $\left(43^{\circ} \mathrm{N}, 0^{\circ} \mathrm{E}\right)$. The vertical mixing ratio profiles of $\mathrm{CH}_{4}$ and $\mathrm{N}_{2} \mathrm{O}$ and the corresponding errors are plotted as a function of pressure for the MIPAS IPF v4.61 together with the balloon profile. An example of the comparison for a single flight sequence (sequence $\mathrm{S}$ of flight 11 ) is given in Fig. $3 a$ and $b$. Oscillations are visible in the MIPAS-E profiles below $100 \mathrm{hPa}$ pressure altitude. Such oscillations were recognized in all profile comparisons between MIPAS-B and MIPAS-E.

The mean deviations between MIPAS-B and MIPAS-E for all balloon flights together are shown in Fig. $4 \mathrm{a}$ and $\mathrm{b}$. The differences MIPAS-B minus MIPAS-E v4.61 have been compared with the combined (root sum squares) error and 


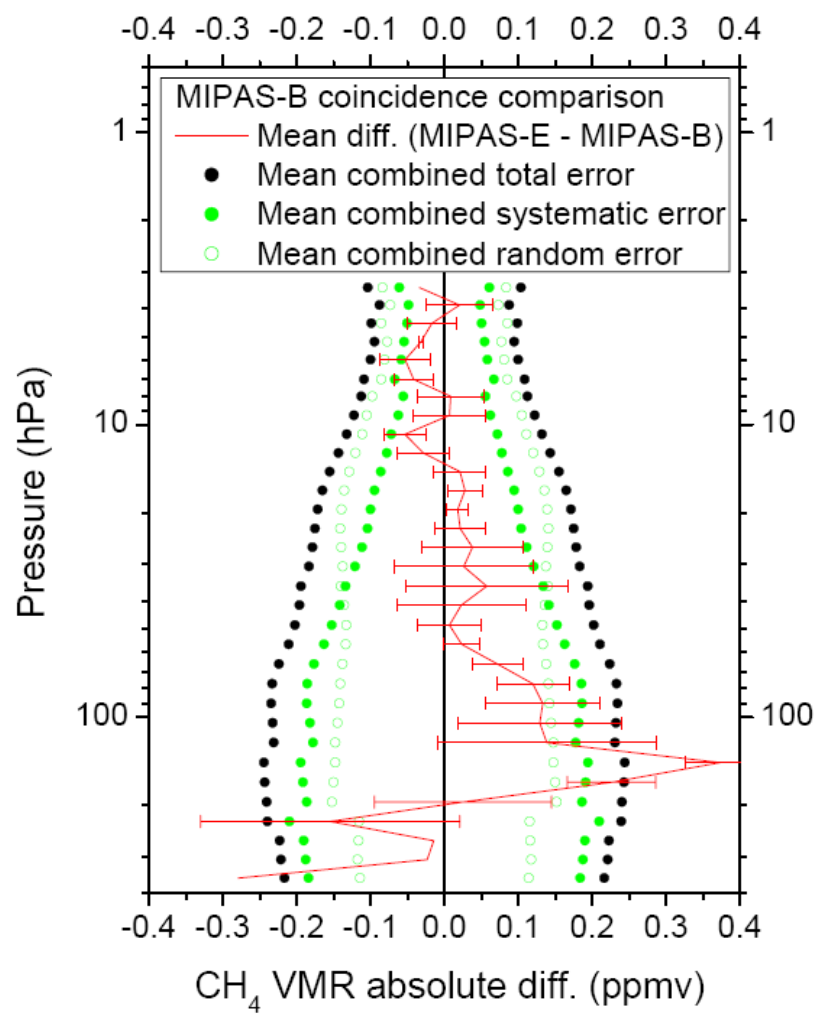

Fig. 4a. $\mathrm{CH}_{4}$ mean deviations between MIPAS-B and MIPAS-E for all MIPAS-B flights considered in this study.

demonstrate the impact of the remaining "oscillations": the mixing ratio values of MIPAS-E around 100 and $300 \mathrm{hPa}$ are clearly overestimated and underestimated, respectively for both species.

\subsection{Bonbon}

The flight of the cryosampler Bonbon (Engel et al., 1998) of Institut für Atmosphäre und Umwelt, J. W. Goethe Universität, Frankfurt, Germany, took place the same day as the MIPAS-B flight on 24 September 2002, also from Aire-surl'Adour. The v4.61 MIPAS mixing ratio profiles from $3 \mathrm{limb}$ scans are plotted as a function of altitude on the left panel of Fig. 5a and b for $\mathrm{CH}_{4}$ and $\mathrm{N}_{2} \mathrm{O}$ respectively, whereas the statistic is improved by combining five-days forward and backward trajectories "MIPAS transported" profiles (shown on the right panel) matching the cryosampler profile. The picture emerging from this comparison is consistent with previous comparison in the mid stratosphere, where MIPAS results appear to have a negative bias (in this case about $-35 \%$ between 10 and $25 \mathrm{hPa}$ ). For this intercomparison the overall agreement in the lower stratosphere for $\mathrm{CH}_{4}$ is good when using the trajectory matched profiles, but in the direct intercomparison a high bias in MIPAS $\mathrm{CH}_{4}$ values is found

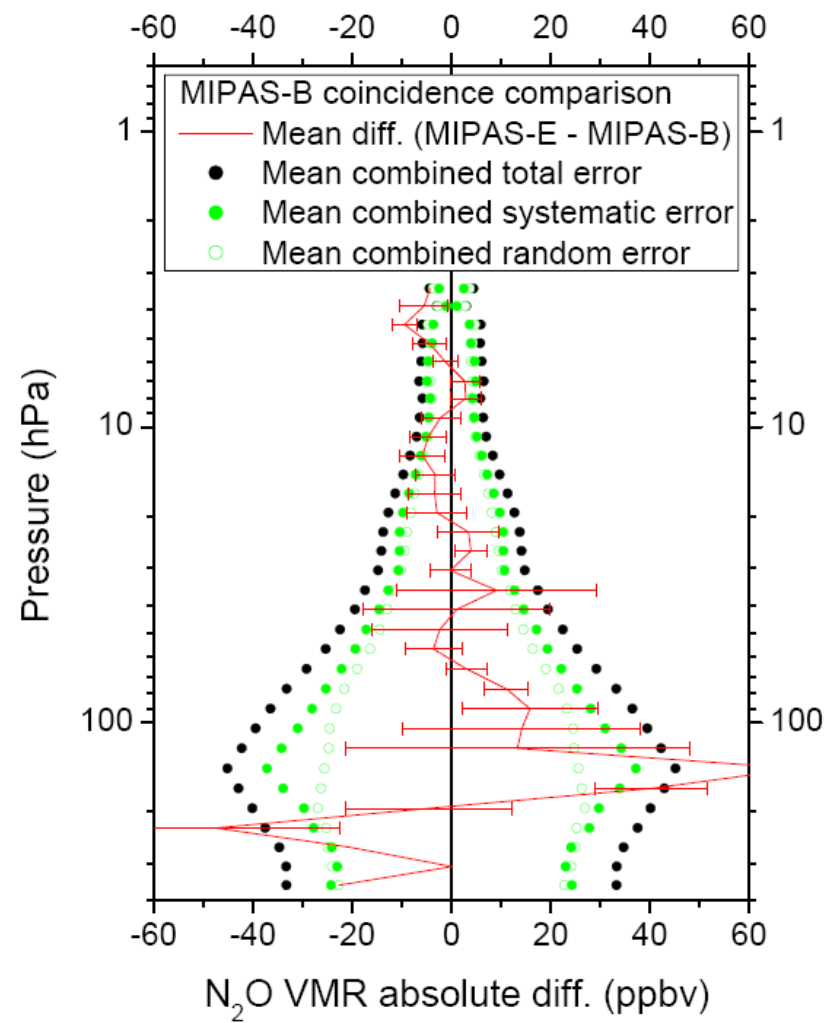

Fig. 4b. $\mathrm{N}_{2} \mathrm{O}$ mean deviations between MIPAS-B and MIPAS-E for all MIPAS-B flights considered in this study.

$\left(+10 \%\right.$ between 100 and $200 \mathrm{hPa}$ ). For $\mathrm{N}_{2} \mathrm{O}$ a low bias in MIPAS values is derived at the higher altitudes, especially when using the trajectory-matched results.

However, in the mid stratosphere, significant differences are observed between the upper parts of the $\mathrm{CH}_{4}$ and $\mathrm{N}_{2} \mathrm{O}$ profiles observed by the cryosampler and those observed by the MIPAS balloon instrument flown on the same day, indicating that the cryosampler measurements above $25 \mathrm{hPa}$ may have been influenced by specific local conditions. This is also indicated by the significant scatter between the three nearest MIPAS profiles. Note that in general the direct intercomparisons seem to give better results, indicating that trajectory matching may introduce an additional uncertainty to the intercomparison under such conditions.

\subsection{SPIRALE}

The SPIRALE instrument (Moreau et al., 2005) from Laboratoire de Physique et Chimie de l'Environnement (LPCE, Orléans, France) is a fast measurement rate in situ diode laser spectrometer. Two flights of SPIRALE took place in the framework of the ENVISAT validation, firstly at midlatitudes in the fall 2002 during the ESABC campaign from Aire-sur-l'Adour, and secondly at high latitudes on 21 January 2003 from Kiruna. For these two flights a detailed 

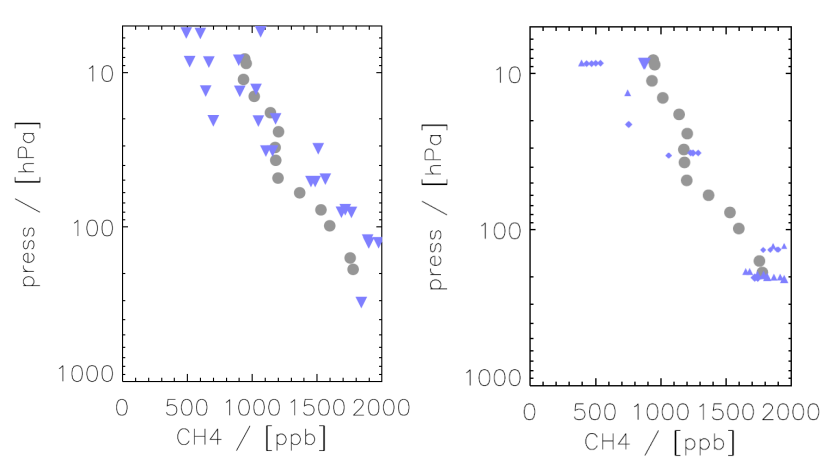

Fig. 5a. Comparison of MIPAS $\mathrm{CH}_{4}$ v4.61 profiles (blue triangles) with the Bonbon cryosampler (gray circles) on 24 September 2002. The left panel is a direct comparison with 3 nearest MIPAS profiles for the same day. The right panel displays 5 days backward and forward trajectory transported profiles matching the cryosampler profile for a larger statistics.
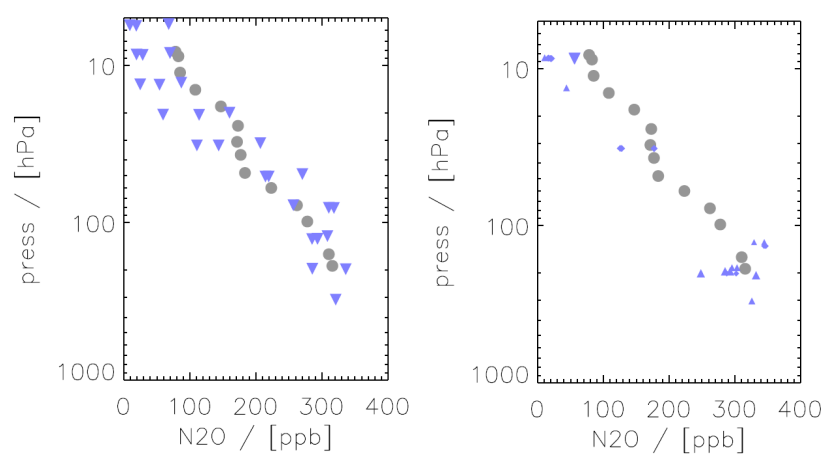

Fig. 5b. Comparison of MIPAS $\mathrm{N}_{2} \mathrm{O}$ v4.61 profiles (blue triangles) with the Bonbon cryosampler (gray circles) on 24 September 2002. The left panel is a direct comparison with 3 nearest MIPAS profiles for the same day. The right panel displays 5 days backward and forward trajectory transported profiles matching the cryosampler profile for a larger statistics.

analysis of the vertical structure of the stratosphere based on the $\mathrm{N}_{2} \mathrm{O}$ and $\mathrm{CH}_{4}$ measurements obtained has been made by Huret et al. (2006).

Figure $6 \mathrm{a}$ and $\mathrm{b}$ present the comparison of SPIRALE and MIPAS profiles, for $\mathrm{CH}_{4}$ and $\mathrm{N}_{2} \mathrm{O}$ respectively, measured on 21 January 2003. In order to take into account the large difference between SPIRALE and MIPAS vertical resolution of $150 \mathrm{~m}$ and $3 \mathrm{~km}$ respectively, the $\mathrm{CH}_{4}$ and $\mathrm{N}_{2} \mathrm{O}$ SPIRALE profiles have been smoothed using MIPAS averaging kernels. A good agreement is obtained from 180 to $26 \mathrm{hPa}$. Above $26 \mathrm{hPa}$ for $\mathrm{CH}_{4}$ the absolute difference between the two sets of data is increasing. It can be noticed that the SPIRALE instrument has intercepted a thin PV filament at $14 \mathrm{hPa}$, in this layer the volume mixing ratios of each species is enhanced (Huret et al., 2006). This thin layer is not observed by MIPAS because of its coarser vertical resolution and the MIPAS/SPIRALE comparison is not granted in this altitude range.

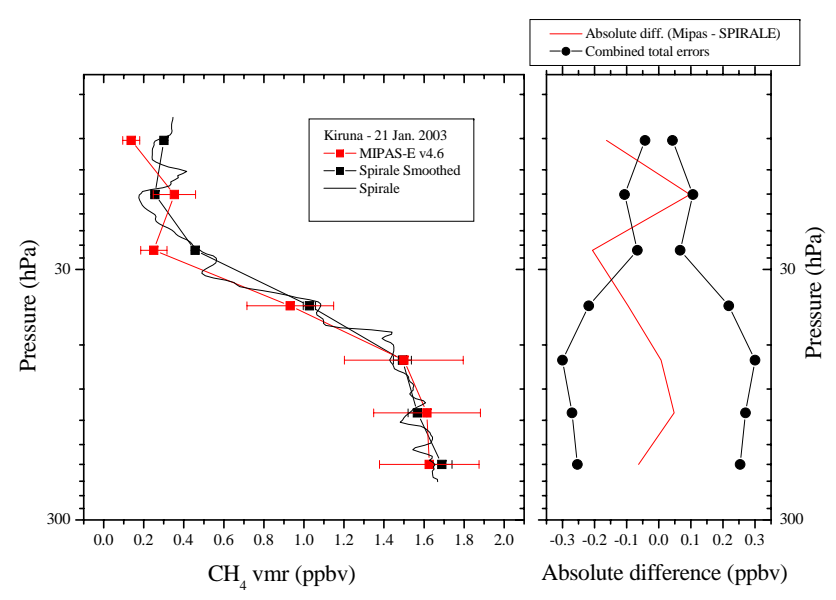

Fig. 6a. Comparison of MIPAS $\mathrm{CH}_{4}$ v4.61 profile with SPIRALE on 21 January 2003, with SPIRALE minus MIPAS v4.61 differences and combined error bars on the left.

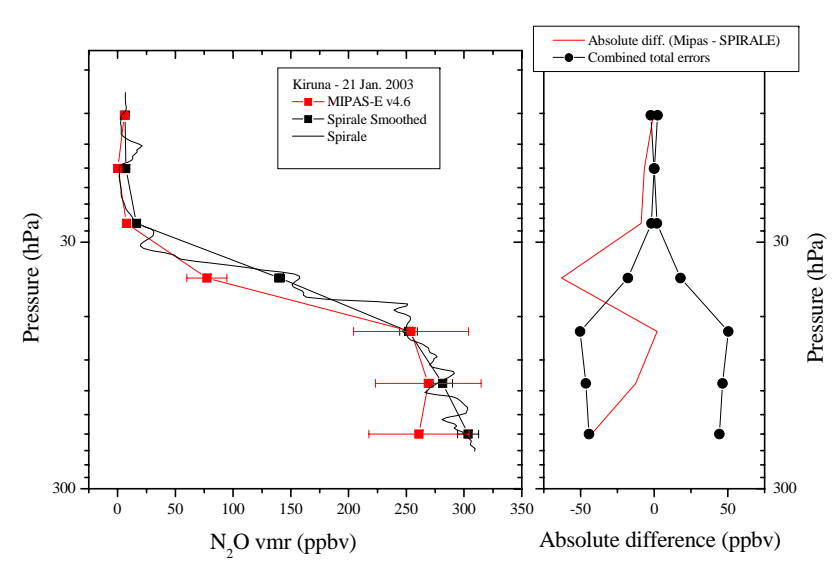

Fig. 6b. Comparison of MIPAS $\mathrm{N}_{2} \mathrm{O}$ v4.61 profile with SPIRALE on 21 January 2003, with SPIRALE minus MIPAS v4.61 differences and combined error bars on the left.

Since MIPAS was not operating on 2 October 2002 when SPIRALE was launched for its second flight, the comparison is only possible with backward trajectories starting from MIPAS measurements on 26, 27 and 28 September and ending at the SPIRALE location on 2 October. The SPIRALE flight took place in pre-vortex formation conditions when air mass exchanges between tropics regions and polar regions occur. The abundance of long lived species is largely modified by these exchanges leading in particular to nonmonotonic profiles. The origin of air masses discussed using $\mathrm{N}_{2} \mathrm{O}-\mathrm{CH}_{4}$ correlation in Huret et al. (2006) is depending on altitude. Then before comparing the MIPAS data to SPIRALE measurements the consistency of dynamical conditions using a potential vorticity analysis must be checked. This is performed with the MIMOSA PV contour advection model (Hauchecorne et al., 2002). 
CH4 02m 301914

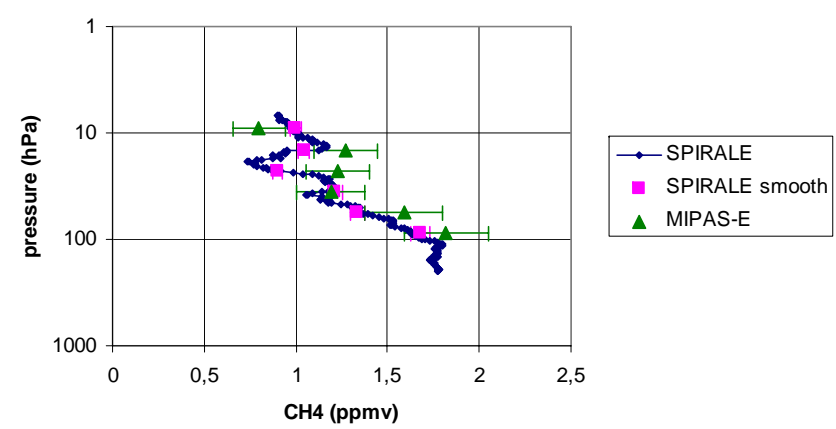

Fig. 7a. Comparison of MIPAS $\mathrm{CH}_{4}$ v4.61 profile transported to SPIRALE time and geolocation with SPIRALE on 2 October 2002.

Backward trajectories ending at the location of the SPIRALE profiles $\left(43.6^{\circ} \mathrm{N}-0^{\circ} \mathrm{E}\right)$ on 2 October 2002 (07:1508:30 UT at the ascent and 09:15-10:30 UT at the descent) have been computed as a function of potential temperature with increments of $25 \mathrm{~K}(\sim 1 \mathrm{~km})$. Profiles 14 and 15 of orbit 3019 have been shown to be the best possible profiles to be compared with SPIRALE. These profiles have been measured close to 00:00 UT on 28 September, 4.5 days before SPIRALE. Latitude and longitude of profile 14 are respectively $42^{\circ} \mathrm{N}-335^{\circ} \mathrm{E}$. Latitude and longitude of profile 15 are respectively $46.5^{\circ} \mathrm{N}-334^{\circ} \mathrm{E}$.

The distance between the points on the trajectories at the time of the MIPAS measurements is varying from $100 \mathrm{~km}$ to $2100 \mathrm{~km}$. SPIRALE data may be used to validate MIPAS if a set of trajectories ending close to each point of the SPIRALE profile $\left(+/-0.5^{\circ}\right.$ in latitude, $+/-0.5^{\circ}$ in longitude, $+/-250 \mathrm{~m}$ in altitude) obeys the two following criteria : (a) the PV is conserved on the 4.5 days which separate MIPAS and SPIRALE measurements and (b) the PV differences between MIPAS and SPIRALE on each isentropic surface is small. From this analysis we conclude that SPIRALE data may be used to validate MIPAS profile 14 of orbit 3019 for MIPAS nominal altitudes 18, 21, 24, 30 and $33 \mathrm{~km}$.

As it can be seen in Fig. 7a and b the SPIRALE instrument resolves atmospheric fine structures during ascent (or descent) of the payload and the comparison with the MIPAS values transported by trajectory mapping to the SPIRALE geolocation is within the combined errors bars (mean relative difference of $-10 \%$ ).

\subsection{LPMA}

The LPMA (Limb Profile Monitor of the Atmosphere) is a remote sensing infrared Fourier transform instrument operating in absorption using the sun (Camy-Peyret et al., 1995). Its high spectral resolution and sensitivity allow the retrieval of vertical profiles of trace species having stratospheric mixing ratios as small as $0.1 \mathrm{ppbv}$. The measurements of three flights
N2O $02 m \lcm{3019} 14$

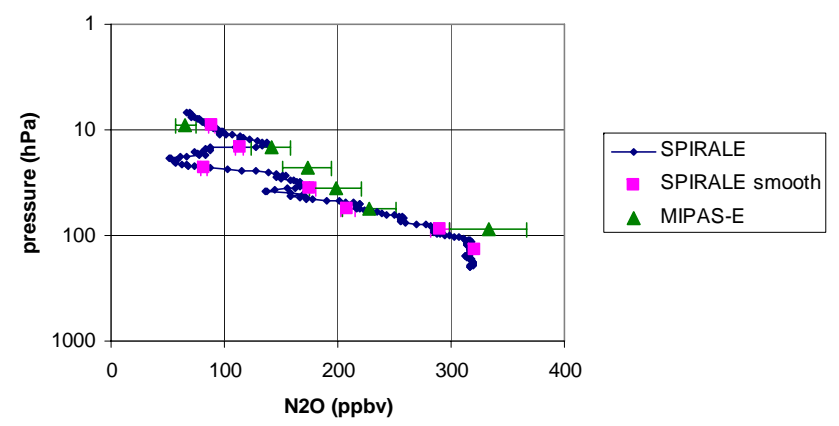

Fig. 7b. Comparison of MIPAS $\mathrm{N}_{2} \mathrm{O}$ v4.61 profile transported to SPIRALE time and geolocation with SPIRALE on 2 October 2002.

have been used for the validation of MIPAS $\mathrm{CH}_{4}$ and $\mathrm{N}_{2} \mathrm{O}$ vertical profiles. As an example of LPMA measurements, during the flight performed on 24 March 2004, the Sun was acquired above a rather elevated cloud deck at about $10 \mathrm{~km}$. The first complete interferograms (after proper setting of the gains of the preamps for each channel) have been obtained just above $10 \mathrm{~km}$. From that point on, the primary pointing system, the heliostat, the interferometer and all the ancillary equipment performed nominally during ascent, float and occultation up to loss of sun, again behind the high cloud cover ( $\sim 10 \mathrm{~km})$. The 180 recorded spectra show sufficient absorption by $\mathrm{CH}_{4}$ and $\mathrm{N}_{2} \mathrm{O}$ for precise retrieval in the appropriate microwindows. The LPMA flight observations started at 14:31 UT (the balloon was at an altitude of $10 \mathrm{~km}$ during its ascent), the $33 \mathrm{~km}$ float was reached at 16:03 UT and occultation measurements (conventionally distinguished from ascent measurements as pertaining to negative solar elevation angles) have been recorded until loss of Sun at 17:29 UT. The altitude range $12-30 \mathrm{~km}$ has been sounded during the flight.

The slant column density (SCD) retrieval of $\mathrm{N}_{2} \mathrm{O}, \mathrm{CH}_{4}$, $\mathrm{O}_{3}, \mathrm{NO}_{2}, \mathrm{NO}, \mathrm{HNO}_{3}, \mathrm{H}_{2} \mathrm{O}, \mathrm{HCl}, \mathrm{CO}_{2}$ and $\mathrm{ClONO}_{2}$ is performed simultaneously using a multi-fit of 11 microwindows. The target microwindow for $\mathrm{N}_{2} \mathrm{O}$ and $\mathrm{CH}_{4}$ are around 1240.38 to $1243.65 \mathrm{~cm}^{-1}$. In addition $\mathrm{CH}_{4}$ appears as an interfering absorber in the $\mathrm{O}_{3}, \mathrm{NO}_{2}, \mathrm{HCl}$ and $\mathrm{HNO}_{3}$ target windows whereas $\mathrm{N}_{2} \mathrm{O}$ contributes in the $\mathrm{HNO}_{3}$ target window. These contributions need to be included for a reliable SCD retrieval. Based on absorption line parameters from HITRAN 2004 (Rothman et al., 2005) and a reasonable a priori guess for the trace gas profiles, a forward model calculates synthetic spectra which are fitted to the measured ones by a non-linear Levenberg-Marquardt algorithm. The calculation of the synthetic spectra relies on atmospheric parameters taken from nearby radiosonde launches and climatological and meteorological model data. Fitting parameters include a polynomial of up to third order, a small additive wavenumber shift and several parameters to adjust the instrumental 


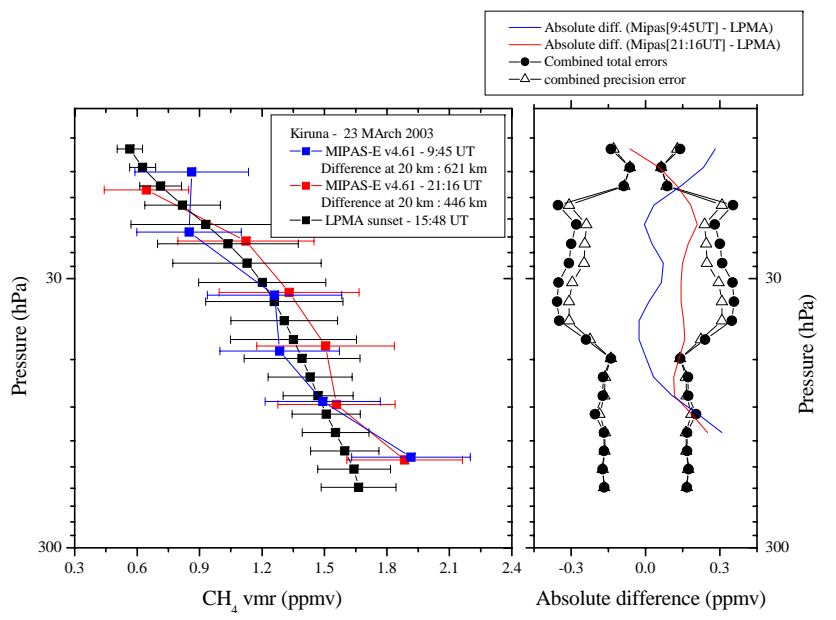

Fig. 8a. Comparison of MIPAS $\mathrm{CH}_{4}$ v4.61 profiles with LPMA on 20 March 2003, with LPMA minus MIPAS v4.61 differences and combined error bars.

line shape (ILS). All auxiliary ILS parameters are determined separately in various test runs and finally set to a fixed value for all spectra during a balloon flight.

The error bars comprise the statistical error of the fitting routine $(1 \sigma)$, the uncertainty in determining the instrumental line shape, the error coming from the ambient atmospheric parameters and their impact on the spectroscopic parameters and the stated error bars of the latter (in total $10 \%$ systematic contribution for both gases). Each spectrum yields an $\mathrm{N}_{2} \mathrm{O}$ and $\mathrm{CH}_{4} \mathrm{SCD}$ according to the specifications described above. Vertical trace gas profiles are then inferred during balloon ascent and solar occultation. For more details on LPMA retrieval and data analysis see Payan et al. $(1998,1999)$ and Dufour et al. (2005).

The vertical mixing ratio profiles of $\mathrm{CH}_{4}$ and $\mathrm{N}_{2} \mathrm{O}$ and the corresponding errors have been plotted as a function of pressure for the MIPAS IPF v4.61 together with the balloon profile. An example is given in Fig. 8a and b for flight LPMA20 taking place 20 March 2003 from Kiruna. Analysis of the set of comparisons allow to conclude that apart from the zigzagging profiles (lower stratosphere), the MIPAS profiles of $\mathrm{CH}_{4}$ and $\mathrm{N}_{2} \mathrm{O}$ agree with the LPMA profiles within the combined error bars.

\section{Comparison with simultaneous aircraft measure- ments}

Whereas balloon measurements provide trace species profiles with high vertical resolution in most of the stratosphere, their specific launch constraints and limited geographical coverage make aircraft measurements interesting especially for optimising the coincidence with MIPAS measurements from orbit, but with a limited vertical coverage of the stratosphere.

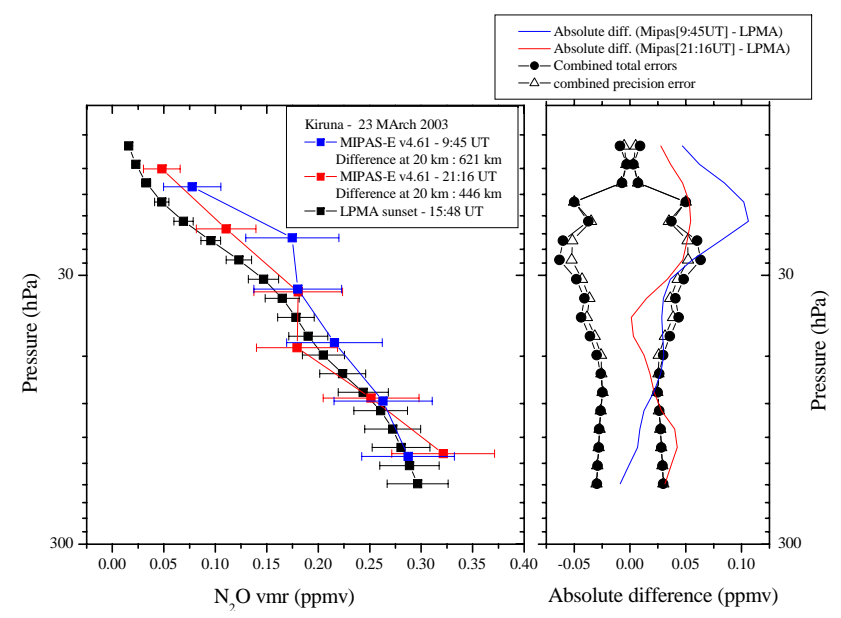

Fig. 8b. Comparison of MIPAS $\mathrm{N}_{2} \mathrm{O}$ v4.61 profiles with LPMA on 20 March 2003, with LPMA minus MIPAS v4.61 differences and combined error bars.

Three aircraft instruments providing remote sensing measurements of $\mathrm{N}_{2} \mathrm{O}$ and/or $\mathrm{CH}_{4}$ have been used within ESABC. Two of them, MIPAS-STR and SAFIRE-A, have been operated during different phases of the deployment of the M-55 Geophysica, whereas ASUR performed measurements during the SCIAVALUE (Sciamachy Validation and Utilization Experiment) campaign (Fix et al., 2005).

\subsection{In situ and remote sensing payload aboard the Geo- physica}

Within the ESABC, three campaigns have been carried out with the M55-Geophysica high altitude aircraft in midlatitude (Forlì, Italy, July and October 2002) and Arctic regions (Kiruna, Sweden, March 2003). All the flights have been planned and performed with the goal of a very good coincidence between the geolocations of MIPAS-E profiles and the profiles measured by the Geophysica payload. Profiles of $\mathrm{N}_{2} \mathrm{O}$ and/or $\mathrm{CH}_{4}$ have been measured by the in situ instrument HAGAR and the two remote sensing instruments MIPAS-STR and SAFIRE-A.

MIPAS-STR (MIPAS-STRatospheric aircraft, FZK-IMK, Karlsruhe, Germany) is a limb viewing Fourier transform spectrometer, measuring the atmospheric emission in the thermal infrared spectral region (Piesch et al., 1996; Keim et al., 2004). Its characteristics and performance is comparable to the satellite version MIPAS-E, but the vertical resolution of $2-3 \mathrm{~km}$ is only achieved up to the flight altitude of about $20 \mathrm{~km}$. The retrieval of the VMR-profiles is performed on a fixed altitude grid (steps of $0.5 \mathrm{~km}$ below $20 \mathrm{~km}$ ). For the validation purposes, at each satellite geolocation, six collocated MIPAS-STR profiles have been averaged. $\mathrm{CH}_{4}$ and $\mathrm{N}_{2} \mathrm{O}$ profiles have been determined from the measured CFC11 and CFC-12 profiles by use of the correlations measured by HAGAR. This method is preferred to the direct retrieval of 


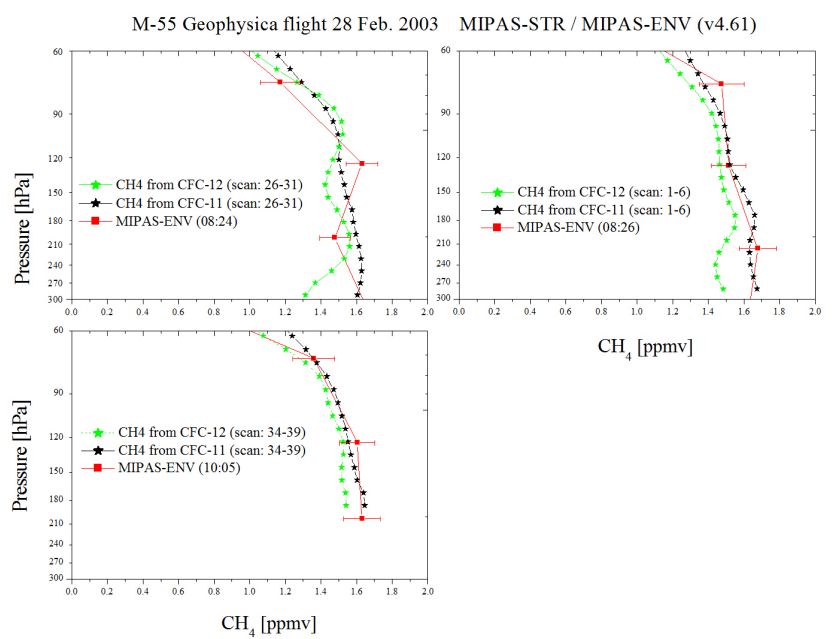

Fig. 9a. MIPAS-E $\mathrm{CH}_{4}$ profiles produced by IPR v4.61 and MIPAS-STR measurements acquired on 28 February 2003 from the M-55.

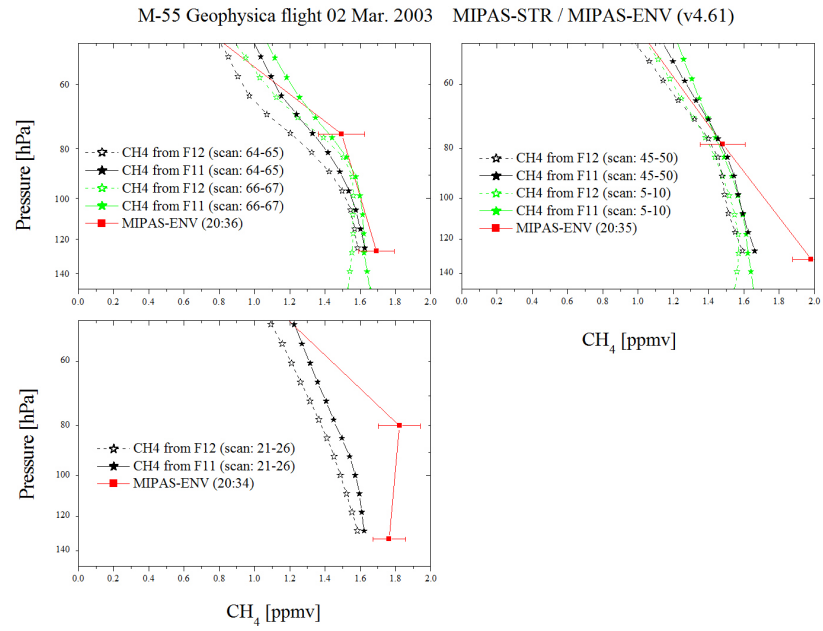

Fig. 9b. MIPAS-E $\mathrm{CH}_{4}$ profiles produced by IPR v4.61 and MIPAS-STR measurements acquired on 03 Mach 2003 from the M-55.

$\mathrm{CH}_{4} / \mathrm{N}_{2} \mathrm{O}$ from their signatures around $1300 \mathrm{~cm}^{-1}$, because the spectral regions of $\mathrm{CFC}-11$ and $\mathrm{CFC} 12$ are much less affected by continuum emission mainly due to water. The resulting total error of the $\mathrm{CH}_{4} / \mathrm{N}_{2} \mathrm{O}$ profiles is smaller with the correlation method. There are two dominating error sources in the retrieval chain. First, the error in the used temperature profile is estimated to be $2 \mathrm{~K}$, which results in an error of 5\% in CFC-11 and CFC-12. The second error source is connected to the use of HITRAN spectral line data for the radiative transfer calculation in the forward model, and this error is estimated to be below $10 \%$. Effects such as non-LTE, uncertainties in the pointing of the instrument, horizontal atmospheric inhomogeneity along the line of sight, or the error
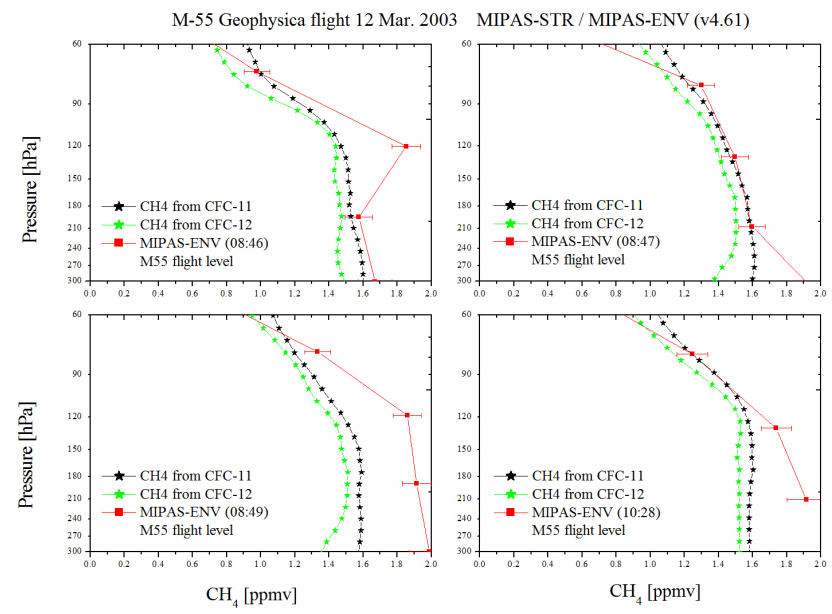

Fig. 9c. MIPAS-E $\mathrm{CH}_{4}$ profiles produced by IPR v4.61 and MIPASSTR measurements acquired on 12 March 2003 from the M-55.

of the used correlation can cause further errors, which were considered of minor importance. As the dominating error sources are independent, they sum up to below $11 \%$. The $\mathrm{CH}_{4} / \mathrm{N}_{2} \mathrm{O}$ profiles derived from the CFC-11 profiles agree within the errors with the profiles derived from CFC-12, but are significantly larger. We suppose this is due to the spectroscopic data. The $\mathrm{N}_{2} \mathrm{O}$ profiles of MIPAS-STR are plotted in Fig. 9a, b, and c as a function of tangent pressure, together with the coinciding profiles of MIPAS-E. The vertical mixing ratio profiles of $\mathrm{CH}_{4}$ are plotted in Fig. 10a, b, and c. The IPF algorithm retrieves the VMR only at given tangent altitudes. This makes regularization unnecessary. But omitting regularisation also removes the smoothing of non-physical zigzagging of the independent profile points. This zigzagging is observable in more or less all $\mathrm{N}_{2} \mathrm{O}$ and $\mathrm{CH}_{4}$ profiles. On 22 July 2002 (not presented in Figs. 9 and 10) there is an unrealistic high $\mathrm{VMR}$ at $\approx 180 \mathrm{hPa}$ in both MIPAS-E $\mathrm{N}_{2} \mathrm{O}$ profiles. The corresponding $\mathrm{CH}_{4}$ profiles of this day also have problems. Both IPF versions (v4.55 and v4.61) do indeed present "oscillations" which are not observed in the MIPAS-STR profiles. In contrast to $\mathrm{N}_{2} \mathrm{O}$, for which the profiles oscillate around the MIPAS-STR values, many of the $\mathrm{CH}_{4}$ profiles are completely different from the MIPAS-STR measurements (e.g. Fig. 9c, 12 March 2003). This kind of problems cannot be explained by the lack of regularization. Apart from the above mentioned obviously wrong profiles (outliers and zigzagging), the MIPAS-E IPR v4.61 profiles of $\mathrm{CH}_{4}$ and $\mathrm{N}_{2} \mathrm{O}$ agree with the profiles of MIPAS-STR within the combined error bars.

\subsection{SAFIRE-A}

SAFIRE-A (Spectroscopy of the Atmosphere by using FarInfrared Emission-Airborne, IFAC-CNR, Firenze, Italy) is also a limb viewing FT spectrometer, but measures the 


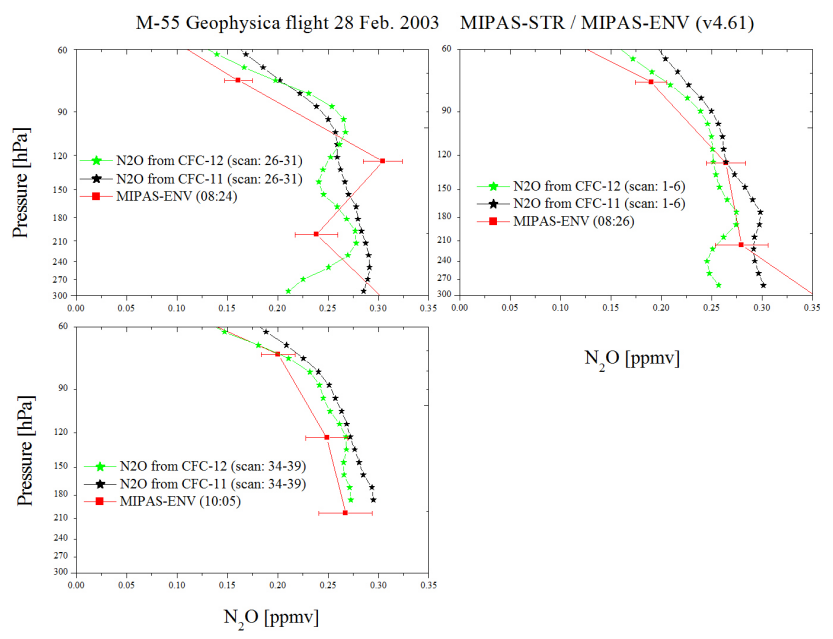

Fig. 10a. MIPAS-E $\mathrm{N}_{2} \mathrm{O}$ profiles produced by IPR v4.61 and MIPAS-STR measurements acquired on 28 February 2003 from the M-55.

far infrared $\left(10-250 \mathrm{~cm}^{-1}\right)$ atmospheric emission in narrow bands $\left(1-2 \mathrm{~cm}^{-1}\right)$. Its characteristics and performance are described by Bianchini et al. (2004).

The geolocation of the SAFIRE-A limb scans and of the corresponding MIPAS tangent points is presented in Fig. 11 for the M-55 flight of 24 October 2002, demonstrating the very good coincidence between aircraft and satellite measurements. The $\mathrm{N}_{2} \mathrm{O}$ mixing ratio values are plotted in Fig. 12 for MIPAS limb scan 15 and for the SAFIRE-A data at flight altitude. A positive bias in the MIPAS profile is clearly evident with respect to the correlative measurements. By comparing individual MIPAS $\mathrm{N}_{2} \mathrm{O}$ VMR values from scan15 with the average of SAFIRE-A measurements at the same pressure level $( \pm 10 \%)$ (SAFIRE-A data highlighted with black circles in Fig. 12), One observes a bias of MIPAS equal to $(20 \pm 4) \%$ at $90 \mathrm{hPa}$ and equal to $(36 \pm 8) \%$ at $57 \mathrm{hPa}$ with a total error on the VMR differences of $6 \%$ and $4 \%$ respectively.

\subsection{ASUR aboard the German Falcon}

ASUR is a passive heterodyne receiver operating in the frequency range of 604.3 to $662.3 \mathrm{GHz}$ (Mees et al., 1995; von Koenig et al., 2000). It is equipped with two spectrometers, an Acousto Optical Spectrometer (AOS) and a Chirp Transform Spectrometer (CTS). Stratospheric measurements performed with the AOS are used in this comparison study. The total bandwidth of the AOS is $1.5 \mathrm{GHz}$ and its resolution is $1.27 \mathrm{MHz}$. In order to avoid absorption by tropospheric water vapour, observations are carried out aboard a research airplane. The instrument looks upward at a stabilized constant zenith angle of $78^{\circ}$. ASUR measures thermal emission around rotational lines of the target molecule. The shape of the pressure broadened line is related to the vertical distribu-

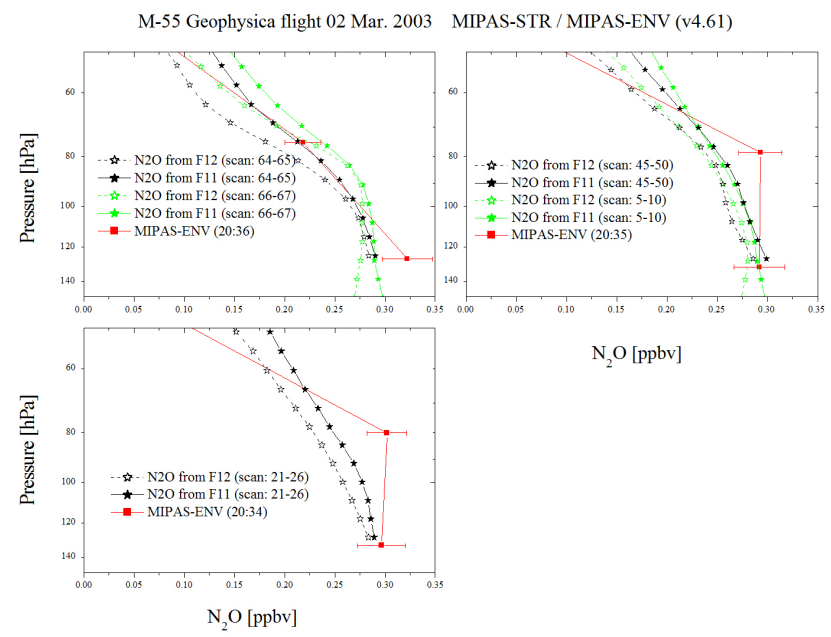

Fig. 10b. MIPAS-E $\mathrm{N}_{2} \mathrm{O}$ profiles produced by IPR v4.61 and MIPAS-STR measurements acquired on 3 March 2003 from the M55.
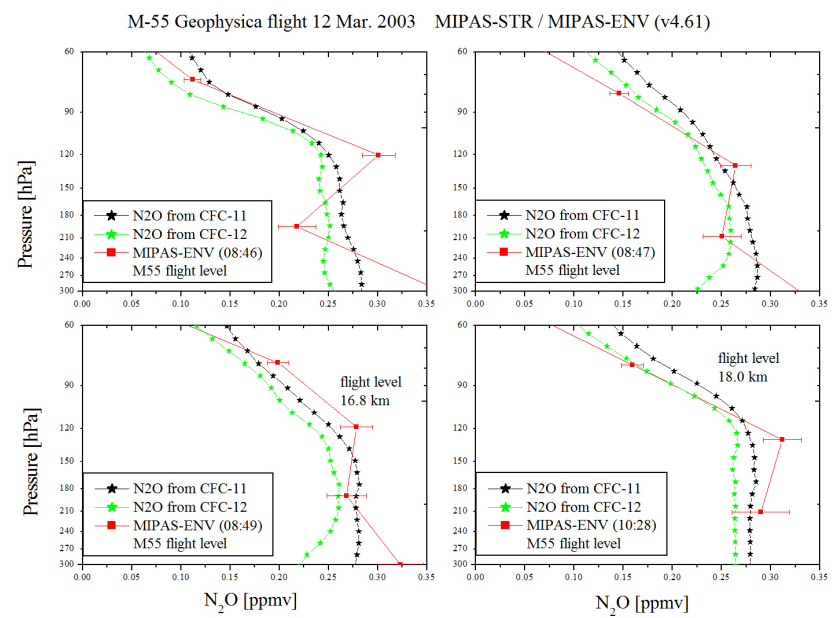

Fig. 10c. MIPAS-E $\mathrm{N}_{2} \mathrm{O}$ profiles produced by IPR v4.61 and MIPAS-STR measurements acquired on 12 March 2003 from the M-55.

tion of the trace gas. Measured spectra are integrated up to $150 \mathrm{~s}$, which leads to a horizontal resolution of about $30 \mathrm{~km}$ along the flight path. Vertical profiles of the molecule are retrieved in an equidistant altitude grid of $2 \mathrm{~km}$ spacing using the Optimal Estimation Method (Rodgers, 1976). Vertical resolution of the $\mathrm{N}_{2} \mathrm{O}$ measurements is about $8-16 \mathrm{~km}$ and vertical range is from 16 to $45 \mathrm{~km}$. The precision of a single measurement is $10 \mathrm{ppb}$ and the accuracy is $15 \%$ or $30 \mathrm{ppb}$, whichever is higher, including systematic uncertainties. Details about the measurement technique and retrieval theory can be found in Bremer et al. (2002) and in Kuttippurath (2005). 


\begin{tabular}{cc}
\multicolumn{2}{c}{ SAFIRE-A } \\
Scan \# & Mean Time \\
01 & $19: 07: 49$ \\
02 & $19: 14: 06$ \\
03 & $19: 23: 50$ \\
04 & $19: 30: 14$ \\
05 & $19: 39: 53$ \\
06 & $19: 46: 21$ \\
07 & $19: 55: 25$ \\
08 & $20: 19: 30$ \\
09 & $20: 28: 51$ \\
10 & $20: 35: 22$ \\
11 & $20: 44: 04$ \\
12 & $20: 52: 56$ \\
13 & $21: 01: 26$ \\
14 & $21: 08: 57$ \\
15 & $21: 17: 47$ \\
16 & $21: 24: 23$ \\
17 & $21: 33: 56$ \\
18 & $21: 41: 06$ \\
19 & $21: 50: 41$ \\
20 & $21: 57: 45$
\end{tabular}

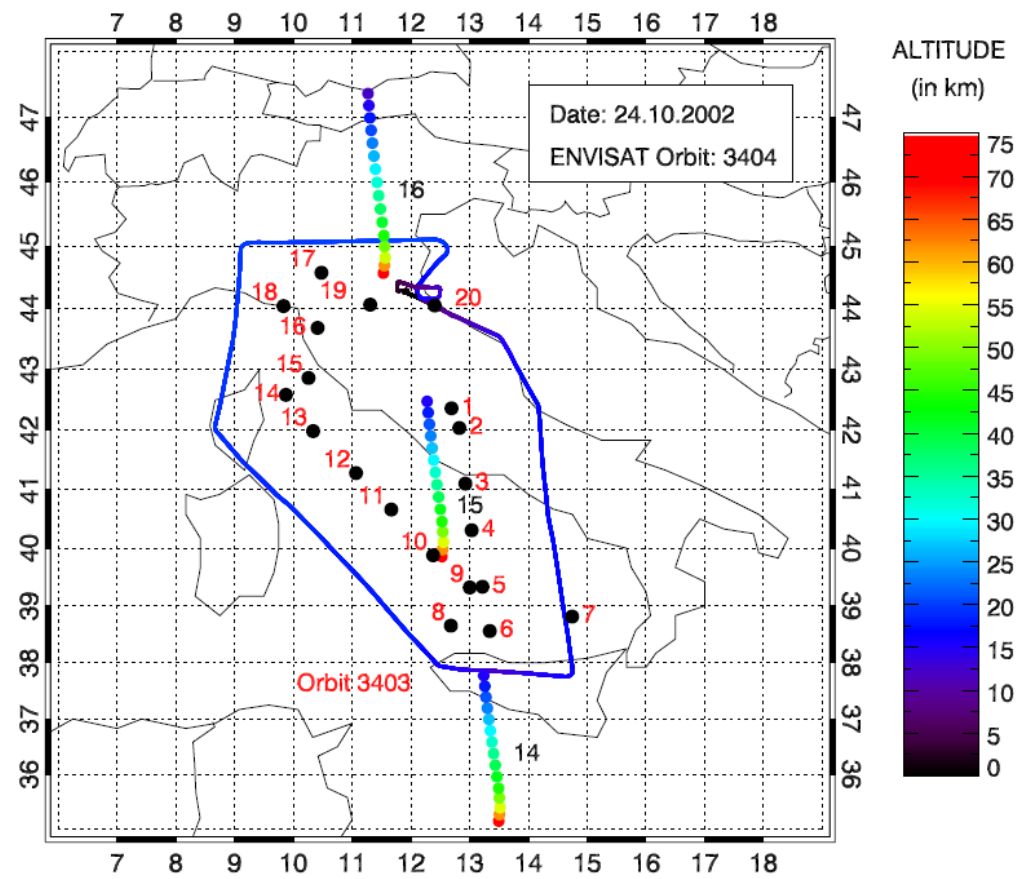

Fig. 11. M-55 Geophysica mid-latitude flight of 24 October 2002: MIPAS $\mathrm{N}_{2} \mathrm{O}$ comparison with SAFIRE-A.

Table 2. ASUR $\mathrm{N}_{2} \mathrm{O}$ measurements performed during the SCIAVALUE campaign.

\begin{tabular}{llll}
\hline No & flight date & flight path & measurement range: latitude and longitude \\
\hline 1 & $04 / 09 / 2002$ & Kiruna - Longyearbyen - Kiruna & $76.48^{\circ} \mathrm{N}, 16.41^{\circ} \mathrm{E}$ to $70.26^{\circ} \mathrm{N}, 19.79^{\circ} \mathrm{E}$ \\
2 & $17 / 09 / 2002$ & Palma de Mallorca - Yaounde & $35.32^{\circ} \mathrm{N}, 4.68^{\circ} \mathrm{E}$ to $12.44^{\circ} \mathrm{N}, 7.08^{\circ} \mathrm{E}$ \\
3 & $18 / 09 / 2002$ & Yaounde - Nairobi & $2.56^{\circ} \mathrm{N}, 16.79^{\circ} \mathrm{E}$ to $0.34^{\circ} \mathrm{S}, 33.66^{\circ} \mathrm{E}$ \\
4 & $19 / 09 / 2002$ & Nairobi - Seychelles & $3.43^{\circ} \mathrm{S}, 39.11^{\circ} \mathrm{E}$ to $4.33^{\circ} \mathrm{S}, 52.69^{\circ} \mathrm{E}$ \\
5 & $25 / 09 / 2002$ & Nairobi - Yaounde & $0.23^{\circ} \mathrm{S}, 33.33^{\circ} \mathrm{E}$ to $3.13^{\circ} \mathrm{N}, 14.25^{\circ} \mathrm{E}$ \\
6 & $26 / 09 / 2002$ & Yaounde - Palma de Mallorca & $7.50^{\circ} \mathrm{N}, 10.13^{\circ} \mathrm{E}$ to $35.28^{\circ} \mathrm{N}, 8.32^{\circ} \mathrm{E}$ \\
7 & $19 / 02 / 2003$ & Munich - Basel - Tozeur & $47.24^{\circ} \mathrm{N}, 10.04^{\circ} \mathrm{E}$ to $38.28^{\circ} \mathrm{N}, 8.91^{\circ} \mathrm{E}$ \\
8 & $24 / 02 / 2003$ & Nairobi - Mombasa - Seychelles & $4.06^{\circ} \mathrm{S}, 43.91^{\circ} \mathrm{E}$ to $4.07^{\circ} \mathrm{S}, 44.29^{\circ} \mathrm{E}$ \\
9 & $26 / 02 / 2003$ & Seychelles - Nairobi & $3.79^{\circ} \mathrm{S}, 51.96^{\circ} \mathrm{E}$ to $1.65^{\circ} \mathrm{S}, 39.03^{\circ} \mathrm{E}$ \\
10 & $28 / 02 / 2003$ & Nairobi - Douala & $0.24^{\circ} \mathrm{S}, 33.39^{\circ} \mathrm{E}$ to $3.07^{\circ} \mathrm{N}, 14.54^{\circ} \mathrm{E}$ \\
11 & $10 / 03 / 2003$ & Munich - Kiruna & $50.27^{\circ} \mathrm{N}, 10.15^{\circ} \mathrm{E}$ to $62.35^{\circ} \mathrm{N}, 15.27^{\circ} \mathrm{E}$ \\
12 & $12 / 03 / 2003$ & Kiruna - Ny-Aalesund - Kiruna & $69.53^{\circ} \mathrm{N}, 22.33^{\circ} \mathrm{E}$ to $71.56^{\circ} \mathrm{N}, 17.03^{\circ} \mathrm{E}$ \\
13 & $13 / 03 / 2003$ & Kiruna - Keflavik & $67.80^{\circ} \mathrm{N}, 14.78^{\circ} \mathrm{E}$ to $64.46^{\circ} \mathrm{N}, 17.34^{\circ} \mathrm{W}$ \\
14 & $14 / 03 / 2003$ & Keflavik - Kangerlussuaq & $66.61^{\circ} \mathrm{N}, 22.71^{\circ} \mathrm{W}$ to $66.95^{\circ} \mathrm{N}, 50.07^{\circ} \mathrm{W}$ \\
\hline
\end{tabular}

The ASUR $\mathrm{N}_{2} \mathrm{O}$ measurements performed during the SCIAVALUE (Sciamachy Validation and Utilization Experiment) campaign (Fix et al., 2005) are used here. Data from 14 selected ASUR measurement flights during the campaign are analyzed. Details about the flights are given in Table 2. A criterion that the ASUR measurements are within $+/-1000 \mathrm{~km}$ and in $+/-12 \mathrm{~h}$ around the satellite observations is chosen for the comparison between datasets. This criterion resulted in 323 coincident measurements (from 14 flights) with the IPF data. The MIPAS volume mixing ratios are convolved with the ASUR $\mathrm{N}_{2} \mathrm{O}$ averaging kernels to account for the lower vertical resolution of the ASUR profiles. The difference $\triangle \mathrm{VMR}=\mathrm{ASUR}-\mathrm{MIPAS}$ is calculated from the individual ASUR and MIPAS profiles. These delta profiles are averaged over the tropics $\left(5^{\circ} \mathrm{S}-30^{\circ} \mathrm{N}\right)$, mid-latitudes $\left(30^{\circ} \mathrm{N}-60^{\circ} \mathrm{N}\right)$, and high latitudes $\left(60^{\circ} \mathrm{N}-90^{\circ} \mathrm{N}\right)$. Results are presented for these latitude bands separately.

Figure 13 shows the results from the comparison between ASUR and IPF v4.61 profiles. There are 101 coincident measurements in the tropics, 38 in mid-latitudes and 184 in 


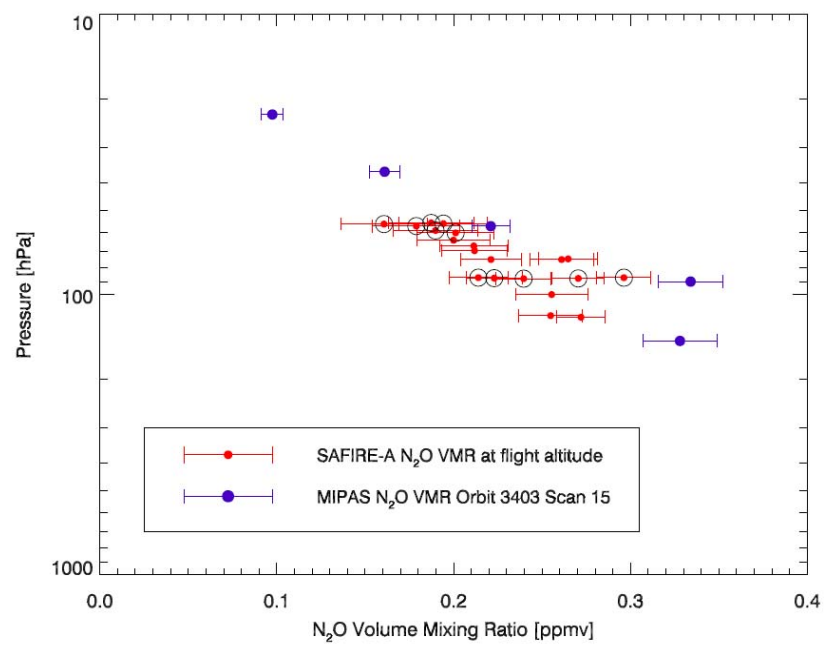

Fig. 12. Comparison of ENVISAT orbit 3403, MIPAS scan $15 \mathrm{~N}_{2} \mathrm{O}$ VMR measurements with SAFIRE-A for 24 October 2002.

high-latitudes. The differences range from -18 to $48 \mathrm{ppb}$ in the tropics, 2 to $31 \mathrm{ppb}$ in the mid-latitudes and -10 to $13 \mathrm{ppb}$ in the high latitudes. The deviation is largest at 24-28 km altitude for all latitude bands, in which the tropical profile shows the highest deviation of about $48 \mathrm{ppb}$. It is found that the MIPAS profiles underestimate the ASUR VMRs in the altitude range $25-30 \mathrm{~km}$ and overestimate the ASUR values above $34 \mathrm{~km}$. However, agreement between the profiles appears to be very good at mid and high latitudes above $30 \mathrm{~km}$ altitude.

In comparison with the MIPAS datasets in the tropics and mid-latitudes, there seems to be a systematic difference. Temporary atmospheric variations and the reduced altitude resolution of ASUR can hardly explain these systematic deviations. Note that the $\mathrm{N}_{2} \mathrm{O}$ values in the tropical lower stratosphere retrieved from ASUR measurements seem relatively high. Comparisons with Odin/SMR have also shown this particular feature of ASUR $\mathrm{N}_{2} \mathrm{O}$ retrievals (Urban et al., 2005). However, for mid and high latitudes and for the lower values of $\mathrm{N}_{2} \mathrm{O}$, agreement between ASUR and MIPAS profiles is very good. This was also true for comparison between ASUR and SMR profiles (Urban et al., 2005). The differences in these latitude and altitude regions are well within the ASUR error bars.

\section{Comparison with ground-based measurements}

\subsection{FTIR products}

Within the framework of NDACC (Network for the Detection of Atmospheric Composition Change, former NDSC or Network for the Detection of Stratospheric Change), FTIR spectrometers are operated at various stations worldwide on a regular basis. These instruments record solar absorption

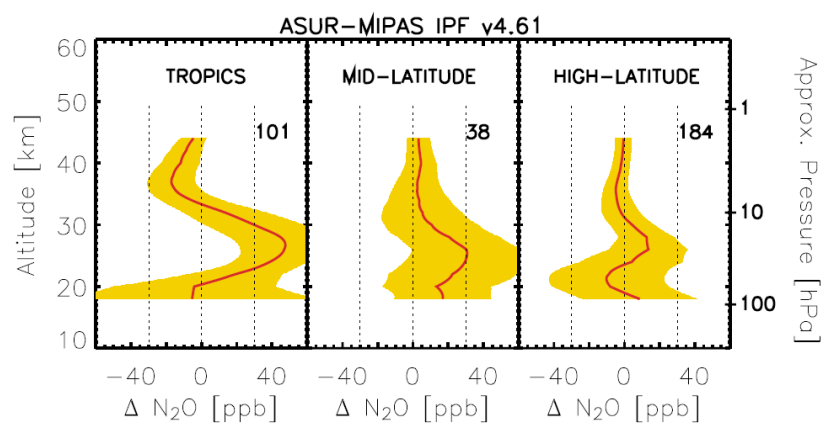

Fig. 13. Comparison of MIPAS $\mathrm{N}_{2} \mathrm{O}$ v4.61 profile with ASUR. The differences $(\triangle$ VMR $=$ ASUR VMR - MIPAS VMR) are averaged over the tropics $\left(5^{\circ} \mathrm{S}-30^{\circ} \mathrm{N}\right)$, mid-latitudes $\left(30^{\circ} \mathrm{N}-60^{\circ} \mathrm{N}\right)$, and high latitudes $\left(60^{\circ} \mathrm{N}-90^{\circ} \mathrm{N}\right)$. Shaded area is the standard deviation of the profiles averaged.

spectra from which one can retrieve the abundances of a large number of atmospheric constituents. In this work, we will present results from data recorded at $\mathrm{Ny}$-Alesund $\left(78.9^{\circ} \mathrm{N}\right.$, $11.9^{\circ} \mathrm{E}, 20 \mathrm{~m}$ a.s.1.), Kiruna $\left(67.8^{\circ} \mathrm{N}, 20.4^{\circ} \mathrm{E}, 420 \mathrm{~m}\right.$ a.s.1.), Jungfraujoch $\left(46.5^{\circ} \mathrm{N}, 8.0^{\circ} \mathrm{E}, 3580 \mathrm{~m}\right.$ a.s.l.), Wollongong $\left(34.4^{\circ} \mathrm{S}, 150.9^{\circ} \mathrm{E}, 30 \mathrm{~m}\right.$ a.s.1.), Lauder $\left(45.0^{\circ} \mathrm{S}, 169.7^{\circ} \mathrm{E}\right.$, $370 \mathrm{ma}$ a.s.1.), and Arrival Heights $\left(77.8^{\circ} \mathrm{S}, 166.7^{\circ} \mathrm{E}\right.$, $200 \mathrm{~m}$ a.s.l.). In addition to total columns, low vertical resolution profiles are retrieved from the spectra by using the Optimal Estimation Method of Rodgers (2000) in the inversion programs. For the Kiruna data, the inversion code used is PROFFIT (PROFile FIT) (Hase, 2000, 2004), based on the forward model KOPRA (Karlsruhe Optimized Precise Radiative transfer Algorithm) (Höpfner et al., 1998). For all other stations, the retrievals have been performed using the SFIT2 algorithm (Pougatchev et al., 1995a, b; Rinsland et al., 1998). The PROFFIT and SFIT2 codes have been crossvalidated successfully by Hase et al., 2004. In all cases, the synthetic spectra were calculated using daily pressure and temperature data of the National Centers for Environmental Prediction (NCEP). All retrieval parameters (spectral microwindows, spectroscopic parameters, instrumental line shape, a priori information, and model parameters) have been optimized independently for each station. For the $\mathrm{N}_{2} \mathrm{O}$ retrievals, all stations used the spectroscopic line parameters from the HITRAN 2000 database including official updates through 2001 (Rothman et al., 2003). For the $\mathrm{CH}_{4}$ retrievals, the Northern Hemisphere stations used the HITRAN 2000 database, while the Southern Hemisphere stations used the HITRAN 2004 database (Rothman et al., 2005).

Following the Optimal Estimation Method of Rodgers (2000), the FTIR retrieved state vector $\boldsymbol{x}_{r}$ is related to the true state vector $\boldsymbol{x}$ by:

$\boldsymbol{x}_{r}=\boldsymbol{x}_{a}+\boldsymbol{A}\left(\boldsymbol{x}-\boldsymbol{x}_{a}\right)+$ error terms, 
with $\boldsymbol{x}_{a}$ the a priori state vector and $\boldsymbol{A}$ the averaging kernel matrix. The FTIR products are low vertical resolution profiles. The vertical information content of the retrieved profile can be quantified by the number of degrees for signal (DOFS), which is the trace of the $\boldsymbol{A}$ matrix. The DOFS are about 3 for $\mathrm{CH}_{4}$ at all stations except Ny-Alesund (4) and about 3.6 for $\mathrm{N}_{2} \mathrm{O}$ at all the stations except $\mathrm{Ny}$-Alesund and Jungfraujoch (4.5). Thus for the comparisons with MIPAS, it is more relevant to consider a limited number of partial columns containing independent information. The lower altitude limit for the partial column comparisons is determined by the MIPAS measurements and is about $12 \mathrm{~km}$. The upper altitude limit for the comparisons is chosen taking into account the ground-based FTIR sensitivity which is reasonable up to around $30 \mathrm{~km}$ for both molecules at all stations. The DOFS within these partial columns limits are about 1.4 for $\mathrm{CH}_{4}$ at all stations except at Kiruna (1.0) and Ny-Alesund (2.0), and about 1.7 for $\mathrm{N}_{2} \mathrm{O}$ for the three Southern Hemisphere stations and 1.3, 2.3 and 2.7 for Kiruna, Ny-Alesund and Jungfraujoch, respectively .

\subsection{Comparison methodology}

In this work, the ground-based FTIR data are used to validate MIPAS ESA data v4.61 for the period when the instrument was operating at its full spectral resolution (i.e., from 6 July 2002 to 26 March 2004). The selected coincidence criteria were temporal and spatial distances of, respectively, $\pm 3 \mathrm{~h}$ and $\pm 300 \mathrm{~km}$ maximum at the MIPAS nominal tangent height of $21 \mathrm{~km}$. For Wollongong, the number of coincidences found using these criteria is very small, so the results of comparisons using relaxed coincidence criteria of $\pm 4 \mathrm{~h}$ and $\pm 400 \mathrm{~km}$ distance have been included.

When the spatial variability of the target gas is high, such as in winter-spring at high latitude stations, the standard deviations of the comparisons would become large and would not represent the agreement between both measurements. This is due to 1) the collocation error of the air masses, and 2) the horizontal smoothing error which corresponds to the gradient of the target gas within the instruments' line of sight (Cortesi et al., 2006, Sect. 4; von Clarmann et al., 2006). For the Kiruna data an additional PV criterion of $15 \%$ difference has been applied to reduce the collocation error. But, as this does not necessarily reduce the smoothing error, we decided to show also comparisons for limited time periods for which the spatial variability is smaller (summer-autumn for high latitude stations).

To avoid a possible geometric altitude error in the MIPAS data, the comparisons between MIPAS and FTIR measurements are made on a pressure grid. Each MIPAS profile $\boldsymbol{x}_{m}$ is degraded to the lower vertical resolution of the groundbased FTIR profile following Rodgers and Connor (2003):

$\boldsymbol{x}_{s}=\boldsymbol{x}_{a}+\boldsymbol{A}\left(\boldsymbol{x}_{m}-\boldsymbol{x}_{a}\right)$, with $\boldsymbol{x}_{a}$ and $\boldsymbol{A}$ the FTIR a priori profile and averaging kernel matrix, respectively, and $\boldsymbol{x}_{s}$ the smoothed MIPAS profile that is then used in the comparisons of profiles and partial columns.

The statistics of the profile and partial column comparisons are given (in percentages) in the tables and figures of the next sections. The relative differences between MIPAS and FTIR products are calculated by taking the mean absolute difference between MIPAS and FTIR data (MIPASFTIR), divided by the mean FTIR value. The means (M) of the statistical comparisons (i.e., the biases) are compared to the $3 \sigma$ standard errors on the means (SEM) to discuss their statistical significance. The SEMs are calculated as $3 \times \mathrm{STD} / \sqrt{N}, \mathrm{~N}$ being the number of coincidences, and STD the standard deviation of the differences. The precision of the instruments will also be discussed by comparing the standard deviations (STD) of the differences with the random error on the difference MIPAS-FTIR.

The random error covariance matrix $\boldsymbol{S}_{\text {diff }}$ of the difference of the profiles MIPAS-FTIR has been evaluated, using the work of Rodgers and Connor (2003) for the comparison of remote sounding instruments and of Calisesi et al. (2005) for the re-gridding between the MIPAS and FTIR data, as done in Vigouroux et al. (2007):

$$
\boldsymbol{S}_{\mathrm{diff}}=\boldsymbol{S}_{\mathrm{FTIR}}+\boldsymbol{A} \boldsymbol{W} \boldsymbol{S}_{\mathrm{MIPAS}} \boldsymbol{W}^{T} \boldsymbol{A}^{T},
$$

where $\boldsymbol{S}_{\mathrm{FTIR}}$ and $\boldsymbol{S}_{\text {MIPAS }}$ are the FTIR and MIPAS random error covariance matrices, respectively, and $\boldsymbol{W}$ a grid transformation matrix (see Calisesi et al., 2005, for details). The FTIR random error budget has been estimated for a typical measurement at Kiruna (F. Hase, pesonal communication, 2007). The dominant error sources are the measurement noise, the spectral baseline error, and the temperature profile uncertainties. The smoothing error associated to the low vertical resolution of the FTIR profiles becomes negligible in the profiles comparisons since the smoothing procedure (Eq. 1) is applied to the MIPAS profiles (Rodgers and Connor, 2003).

\section{3 $\mathrm{CH}_{4}$ comparisons}

Table 3 gives for every station, the height region of the partial columns (in pressure units), the mean (M) and the standard deviation (STD) of the partial column relative differences, along with the number $\mathrm{N}$ of coincident pairs, the estimated random error on the partial column differences and the $3 \sigma$ standard error on the mean (SEM).

It can be seen from Table 3 that there is a statistically significant positive bias in the relative differences of partial columns for all the stations except $\mathrm{Ny}$-Alesund and $\mathrm{Ar}$ rival Heights. Due to the high standard deviation at Arrival Heights during the whole period of comparison, the bias is not significant. If the comparisons are limited to the summerautumn period, the bias at Arrival Heights appears to be also significant. 
Table 3. Statistical means (M) and standard deviations (STD) of the relative differences (MIPAS-FTIR)/mean (FTIR) [\%] of the $\mathrm{CH}_{4}$ partial columns defined in the given pressure ranges. The number of coincidences $(\mathrm{N})$ within $\pm 3 \mathrm{~h}$ and $\pm 300 \mathrm{~km}$, the combined random error, and the $3 \sigma$ standard error on the bias (SEM) are also given. For Wollongong the coincidence criteria is $\pm 4 \mathrm{~h}$ and $\pm 400 \mathrm{~km}$ distance.

\begin{tabular}{|c|c|c|c|c|c|c|c|}
\hline Station & & Period & $\begin{array}{l}\text { Pressure } \\
\text { range }[\mathrm{hPa}]\end{array}$ & $\begin{array}{l}\mathrm{M} \pm \mathrm{STD} \\
{[\%]}\end{array}$ & $\begin{array}{l}\text { Random } \\
\text { error [\%] }\end{array}$ & $\mathrm{N}$ & $\begin{array}{l}\text { SEM } \\
{[\%]}\end{array}$ \\
\hline \multirow[t]{2}{*}{ Ny-Alesund } & $79^{\circ} \mathrm{N}$ & Jul 2002-Mar 2004 & $12-222$ & $+0.1 \pm 4.4$ & 4.4 & 11 & 4.0 \\
\hline & & Jul-Oct 2003 & & $-3.8 \pm 0.9$ & 3.1 & 3 & 1.6 \\
\hline \multirow[t]{2}{*}{ Kiruna } & $68^{\circ} \mathrm{N}$ & Jul 2002-Mar 2004 & $2-168$ & $+7.7 \pm 6.6$ & 3.8 & 21 & 4.3 \\
\hline & & Jul-Oct 2003 & & $+6.5 \pm 6.2$ & 3.8 & 14 & 5.0 \\
\hline Jungfraujoch & $47^{\circ} \mathrm{N}$ & Jul 2002-Mar 2004 & $6-224$ & $+14.3 \pm 4.6$ & 3.6 & 12 & 4.0 \\
\hline \multirow[t]{2}{*}{ Wollongong } & $34^{\circ} \mathrm{S}$ & Jul 2002-Mar 2004 & $9-201$ & $+14.9 \pm 5.6$ & 3.7 & 5 & 7.5 \\
\hline & & Jul 2002-Mar 2004 & & $+11.3 \pm 7.5$ & & 16 & 5.6 \\
\hline Lauder & $45^{\circ} \mathrm{S}$ & Jul 2002-Mar 2004 & $12-199$ & $+10.2 \pm 4.7$ & 3.4 & 15 & 3.6 \\
\hline \multirow{2}{*}{ Arrival Heights } & $78^{\circ} \mathrm{S}$ & Jul 2002-Mar 2004 & $13-181$ & $+5.1 \pm 15.0$ & 3.8 & 26 & 8.8 \\
\hline & & Jan-Mar 2003 & & $+5.1 \pm 4.1$ & 3.2 & 9 & 4.1 \\
\hline
\end{tabular}
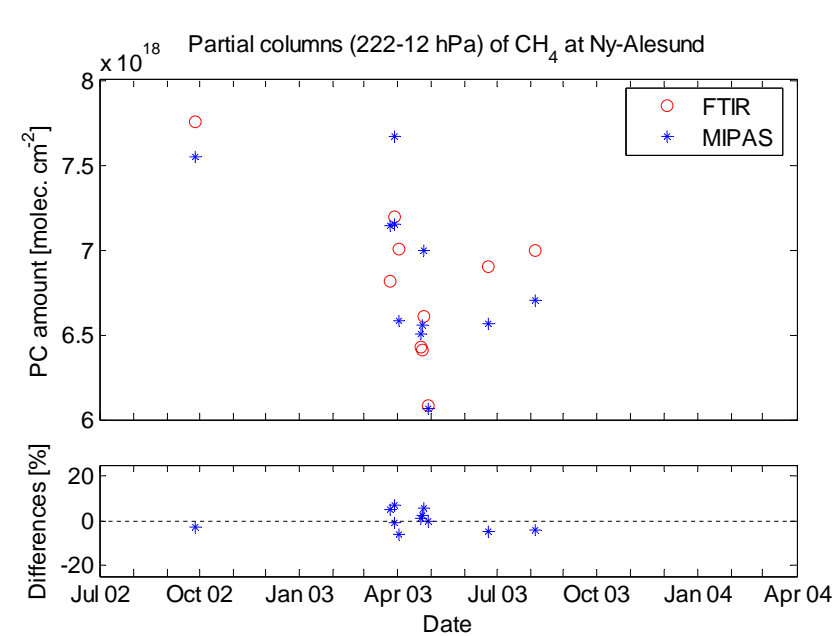

Fig. 14a. Time series of $\mathrm{CH}_{4}$ partial column comparisons. Upper panel: ground-based FTIR (circles) and MIPAS v4.61 (stars) $\mathrm{CH}_{4}$ partial columns for collocated measurements at $\mathrm{Ny}$-Alesund. Lower panel: relative differences between ground-based FTIR and MIPAS partial columns.

Figure 14a to $\mathrm{f}$ present plots of the time series of partial columns of $\mathrm{CH}_{4}$ at the six ground-based stations, together with the time series of the relative differences (MIPASFTIR)/mean (FTIR). It can be seen from these figures that the biases do not show a seasonal dependence.

Table 3 also shows that the statistical standard deviation (i.e. the dispersion) is usually slightly larger than the estimated random error which is probably due to collocation and horizontal smoothing errors. It is clear from Fig. 14a to f that the standard deviations are higher during winter-spring periods for the high latitude stations, which is confirmed by the statistics in Table 3 for reduced time periods.

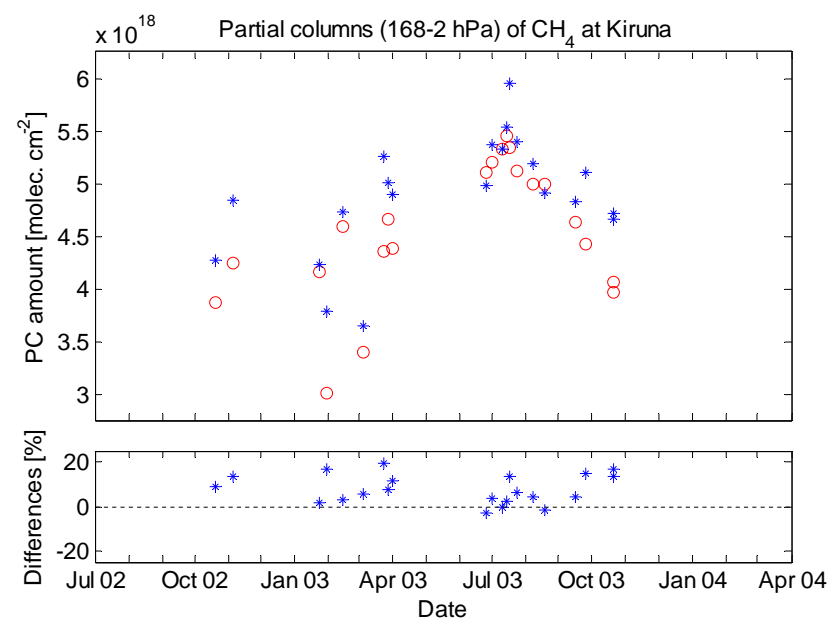

Fig. 14b. Time series of $\mathrm{CH}_{4}$ partial column comparisons. Upper panel: ground-based FTIR (circles) and MIPAS v4.61 (stars) $\mathrm{CH}_{4}$ partial columns for collocated measurements at Kiruna. Lower panel: relative differences between ground-based FTIR and MIPAS partial columns.

The $\mathrm{CH}_{4}$ difference profiles shown in Fig. 15a to $\mathrm{f}$ confirm what has been seen for the partial columns comparisons: a significant positive bias is observed at Jungfraujoch, Kiruna, Lauder and Arrival Heights in the lower stratosphere. At Wollongong, the bias is maximum in the middle stratosphere. At Ny-Alesund, no bias was seen in the partial columns. We can see, however, in Fig. 15a to $\mathrm{f}$ that a positive bias exists in the lower stratosphere but is compensated by a negative bias in the middle and upper stratosphere. These unrealistic oscillations in the difference of profiles are due to the FTIR products at Ny-Alesund. The constraints on the a priori information (Rodgers, 2000) are probably too small, leading 


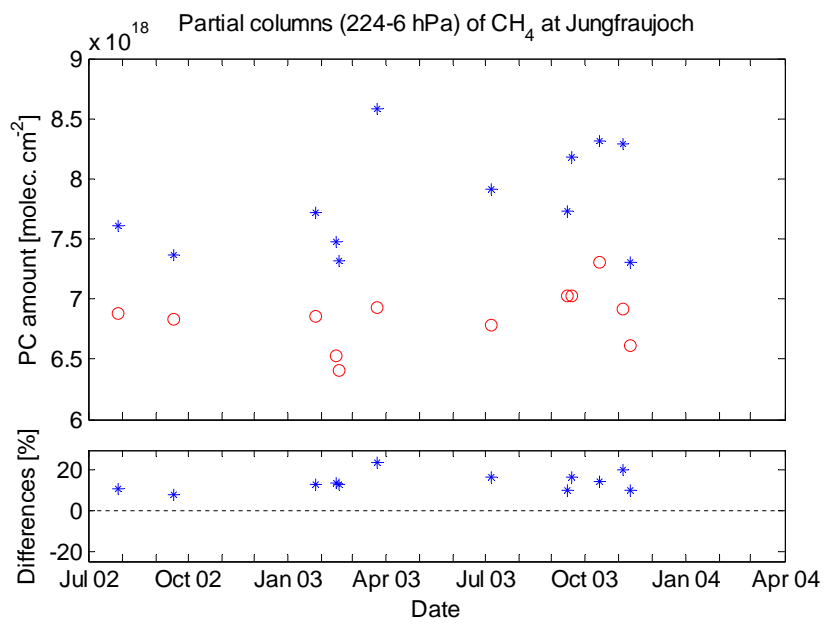

Fig. 14c. Time series of $\mathrm{CH}_{4}$ partial column comparisons. Upper panel: ground-based FTIR (circles) and MIPAS v4.61 (stars) $\mathrm{CH}_{4}$ partial columns for collocated measurements at Jungfraujoch. Lower panel: relative differences between ground-based FTIR and MIPAS partial columns.

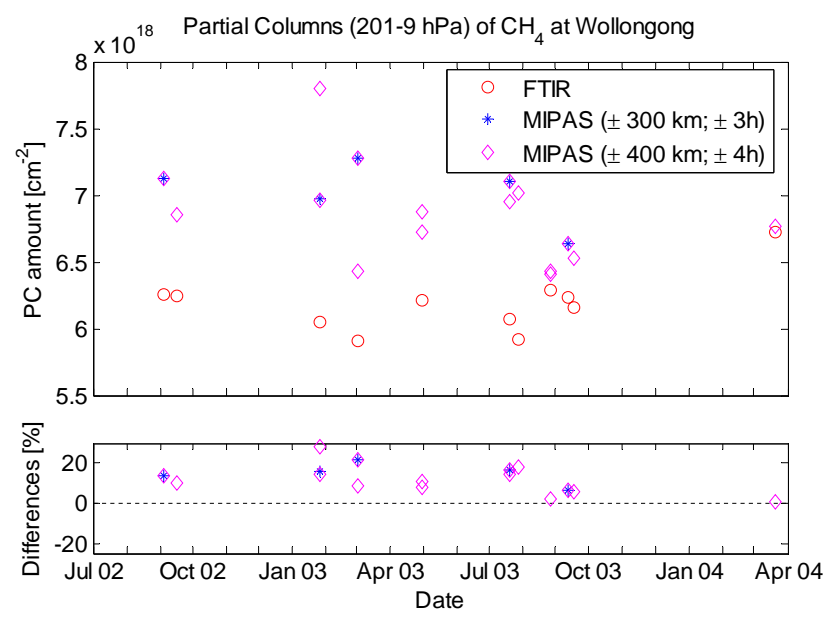

Fig. 14d. Time series of $\mathrm{CH}_{4}$ partial column comparisons. Upper panel: ground-based FTIR (circles) and MIPAS v4.61 (stars) $\mathrm{CH}_{4}$ partial columns for collocated measurements at Wollongong. Lower panel: relative differences between ground-based FTIR and MIPAS partial columns.

to oscillations in the profiles. This would also explain the larger degrees of freedom for signal at $\mathrm{Ny}$-Alesund, given in Sect. 6.1.

\section{$6.4 \quad \mathrm{~N}_{2} \mathrm{O}$ comparisons}

The FTIR datasets used here are the same ones as used already by Vigouroux et al. (2007) for the validation of MIPAS $\mathrm{N}_{2} \mathrm{O}$ v4.61 products, for all the stations except $\mathrm{Ny}$-Alesund. But the coincidence criteria were less strict, which was compensated by the use of the data assimilation system BAS-

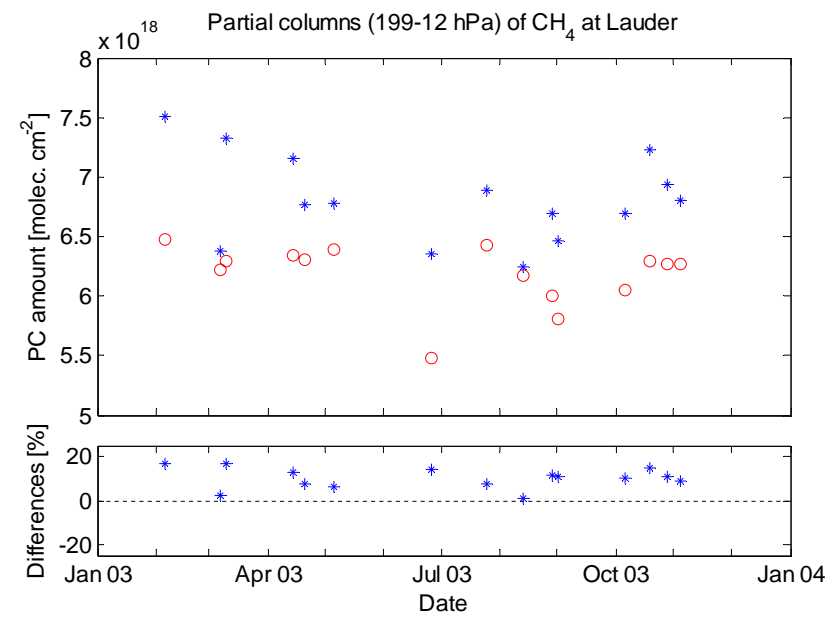

Fig. 14e. Time series of $\mathrm{CH}_{4}$ partial column comparisons. Upper panel: ground-based FTIR (circles) and MIPAS v4.61 (stars) $\mathrm{CH}_{4}$ partial columns for collocated measurements at Lauder. Lower panel: relative differences between ground-based FTIR and MIPAS partial columns.

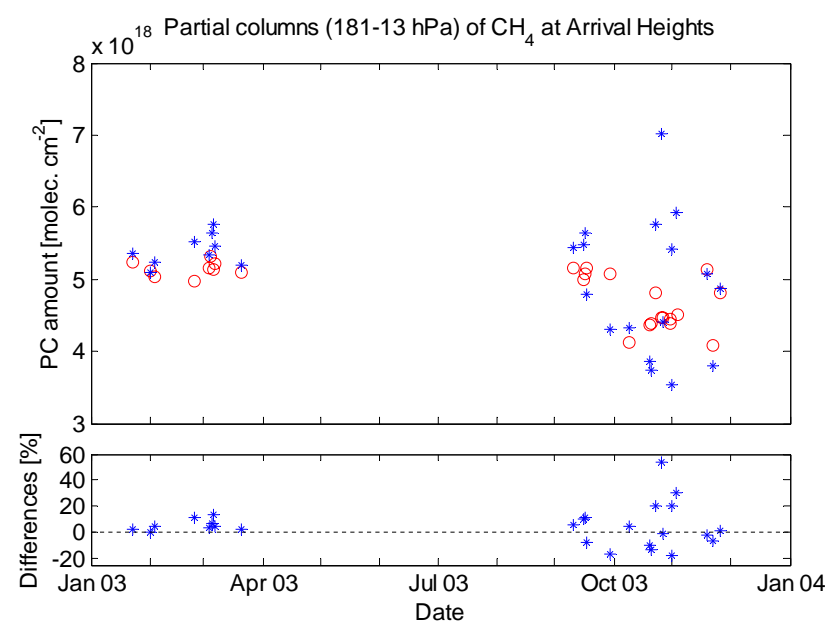

Fig. 14f. Time series of $\mathrm{CH}_{4}$ partial column comparisons. Upper panel: ground-based FTIR (circles) and MIPAS v4.61 (stars) $\mathrm{CH}_{4}$ partial columns for collocated measurements at Arrival Heights. Lower panel: relative differences between ground-based FTIR and MIPAS partial columns.

COE. Results obtained with the same criteria as adopted elsewhere in the present paper $( \pm 3 \mathrm{~h} ; \pm 300 \mathrm{~km})$ have been used.

Considering the means and their statistical $3 \sigma$ standard errors (SEM) given in Table 4, there is no statistically significant bias in the relative differences of partial columns for the Kiruna, Jungfraujoch, Wollongong, and Lauder stations. A statistically significant negative bias is seen for the highest latitude stations: Ny-Alesund $(-10.1 \%)$ and Arrival Heights $(-8.5 \%)$. For Arrival Heights, we can see in Fig. 16a to $\mathrm{f}$ and Table 4 that the bias is more pronounced during the 
Table 4. Statistical means (M) and standard deviations (STD) of the relative differences (MIPAS-FTIR)/mean (FTIR) [\%] of the $\mathrm{N}_{2} \mathrm{O}$ partial columns defined in the given pressure ranges. The number of coincidences $(\mathrm{N})$ within $\pm 3 \mathrm{~h}$ and $\pm 300 \mathrm{~km}$, the combined random error, and the $3 \sigma$ standard error on the bias (SEM) are also given. For Wollongong the coincidence criteria is $\pm 4 \mathrm{~h}$ and $\pm 400 \mathrm{~km}$ distance.

\begin{tabular}{llllllll}
\hline Station & & Period & $\begin{array}{l}\text { Pressure } \\
\text { range [hPa] }\end{array}$ & $\begin{array}{l}\text { M } \pm \text { STD } \\
{[\%]}\end{array}$ & $\begin{array}{l}\text { Random } \\
\text { error [\%] }\end{array}$ & N & $\begin{array}{l}\text { SEM } \\
{[\%]}\end{array}$ \\
\hline Ny-Alesund & $79^{\circ} \mathrm{N}$ & Jul 2002-Mar 2004 & $9-222$ & $-10.1 \pm 5.5$ & 5.9 & 9 & 5.5 \\
& & & $-10.1 \pm 2.0$ & 4.8 & 3 & 3.5 \\
Kiruna & $68^{\circ} \mathrm{N}$ & Jul 2002-Mar 2003 & $2-1684$ & $-2.3 \pm 4.0$ & 5.3 & 21 & 2.6 \\
& & Jul-Oct 2003 & & $-1.6 \pm 2.5$ & 5.3 & 14 & 2.0 \\
Jungfraujoch & $47^{\circ} \mathrm{N}$ & Jul 2002-Mar 2004 & $2-224$ & $+1.3 \pm 2.8$ & 5.0 & 12 & 2.4 \\
Wollongong & $34^{\circ} \mathrm{S}$ & Jul 2002-Mar 2004 & $12-196$ & $+8.8 \pm 8.7$ & 5.1 & 5 & 11.7 \\
& & Jul 2002-Mar 2004 & & $+4.3 \pm 6.8$ & & 18 & 5.1 \\
Lauder & $45^{\circ} \mathrm{S}$ & Jul 2002-Mar 2004 & $12-199$ & $+3.1 \pm 4.8$ & 4.9 & 15 & 3.7 \\
Arrival Heights & $78^{\circ} \mathrm{S}$ & Jul 2002-Mar 2004 & $17-181$ & $-8.5 \pm 9.1$ & 6.0 & 20 & 6.1 \\
& & Jan-Mar 2003 & & $-4.3 \pm 5.0$ & 5.1 & 8 & 5.3 \\
\hline
\end{tabular}

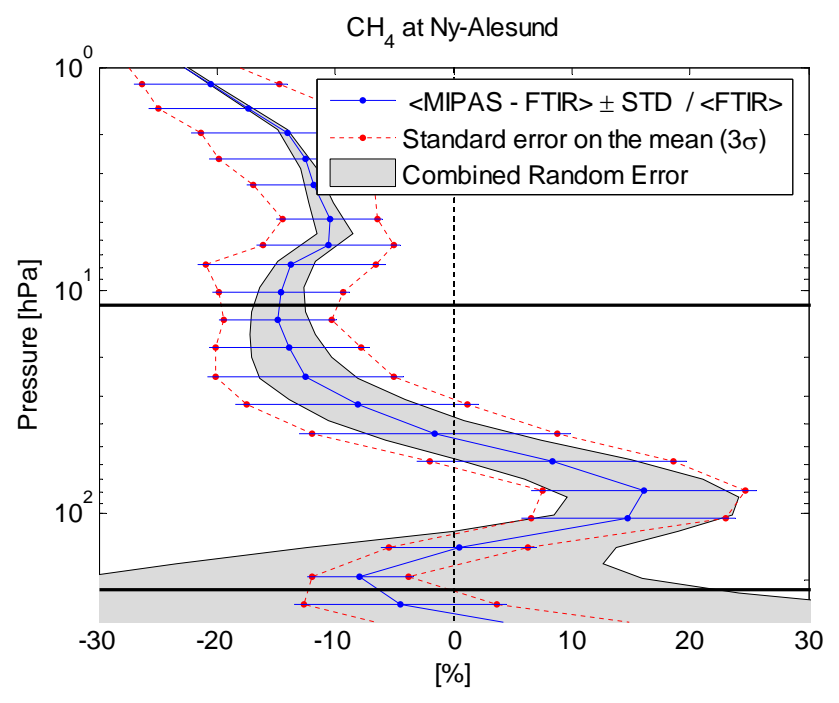

Fig. 15a. Statistical means and standard deviations of the relative differences mean(MIPAS-FTIR)/mean(FTIR) [\%] of the $\mathrm{CH}_{4}$ profiles measured at NY-Alesund. The shaded areas correspond to the estimated random error on the relative differences. The two black horizontal bars show the pressure ranges used for the partial column comparisons of Table 3.

local spring period, and that it is no longer significant when the comparisons are limited to summer-autumn. For NyAlesund, the number of coincidences (3) in the limited time period is too small to draw any significant conclusions.

From Table 4, it can be seen that the statistical standard deviations are within the estimated random error for $\mathrm{Ny}$ Alesund, Jungfraujoch, Lauder and Kiruna. For Wollongong, we see in Fig. 16a to $\mathrm{f}$ that the larger standard deviation for the statistics (with coincidence criteria of $\pm 3 \mathrm{~h} ; \pm 300 \mathrm{~km}$ ) is due to one single coincidence only, on the 1st of March 2003. Thus, results for Wollongong are better using the relaxed cri-

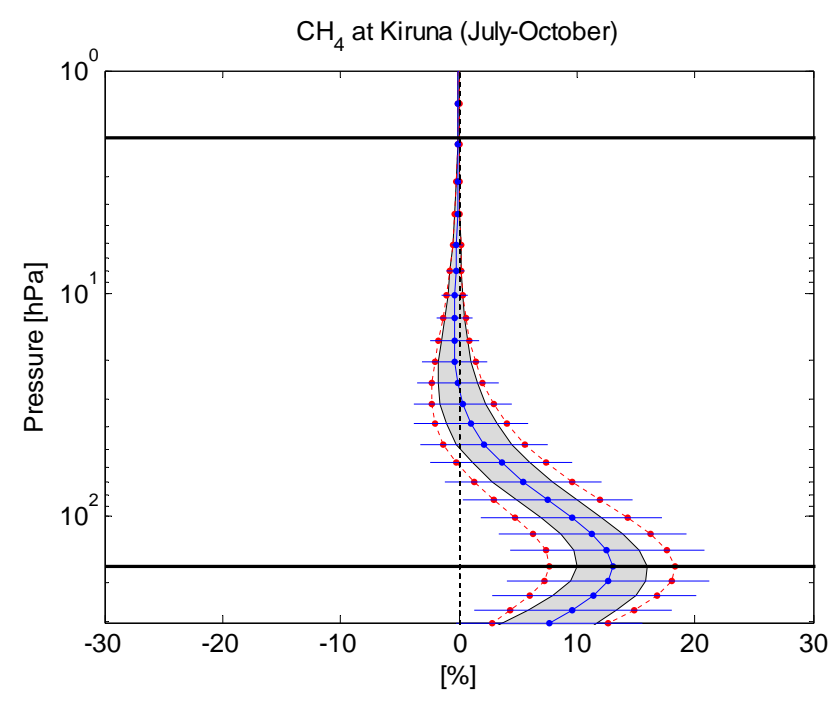

Fig. 15b. Statistical means and standard deviations of the relative differences mean(MIPAS-FTIR)/mean(FTIR) [\%] of the $\mathrm{CH}_{4}$ profiles measured at Kiruna. The shaded areas correspond to the estimated random error on the relative differences. The two black horizontal bars show the pressure ranges used for the partial column comparisons of Table 3 .

teria of $\pm 4 \mathrm{~h}, \pm 400 \mathrm{~km}$. For Arrival Heights, considering the whole period, the statistical standard deviation is also larger than the estimated random error, but this is no longer the case in the reduced time period. Indeed, we see in Fig. 16a to $f$ that the dispersion is larger during local spring for the three highest latitude stations. 


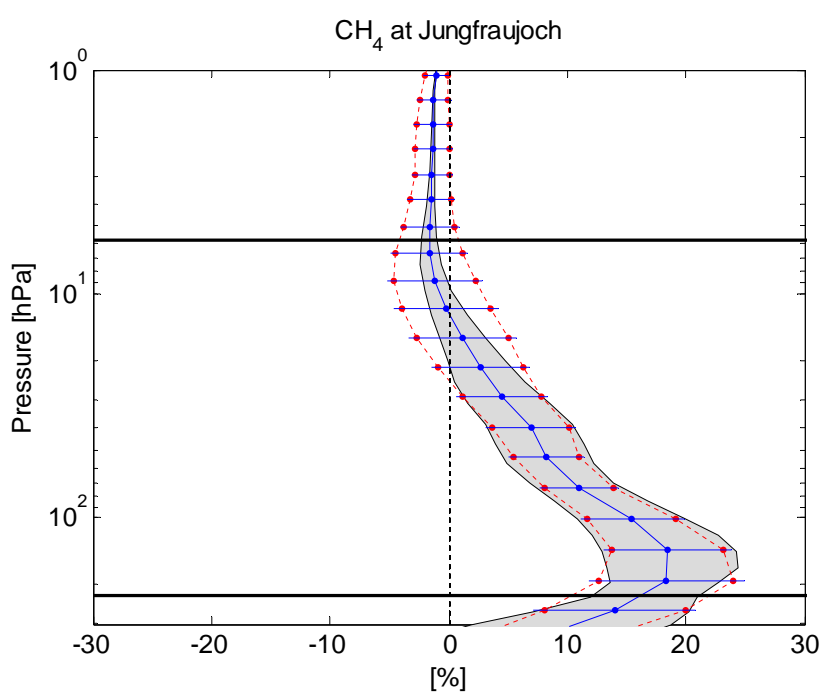

Fig. 15c. Statistical means and standard deviations of the relative differences mean(MIPAS-FTIR)/mean(FTIR) [\%] of the $\mathrm{CH}_{4}$ profiles measured at Jungfraujoch. The shaded areas correspond to the estimated random error on the relative differences. The two black horizontal bars show the pressure ranges used for the partial column comparisons of Table 3.

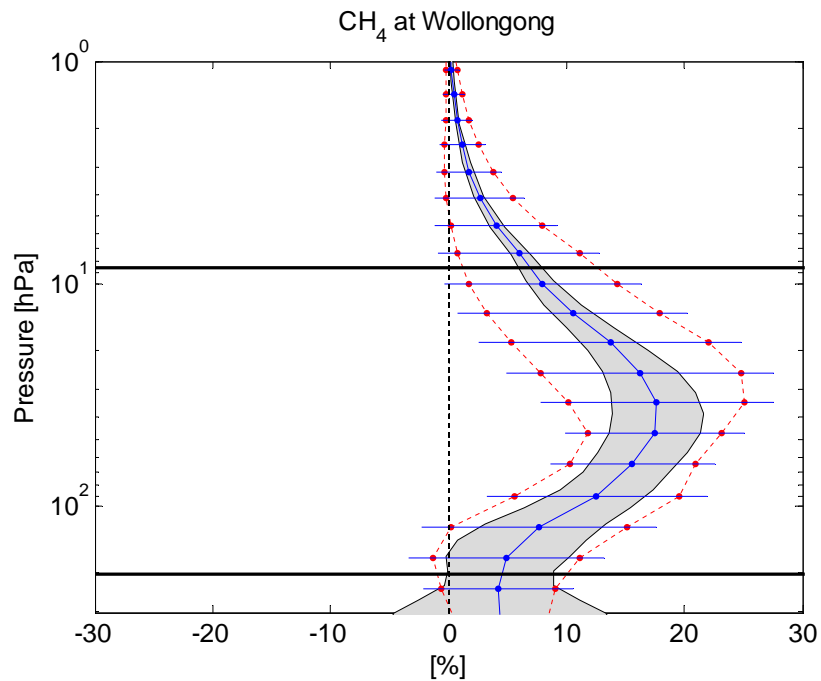

Fig. 15d. Statistical means and standard deviations of the relative differences mean(MIPAS-FTIR)/mean(FTIR) [\%] of the $\mathrm{CH}_{4}$ profiles measured at Wollongong. The shaded areas correspond to the estimated random error on the relative differences. The two black horizontal bars show the pressure ranges used for the partial column comparisons of Table 3. The statistics shown is for the $\pm 4 \mathrm{~h}$ and $\pm 400 \mathrm{~km}$ coincidence criteria.

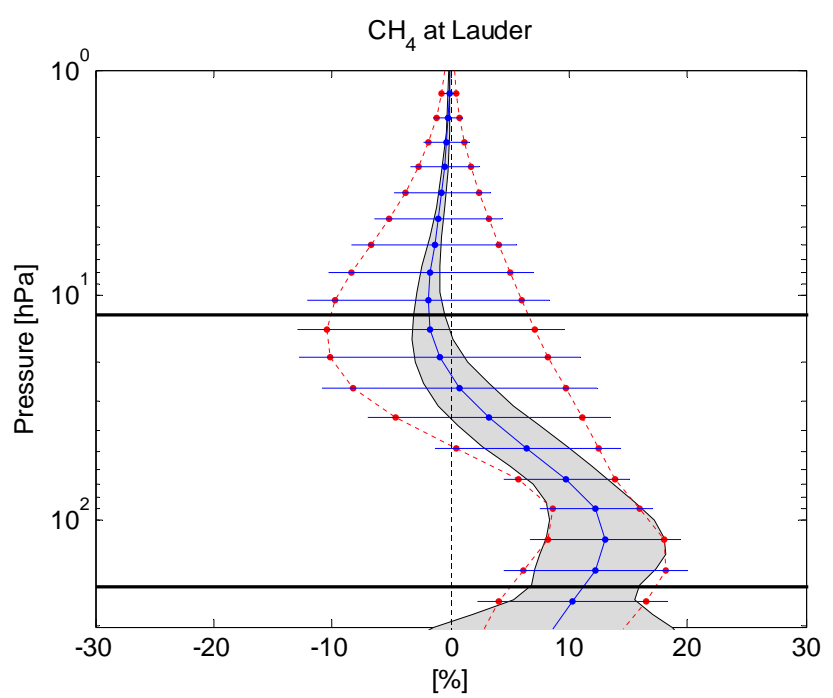

Fig. 15e. Statistical means and standard deviations of the relative differences mean(MIPAS-FTIR)/mean(FTIR) [\%] of the $\mathrm{CH}_{4}$ profiles measured at Lauder. The shaded areas correspond to the estimated random error on the relative differences. The two black horizontal bars show the pressure ranges used for the partial column comparisons of Table 3 .

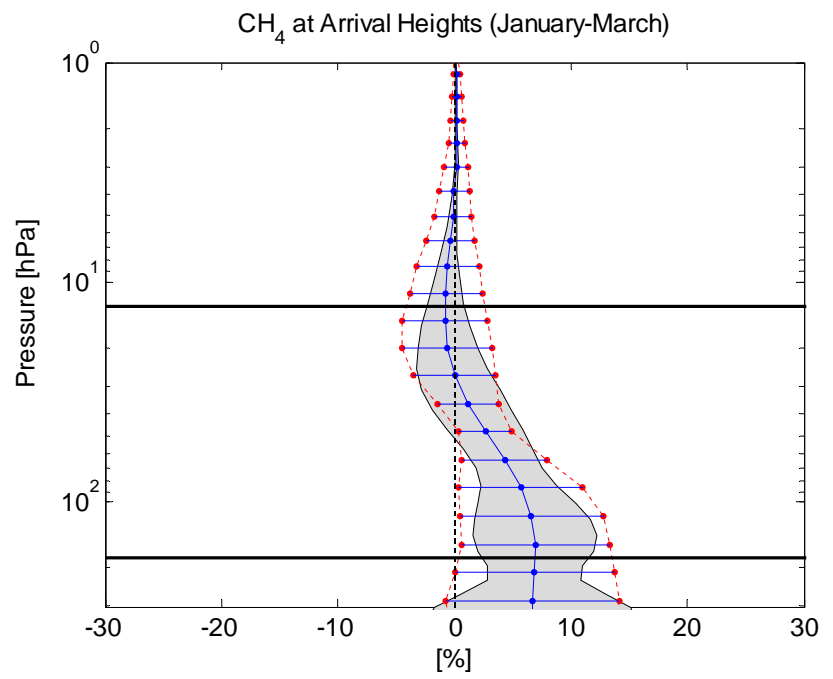

Fig. 15f. Statistical means and standard deviations of the relative differences mean(MIPAS-FTIR)/mean(FTIR) [\%] of the $\mathrm{CH}_{4}$ profiles measured at Arrival Heights. The shaded areas correspond to the estimated random error on the relative differences. The two black horizontal bars show the pressure ranges used for the partial column comparisons of Table 3 . 

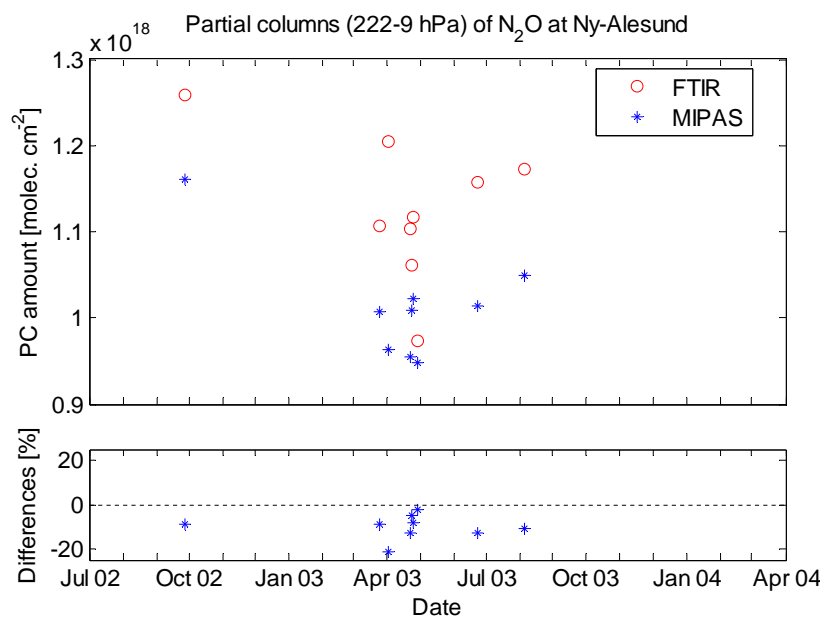

Fig. 16a. Time series of $\mathrm{N}_{2} \mathrm{O}$ partial columns comparisons. Upper panel: ground-based FTIR (circles) and MIPAS v4.61 (stars) $\mathrm{N}_{2} \mathrm{O}$ partial columns for collocated measurements at $\mathrm{Ny}$-Alesund. Lower panel: relative differences between ground-based FTIR and MIPAS partial columns.

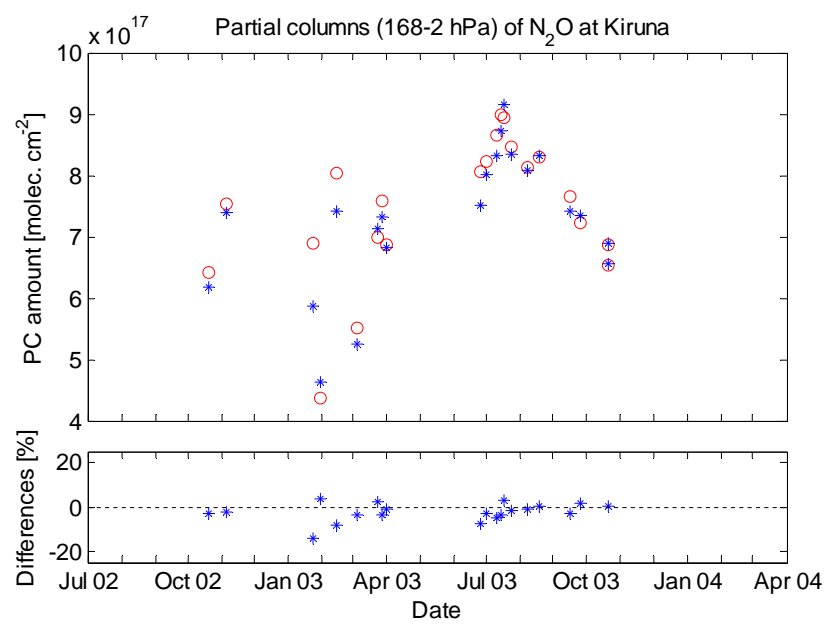

Fig. 16b. Time series of $\mathrm{N}_{2} \mathrm{O}$ partial columns comparisons. Upper panel: ground-based FTIR (circles) and MIPAS v4.61 (stars) $\mathrm{N}_{2} \mathrm{O}$ partial columns for collocated measurements at Kiruna. Lower panel: relative differences between ground-based FTIR and MIPAS partial columns.

Figure 17a to $\mathrm{f}$ confirm that, except at Ny-Alesund and to a smaller extent at Lauder, there is no statistically significant bias in $\mathrm{N}_{2} \mathrm{O}$ comparisons in the lower stratosphere where the $\mathrm{N}_{2} \mathrm{O}$ concentration is the highest. At higher altitude, a high positive bias is seen at Wollongong, and a small negative one at Kiruna.

\subsection{Summary for ground based measurements}

The $\mathrm{CH}_{4}$ comparisons show a statistically significant positive bias of 5 to $11 \%$ between MIPAS and FTIR lower-middle

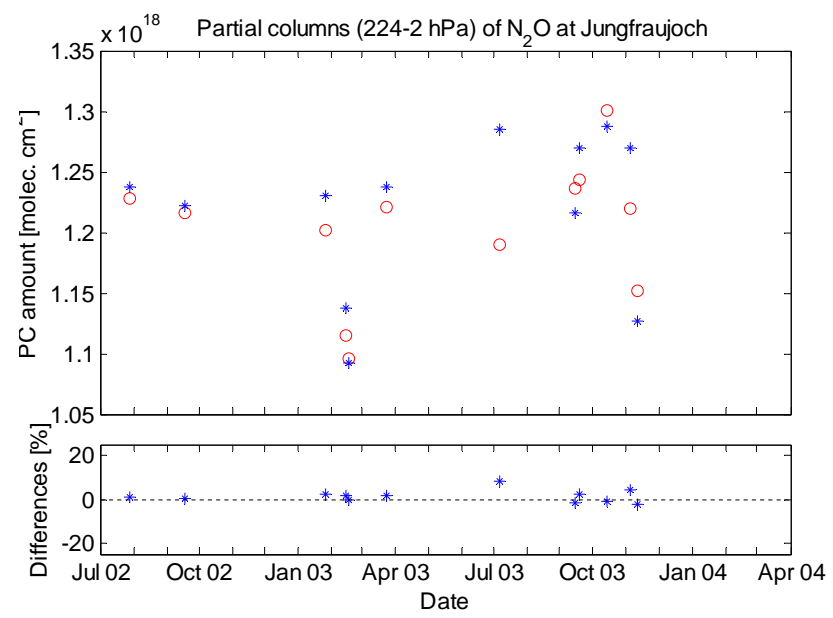

Fig. 16c. Time series of $\mathrm{N}_{2} \mathrm{O}$ partial columns comparisons. Upper panel: ground-based FTIR (circles) and MIPAS v4.61 (stars) $\mathrm{N}_{2} \mathrm{O}$ partial columns for collocated measurements at Junhgfraujoch. Lower panel: relative differences between ground-based FTIR and MIPAS partial columns.

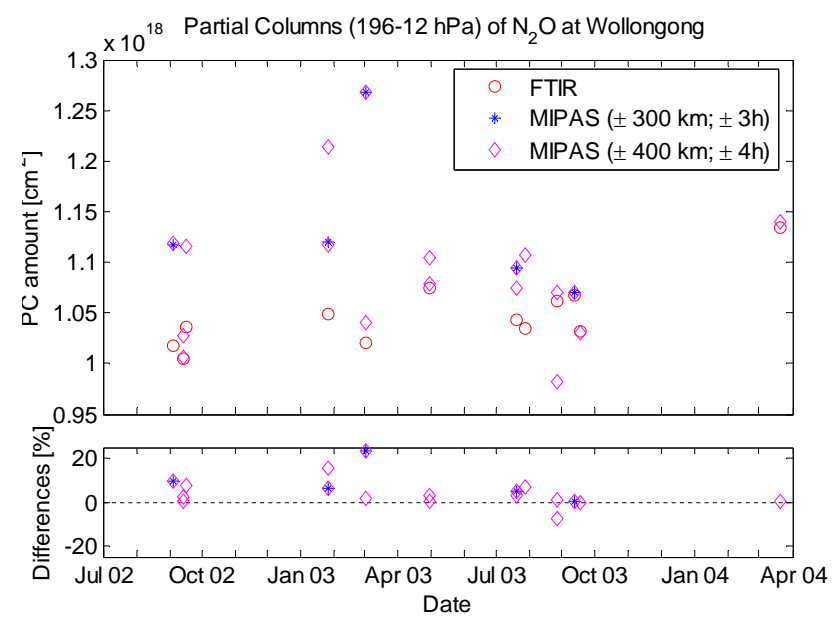

Fig. 16d. Time series of $\mathrm{N}_{2} \mathrm{O}$ partial columns comparisons. Upper panel: ground-based FTIR (circles) and MIPAS v4.61 (stars) $\mathrm{N}_{2} \mathrm{O}$ partial columns for collocated measurements at Wollongong. Lower panel: relative differences between ground-based FTIR and MIPAS partial columns.

stratosphere partial columns, and a standard deviation of 4 to $7.5 \%$, when the high variability period (winter-spring) for high latitude stations is not taken into account.

For $\mathrm{N}_{2} \mathrm{O}$ comparisons, no statistically significant bias is seen between MIPAS and FTIR lower-middle stratosphere partial columns, and the standard deviation is between 2.5 and $6.8 \%$, when the high variability period (winter-spring) for high latitude stations is not taken into account. 


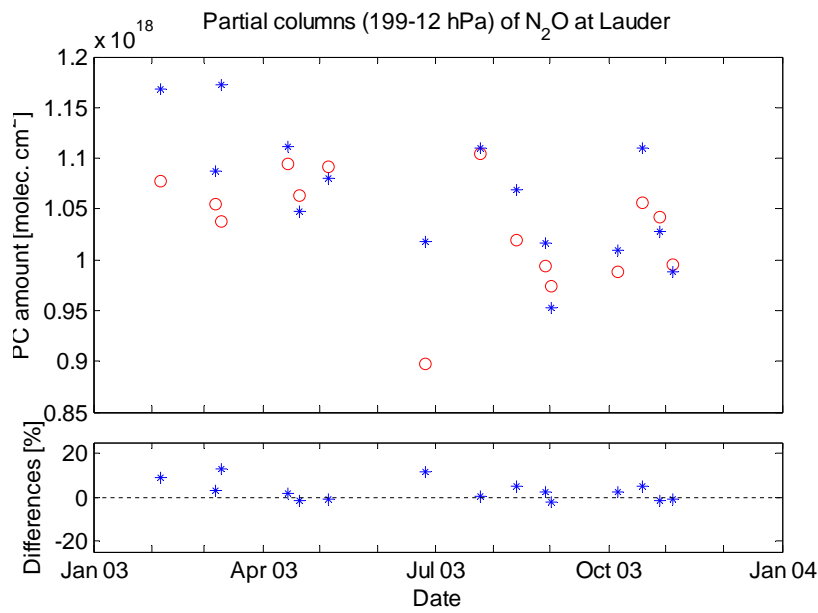

Fig. 16e. Time series of $\mathrm{N}_{2} \mathrm{O}$ partial columns comparisons. Upper panel: ground-based FTIR (circles) and MIPAS v4.61 (stars) $\mathrm{N}_{2} \mathrm{O}$ partial columns for collocated measurements at Lauder. Lower panel: relative differences between ground-based FTIR and MIPAS partial columns.

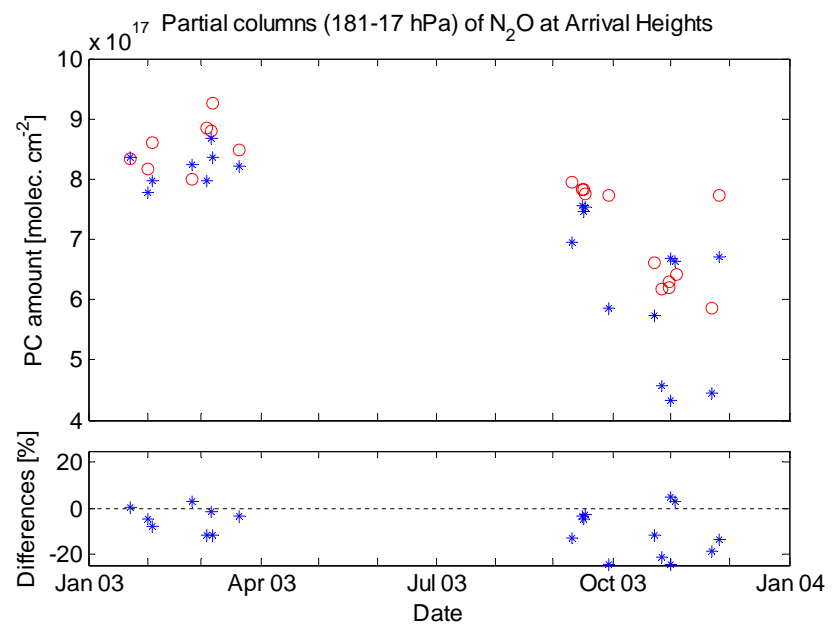

Fig. 16f. Time series of $\mathrm{N}_{2} \mathrm{O}$ partial columns comparisons. Upper panel: ground-based FTIR (circles) and MIPAS v4.61 (stars) $\mathrm{N}_{2} \mathrm{O}$ partial columns for collocated measurements at Arrival Heights. Lower panel: relative differences between ground-based FTIR and MIPAS partial columns.

When the winter-spring period is included in the comparisons for the high latitude stations, Standard deviations of 9 and $15 \%$ can be reached, for $\mathrm{N}_{2} \mathrm{O}$ and $\mathrm{CH}_{4}$ respectively, probably due to collocation and horizontal smoothing errors.

\section{Intercomparison of simultaneous MIPAS and HALOE measurements}

Satellite-satellite intercomparisons are another method to assess the quality of a new space instrument, considered to be

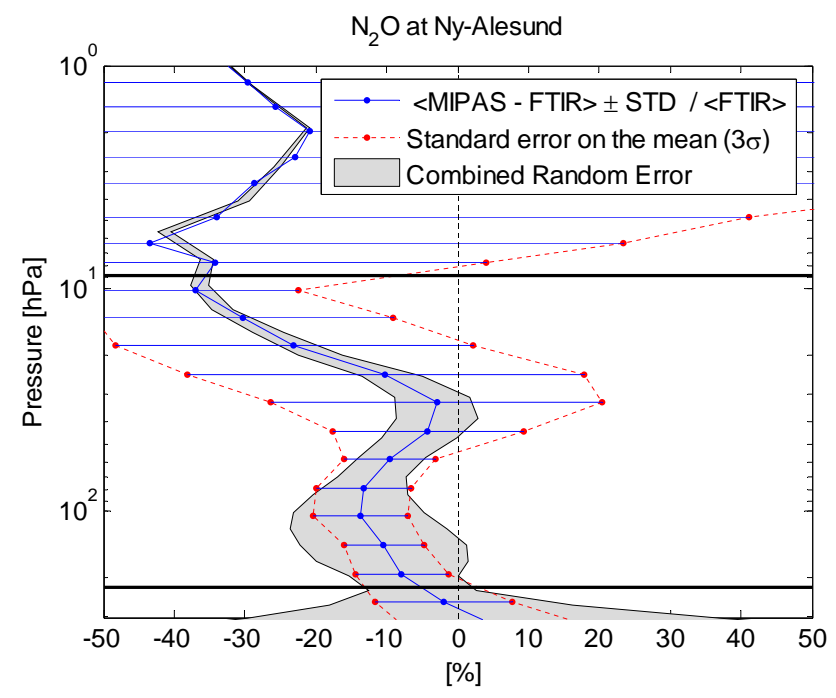

Fig. 17a. Statistical means and standard deviations of the relative differences mean(MIPAS-FTIR)/mean(FTIR) [\%] of the $\mathrm{N}_{2} \mathrm{O}$ profiles measured at $\mathrm{Ny}$-Alesund. The shaded areas correspond to the estimated random error on the relative differences. The two black horizontal bars show the pressure ranges used for the partial columns of Table 4.

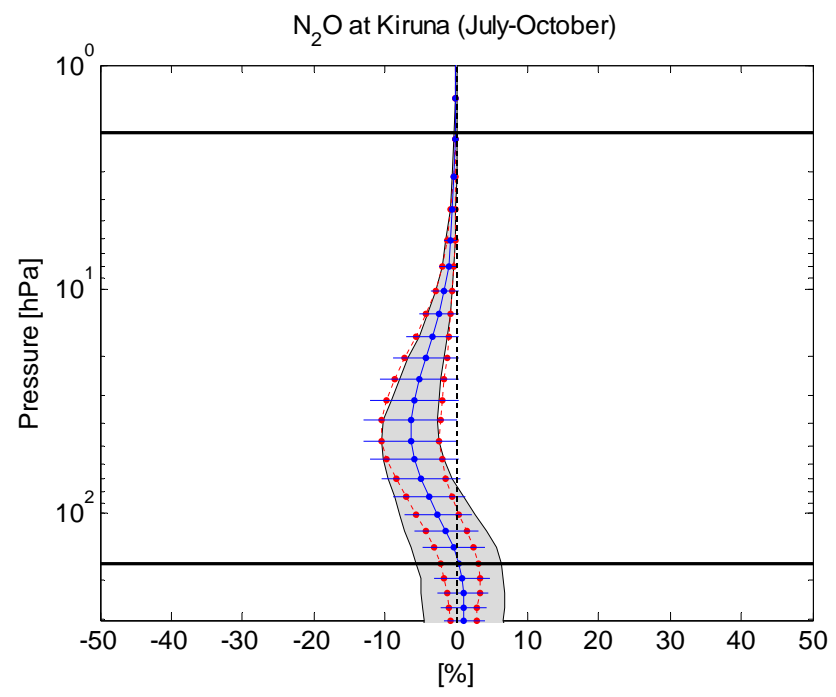

Fig. 17b. Statistical means and standard deviations of the relative differences mean(MIPAS-FTIR)/mean(FTIR) [\%] of the $\mathrm{N}_{2} \mathrm{O}$ profiles measured at Kiruna. The shaded areas correspond to the estimated random error on the relative differences. The two black horizontal bars show the pressure ranges used for the partial columns of Table 4 .

already validated by independent measurements, to be stable, and to be producing reliable profiles. Several papers cover in detail the comparison between MIPAS and ACE measurements of $\mathrm{CH}_{4}$ (De Mazière et al., 2007), between MIPAS and ACE measurements of $\mathrm{N}_{2} \mathrm{O}$ (Strong et al., 2007), and 


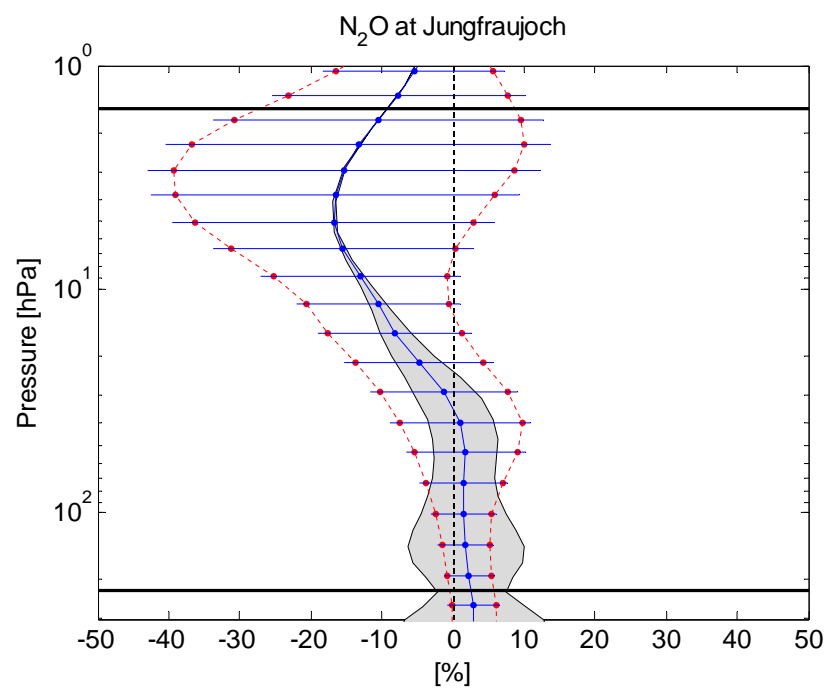

Fig. 17c. Statistical means and standard deviations of the relative differences mean(MIPAS-FTIR)/mean(FTIR) [\%] of the $\mathrm{N}_{2} \mathrm{O}$ profiles measured at Jungfrau. The shaded areas correspond to the estimated random error on the relative differences. The two black horizontal bars show the pressure ranges used for the partial columns of Table 4 .

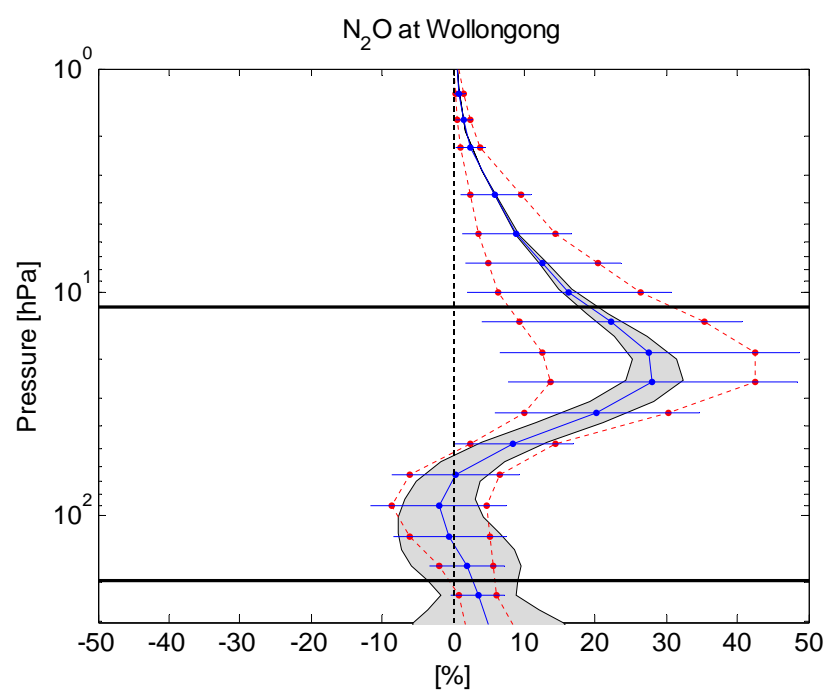

Fig. 17d. Statistical means and standard deviations of the relative differences mean(MIPAS-FTIR)/mean(FTIR) [\%] of the $\mathrm{N}_{2} \mathrm{O}$ profiles measured at Wollongong. The shaded areas correspond to the estimated random error on the relative differences. The two black horizontal bars show the pressure ranges used for the partial columns of Table 4. The statistics shown is for the $\pm 4 \mathrm{~h}$ and $\pm 400 \mathrm{~km}$ coincidence criteria.

between MIPAS and Aura Microwave Limb Sounder measurements of $\mathrm{N}_{2} \mathrm{O}$ (Lambert et al., 2007). These papers report differences generally consistent with the reported uncertainties of each instrument.

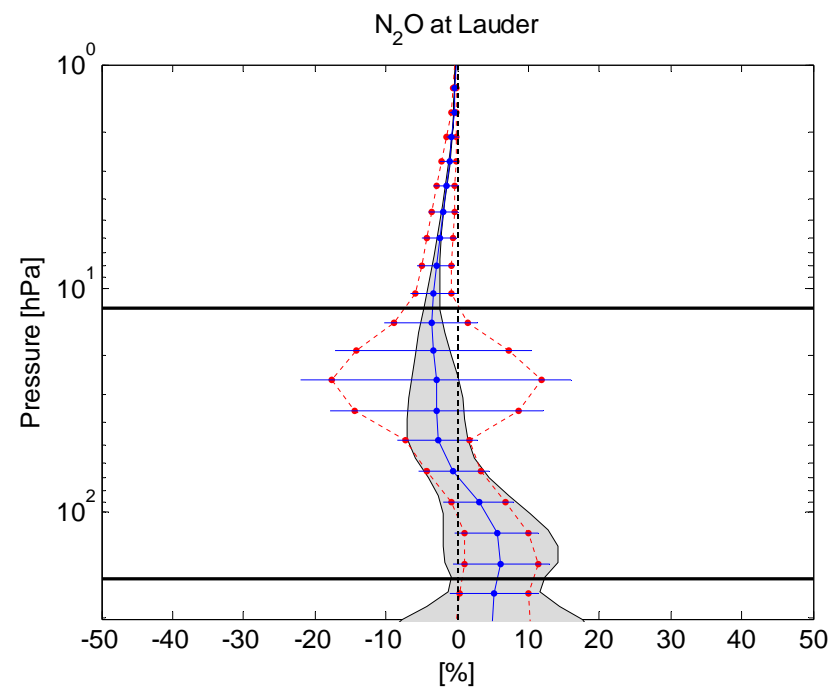

Fig. 17e. Statistical means and standard deviations of the relative differences mean(MIPAS-FTIR)/mean(FTIR) [\%] of the $\mathrm{N}_{2} \mathrm{O}$ profiles measured at Lauder. The shaded areas correspond to the estimated random error on the relative differences. The two black horizontal bars show the pressure ranges used for the partial columns of Table 4.

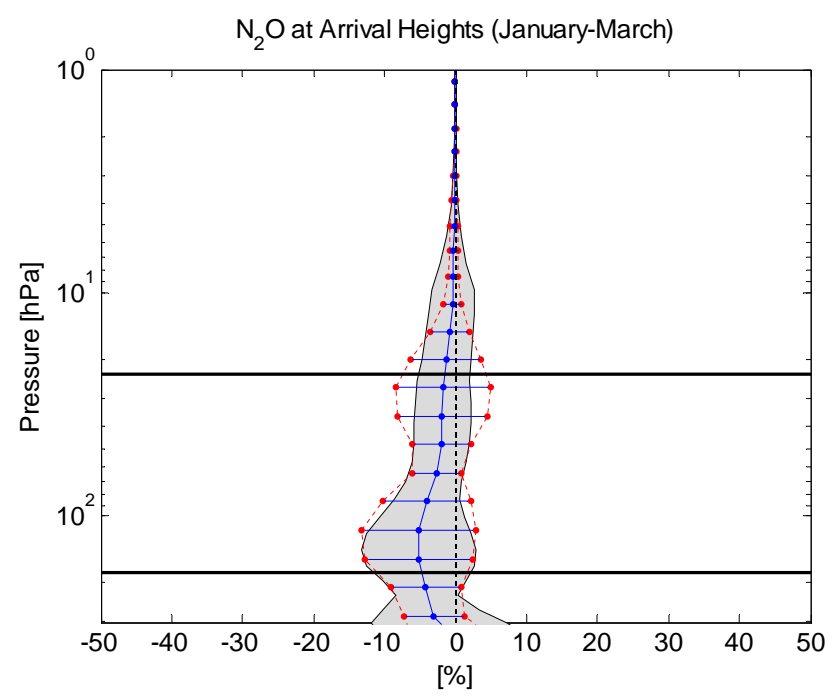

Fig. 17f. Statistical means and standard deviations of the relative differences mean(MIPAS-FTIR)/mean(FTIR) [\%] of the $\mathrm{N}_{2} \mathrm{O}$ profiles measured at Arrival Heights. The shaded areas correspond to the estimated random error on the relative differences. The two black horizontal bars show the pressure ranges used for the partial columns of Table 4.

The Halogen occultation Experiment (HALOE on board UARS) providing since 1991 vertical mixing ratio profiles of $\mathrm{CH}_{4}$ (Park et al., 1996) (and several other species) from the lower stratosphere to the mesosphere using solar absorption and gas correlation radiometry. 


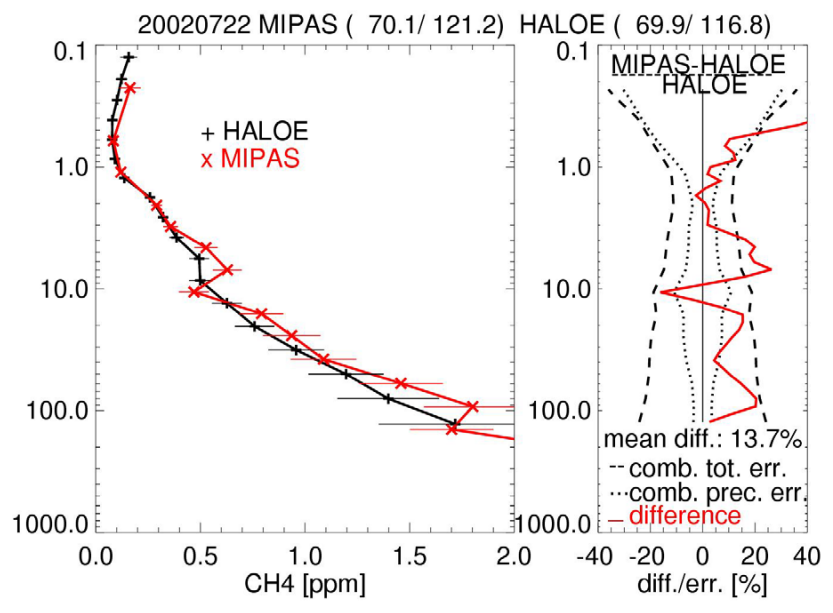

Fig. 18a. Comparison between individual HALOE and MIPAS profiles in Arctic region.

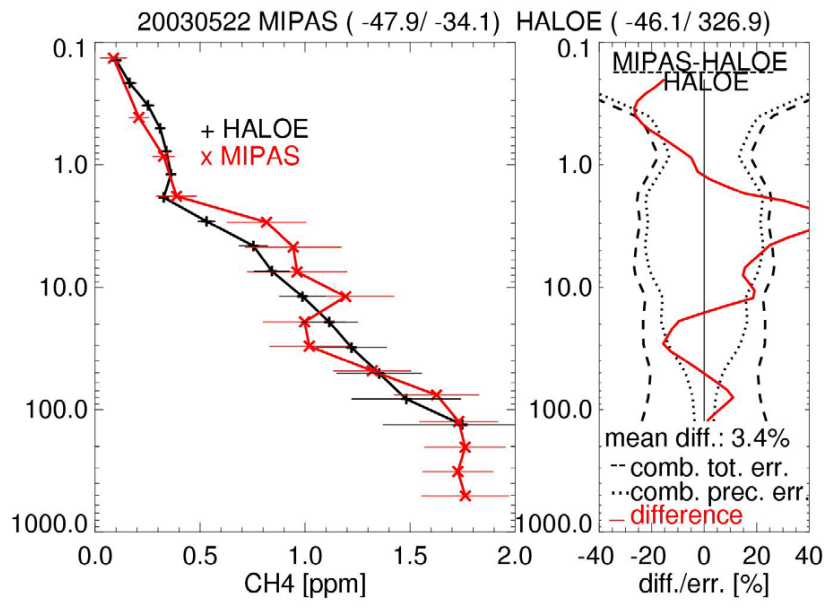

Fig. 18b. Comparison between individual HALOE and MIPAS profiles in southern mid-latitudes region.

HALOE version v19 data have been used for comparison with coincident MIPAS measurements. No averaging kernels have been applied because of similar vertical resolution between the two satellite instruments $(3 \mathrm{~km}$ for MIPAS, $2-3 \mathrm{~km}$ for HALOE). The following accuracy/precision is given by Park et al. (1996) for HALOE version v17: (a) at 0.3 and $50 \mathrm{hPa}$ accuracy between 6 and $15 \%$, precision between 0 and $14 \%$, (b) at 0.1 and $100 \mathrm{hPa}$ accuracy between 6 and 27\%, precision between 0 and 27\%. The validation study performed by Park et al. (1996) shows an agreement within 10 to $15 \%$ of HALOE profiles with balloon-borne (FTS, cryosampler), rocket (cryogenic whole air sampler) and satellite/shuttle (ATLAS1+ATLAS2/ATMOS) measurements from 0.3 to $100 \mathrm{hPa}$. Dessler and Kim (1999) indicated that the $\mathrm{v} 19 \mathrm{CH}_{4}$ data have an accuracy of $+/-5$ to $10 \%$ similar to v17 data.

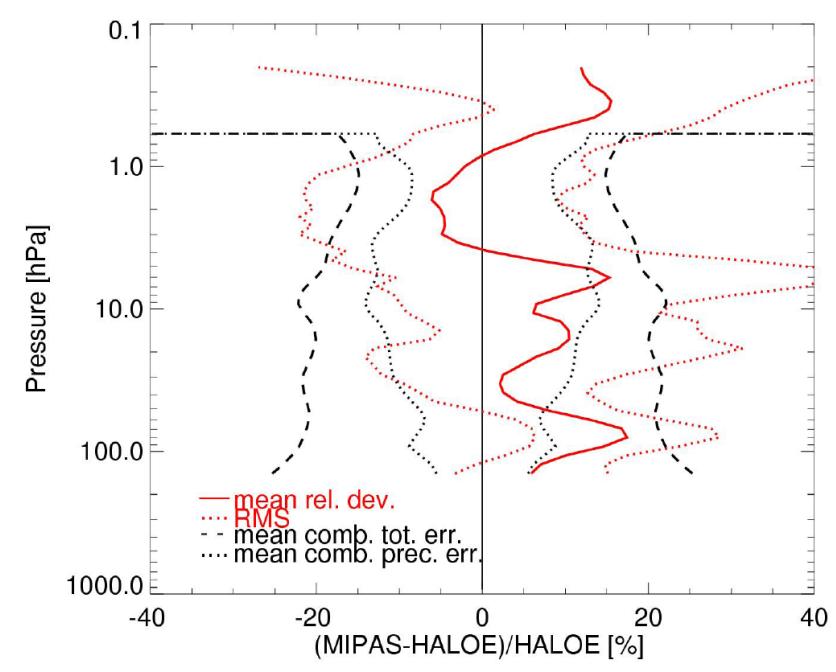

Fig. 19a. Mid latitude $\left(30^{\circ}\right.$ to $\left.60^{\circ}\right)$ Northern Hemisphere statistics of comparison between MIPAS and HALOE.

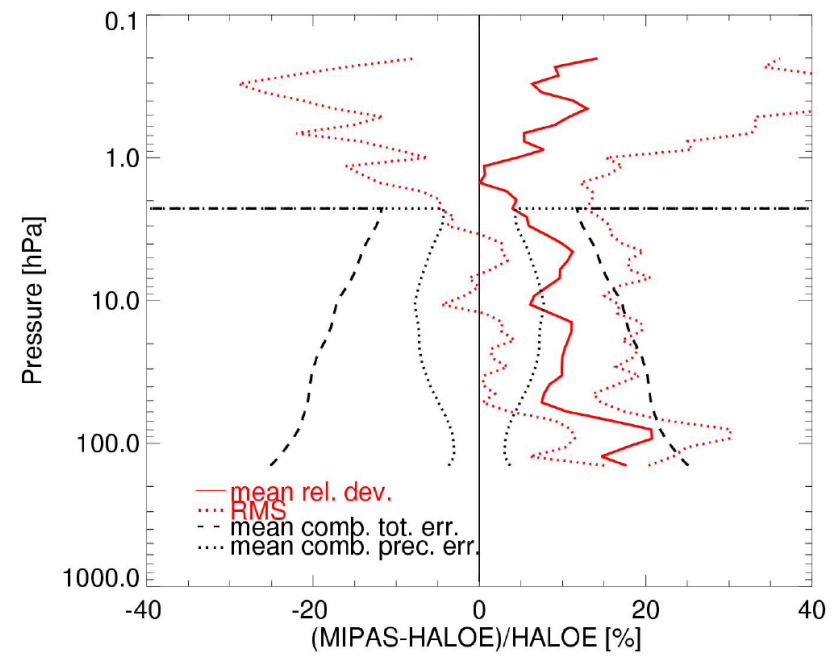

Fig. 19b. High latitude $\left(60^{\circ}\right.$ to $\left.90^{*}\right)$ Northern Hemisphere statistics of comparison between MIPAS and HALOE.

Figure 18a and $\mathrm{b}$ displays comparisons for a high latitude profile and a tropical profile in good coincidence (distance between HALOE and MIPAS tangent point less than $300 \mathrm{~km}$, time difference less than $3 \mathrm{~h}$ ). This choice of two quite different profiles is made to demonstrate the possibility of global coverage for the satellite-satellite comparison.

A statistical comparison is then feasible as summarised in Table 5 and illustrated by Figs. 19a, b, 20a, and b. MIPAS $\mathrm{CH}_{4}$ profiles show in the pressure range $0.5-140 \mathrm{hPa}$ a positive bias of 5 to $20 \%$ ( +0.009 to $+0.269 \mathrm{ppmv})$ compared to HALOE. Comparisons from high latitudes look similar for both hemispheres, with a positive bias for both: $5-26 \%$ (+0.001 to $+0.295 \mathrm{ppmv})$ for the Southern Hemisphere and $1-26 \%(+0.002$ to +0.285 ppmv) for the Northern 
Table 5. Statistics over all comparisons of MIPAS to HALOE: (MIPAS-HALOE)/HALOE.

\begin{tabular}{llll}
\hline Zone & Mean relative deviation RMS & $\begin{array}{l}\text { nb of } \\
\text { coincidence }\end{array}$ & Month of year \\
\hline $80^{\circ} \mathrm{S}-63^{\circ} \mathrm{S}$ & at $140-2 \mathrm{hPa}+5 \pm 20 \%(7-20 \%)$ & 153 & Nov to Jan 2003, Nov to Feb 2004 \\
$28^{\circ} \mathrm{S}-55^{\circ} \mathrm{S}$ & at $140-2 \mathrm{hPa}-1 \pm 20 \%(7-35 \%)$ & 38 & Jan 2003/2004, May 2003, Jul and Aug 2002/2003 \\
$45^{\circ} \mathrm{N}-60^{\circ} \mathrm{N}$ & at $140-2 \mathrm{hPa}-5 \pm 17 \%(8-25 \%)$ & 69 & Jan 2003/2004, Feb 2003, Nov 2003 \\
$60^{\circ} \mathrm{N}-76^{\circ} \mathrm{N}$ & at $140-2 \mathrm{hPa}+4 \pm 20 \%(7-10 \%)$ & 125 & Apr and May 2003, Jul 2002/2003 \\
All & at 140-2 $\mathrm{hPa}+5 \pm 20 \%(11-18 \%)$ & 385 & \\
\hline
\end{tabular}

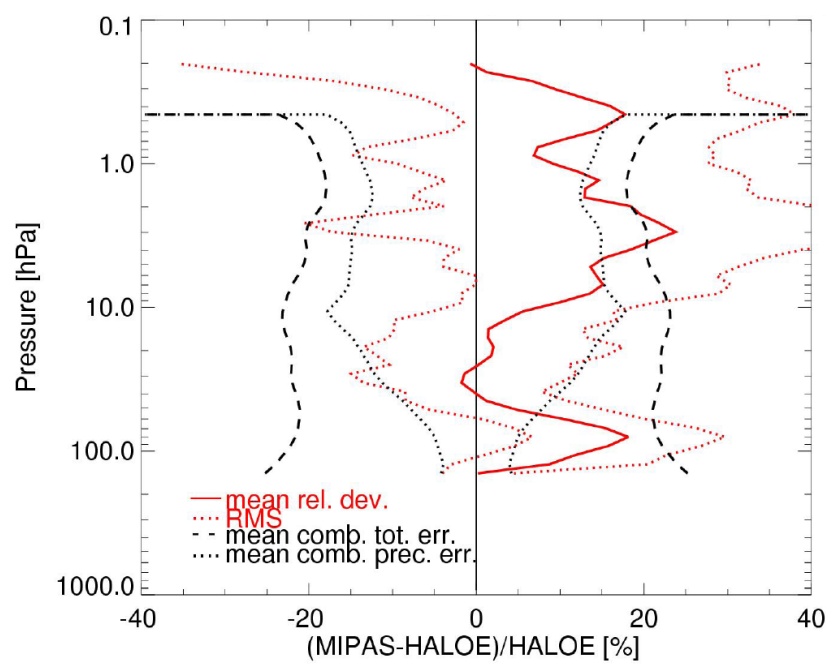

Fig. 20a. Mid latitude $\left(-60^{\circ}\right.$ to $\left.28^{\circ}\right)$ Southern Hemisphere statistics of comparison between MIPAS and HALOE.

Hemisphere. Comparisons from mid-latitudes (also the only comparisons in fall) look a bit different. The agreement varies between no or low negative bias to the same high positive bias values (with -1 to $+20 \%$ and -0.013 to $+0.250 \mathrm{ppmv}$ for the Southern Hemisphere and -6 to $+18 \%$ and -0.029 to +0.234 ppmv for the Northern Hemisphere), but the RMS is generally higher (up to $30 \%$ ). However, the number of comparisons are only half or a third of the comparisons in high latitudes. Comparisons from winter, spring and summer look similar for both hemispheres. The generally low bias of HALOE in the mid to high stratosphere has already been diagnosed in other comparison exercise (De Mazière et al., 2007).

\section{Correlation plots of nitrous oxide versus methane}

Since methane and nitrous oxide are passive tracers in the lower stratosphere, the availability of simultaneous profiles of these 2 species affords the possibility of internal consistency checks by examining the corresponding $\mathrm{CH}_{4} / \mathrm{N}_{2} \mathrm{O}$ correlation plots, which will be discussed in this paper for correlative balloon datasets.

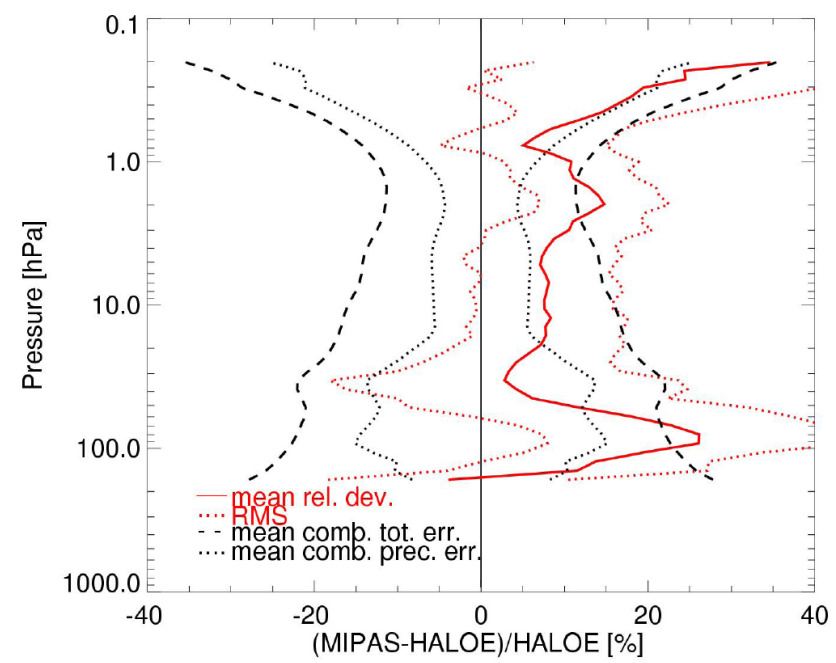

Fig. 20b. High latitude $\left(-90^{\circ}\right.$ to $\left.-60^{\circ}\right)$ Southern Hemisphere statistics of comparison between MIPAS and HALOE.

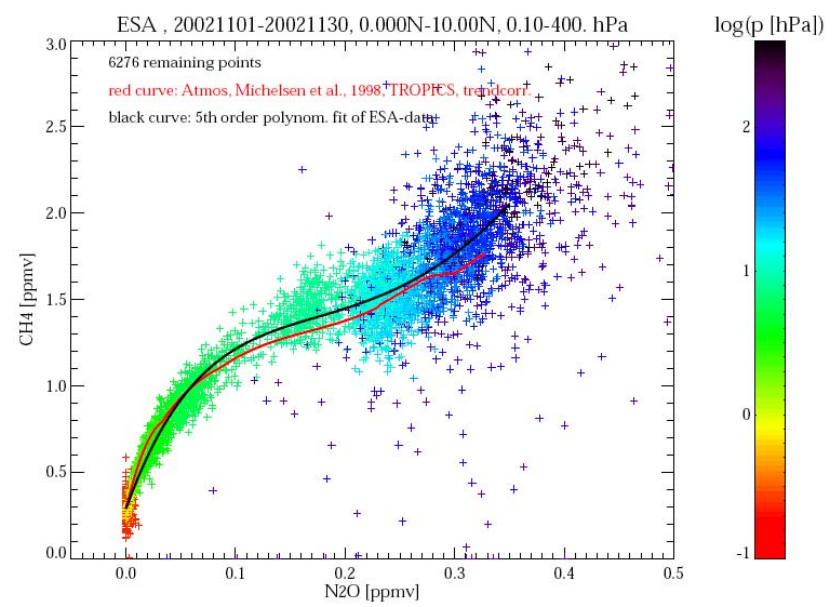

Fig. 21. ESA MIPAS $\mathrm{CH}_{4}$ and $\mathrm{N}_{2} \mathrm{O}$ data plotted against each other and compared with $\mathrm{CH}_{4}-\mathrm{N}_{2} \mathrm{O}$-regression-curves fitted to ATMOS $\left(2002 / 11 / 01-2002 / 11 / 30,0.000^{\circ} \mathrm{N}-10.00+\mathrm{N}\right)$. 


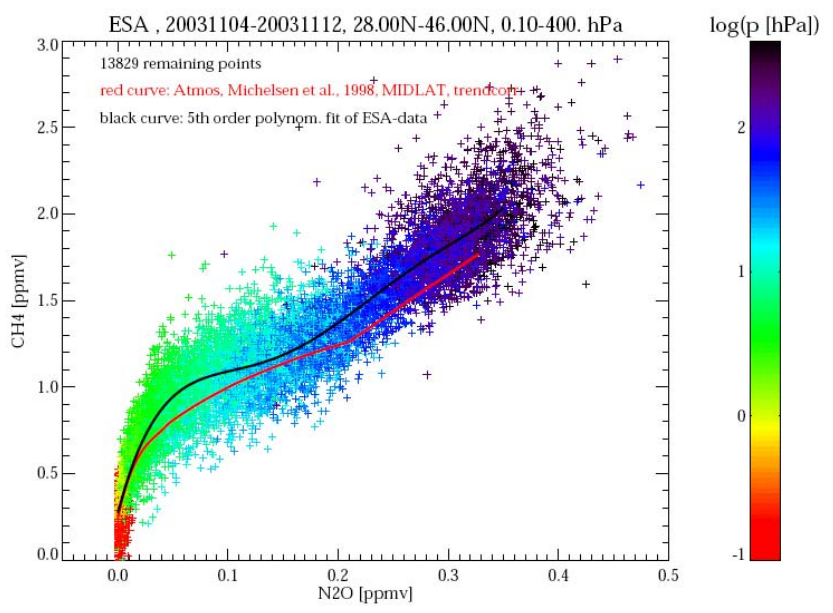

Fig. 22. ESA MIPAS $\mathrm{CH}_{4}$ and $\mathrm{N}_{2} \mathrm{O}$ data plotted against each other and compared with $\mathrm{CH}_{4}-\mathrm{N}_{2} \mathrm{O}$-regression-curves fitted to ATMOS $\left(2003 / 11 / 04-2003 / 11 / 12,28.00^{\circ} \mathrm{N}-46.00^{\circ} \mathrm{N}\right)$.

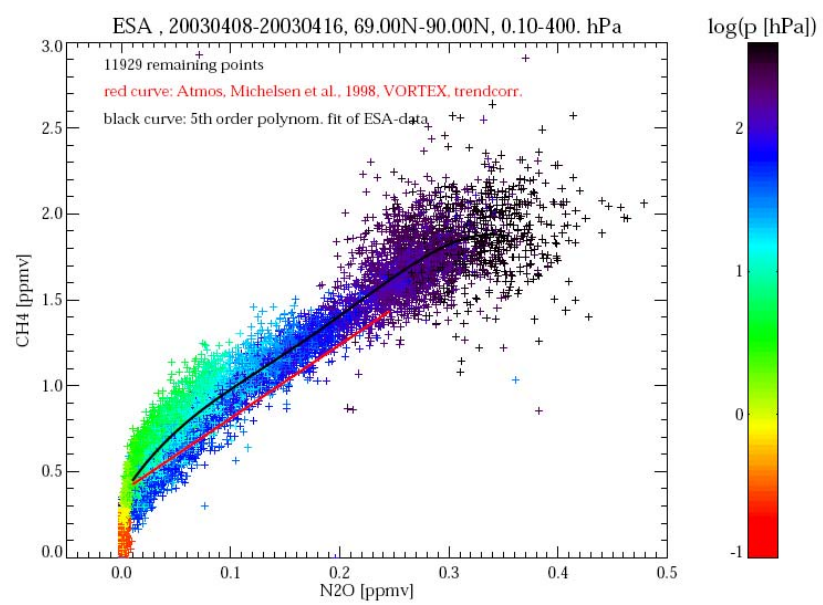

Fig. 23. ESA MIPAS $\mathrm{CH}_{4}$ and $\mathrm{N}_{2} \mathrm{O}$ data plotted against each other and compared with $\mathrm{CH}_{4}-\mathrm{N}_{2} \mathrm{O}$-regression-curves fitted to ATMOS (2003/04/08-2003/04/16, 69.00 $\left.{ }^{\circ} \mathrm{N}-90.00^{\circ} \mathrm{N}\right)$.

\subsection{Satellite/satellite correlation}

MIPAS $\mathrm{CH}_{4}$ and $\mathrm{N}_{2} \mathrm{O}$ data retrieved under ESA responsibility were plotted against each other and compared with the $\mathrm{CH}_{4}-\mathrm{N}_{2} \mathrm{O}$ regression curves fitted to ATMOS (Atmospheric Trace MOlecule Spectroscopy) data obtained in the early 1990s (see Figs. 21, 22, and 23 as an example). The ESA data shown were produced with software versions MIPAS/4.61 and MIPAS/4.62 on basis of re-calibrated MIPAS spectra. The altitude range extends from 400 to $0.1 \mathrm{hPa}$ (about 6 to $60 \mathrm{~km}$ ). Different plots were produced representing data subsets from the northern hemispheric tropics $\left(0-10^{\circ} \mathrm{N}\right.$, Fig. 21$)$, mid- and high latitudes $\left(28-69^{\circ} \mathrm{N}\right.$, Fig. 22) and Arctic latitudes (69-90 $0^{\circ}$ N, Fig. 23). In addition, the data shown are restricted in time to March/April 2003

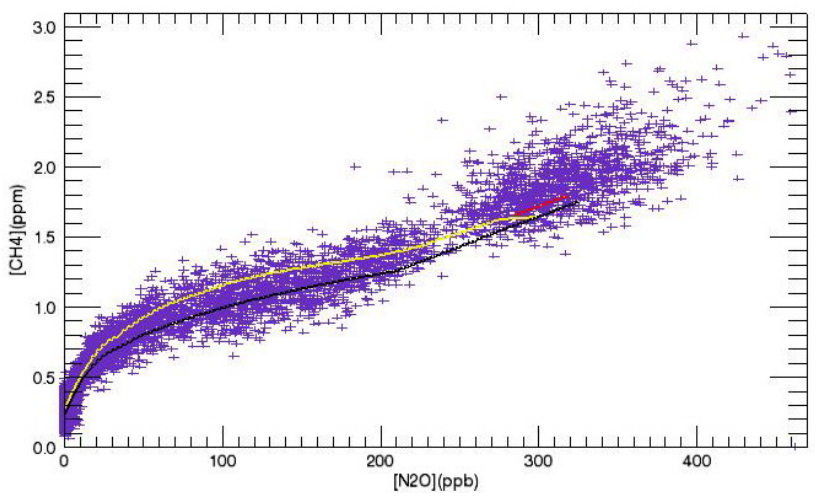

Fig. 24. ESA MIPAS $\mathrm{CH}_{4}$ and $\mathrm{N}_{2} \mathrm{O}$ data (blue, September $2003,40^{\circ} \mathrm{N}-45^{\circ} \mathrm{N}$ ) plotted against each other and compared with $\mathrm{CH}_{4}-\mathrm{N}_{2} \mathrm{O}$-regression-curves mid-latitude reference values (black) (Michelsen et al., 1998), low-latitude reference values (yellow) (Michelsen et al., 1998), and the recent low latitude at low altitude curve deduced from SPIRALE measurements (red) (Huret et al., 2006).

and November 2002/2003, resulting in samples consisting of 3332 to 13829 values, respectively. These restrictions have been applied to obtain the best possible temporal and latitudinal agreement with the ATMOS data used to derive previous regression curves (Michelsen et al., 1998a, b).

The ATMOS data considered here were obtained on three ATLAS Space Shuttle missions: 25 March to 2 April 1992 (ATMOS-1), 8-16 April 1993 (ATMOS-2) and 4-12 November 1994 (ATMOS-3). Polynomial fits were performed for data from the northern hemispheric tropics, mid- and high latitudes and from the Arctic vortex. The tropical polynomial was fitted to data obtained on ATMOS-1 and ATMOS-3 between 0 and $10^{\circ} \mathrm{N}$, the mid- and high latitude polynomial to data from ATMOS-3 from 28 to $69^{\circ} \mathrm{N}$ and the Arctic vortex polynomial to data obtained on ATMOS-2.

Generally, the MIPAS $\mathrm{N}_{2} \mathrm{O}$ and $\mathrm{CH}_{4}$ values extend up to about 0.4 and $2.5 \mathrm{ppmv}$, respectively, which exceed the tropospheric climatological values of 0.32 and $1.8 \mathrm{ppmv}$. The mid-latitude and Arctic correlations are reasonably compact, whereas the tropical correlations exhibit a somewhat larger scatter. The black curves are 5th order polynomials fitted to the ESA data, and the red curves are third order polynomials fitted piecewise to the ATMOS data (Michelsen et al., 1998a, b). To take into account the difference of about 10 years between ATMOS and MIPAS measurements, the ATMOS polynomials have been trend-corrected by addition of $2.3 \%\left(\mathrm{~N}_{2} \mathrm{O}\right)$ and 3.2\% $\left(\mathrm{CH}_{4}\right)$ (Wetzel et al., 2008). A similar $\mathrm{CH}_{4}$ trend of $2.8 \%$ for the relevant period has been derived by Rohs et al. (2006) (see their Fig. 2). Apart from the highest altitudes (low $\mathrm{N}_{2} \mathrm{O}$ and $\mathrm{CH}_{4}$ values) the Michelsen polynomials are generally below the ESA polynomials for Northern middle and high latitudes (Figs. 22 and 23). This indicates a $\sim 10 \%$ high bias of MIPAS $\mathrm{CH}_{4}$ versus the ATMOS $\mathrm{CH}_{4}$ 
data for this latitude range; assuming a smaller $\mathrm{CH}_{4}$ trend as suggested by Rohs et al. (2006) would even increase the high bias of MIPAS versus ATMOS data. The ATMOS $\mathrm{CH}_{4}$ data are assessed to be accurate to 5\% (Abrams et al., 1996), and no systematic bias of ATMOS $\mathrm{CH}_{4}$ data is reported in the literature. Therefore we conclude from the intercomparison to ATMOS that the MIPAS $\mathrm{CH}_{4}$ data are biased high by about $10 \%$ in Northern middle and high latitudes, while tropical $\mathrm{CH}_{4}$ VMR values are in fair agreement with ATMOS observations (see Fig. 21).

\subsection{Balloon/satellite correlation}

The simultaneous measurements of $\mathrm{N}_{2} \mathrm{O}$ and $\mathrm{CH}_{4}$ from several balloon experiments are providing another consistency check. All available MIPAS data for January, May and September 2003 have been used and binned into 3 latitude bands $\left(15-20^{\circ} \mathrm{N} ; 40-45^{\circ} \mathrm{N}\right.$ and $\left.75-80^{\circ} \mathrm{N}\right)$ to generate $\mathrm{CH}_{4} / \mathrm{N}_{2} \mathrm{O}$ correlation plots. An example is given in Fig. 24 for the MIPAS mid-latitude band. On this figure are also reported the reference regression curve for tropics and midlatitudes recommended by Michelsen et al. (1998a and b, corrected from trends as described above) and the new correlation curve for tropics deduced from SPIRALE measurements. This new correlation has been established in the paper of Huret et al. (2006). Its corresponds to an air mass originating from tropics, transported by large scale circulation to mid-latitudes and sampled by SPIRALE above Air-surl'Adour in October 2002, and this tropical correlation differs from the Michelsen one. Note, however, that for $\mathrm{N}_{2} \mathrm{O}$ values higher than $280 \mathrm{ppbv}$ and $\mathrm{CH}_{4}$ values higher than 1.5 ppmv (i.e. in the upper troposphere/lower stratosphere) the SPIRALE measurements are in agreement as expected with the Michelsen (1998) mid-latitude curve. When MIPAS data are averaged to generate zonal mean a good agreement with Michelsen curves for $\mathrm{N}_{2} \mathrm{O}$ VMR lower than $200 \mathrm{ppbv}$ is observed. For $\mathrm{N}_{2} \mathrm{O}$ values higher than $330 \mathrm{ppbv}$, and $\mathrm{CH}_{4}$ values higher than 2 ppmv (UT/LS MIPAS profiles often affected by zigzagging), Michelsen curves are outside error bars associated to zonal means.

Figure 25 shows $\mathrm{N}_{2} \mathrm{O}-\mathrm{CH}_{4}$ relationships as measured by MIPAS and the balloon-borne MIPAS-B instrument. For comparison, trend-corrected correlations observed by ATMOS (Michelsen et al., 1998) and in situ balloon measurements (Engel et al., 1996) are also shown. A polynomial fit has been applied to MIPAS and MIPAS-B. The fitted MIPAS$\mathrm{B}$ correlation is very close to the in situ balloon reference. A small bias towards the MIPAS-B data is visible in the fitted MIPAS correlation giving a hint that MIPAS $\mathrm{CH}_{4}$ is slightly overestimated and/or $\mathrm{N}_{2} \mathrm{O}$ slightly underestimated. Some unphysical outliers are also obvious in the MIPAS data which are connected to oscillations in the $\mathrm{N}_{2} \mathrm{O}$ and $\mathrm{CH}_{4}$ profiles at lower altitudes.

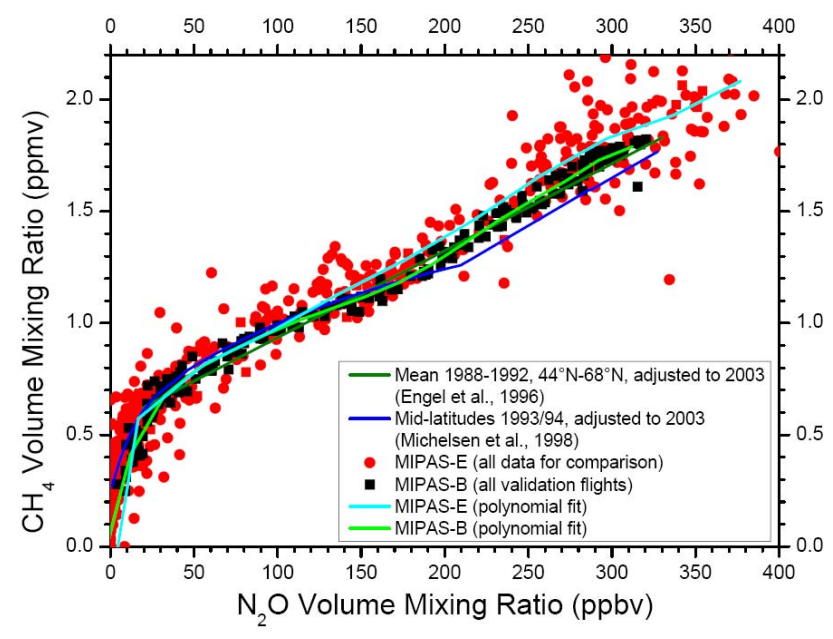

Fig. 25. ESA MIPAS $\mathrm{CH}_{4}$ and $\mathrm{N}_{2} \mathrm{O}$ data plotted against each other and compared with $\mathrm{CH}_{4}-\mathrm{N}_{2} \mathrm{O}$-regression-curves mid-latitude reference values, and MIPAS-B measurements.

\section{Conclusions}

Separate summaries of the results of the validation exercise are provided first here for the ground-based, balloon, aircraft, and other satellite and for checking the consistency of the $\mathrm{CH}_{4} / \mathrm{N}_{2} \mathrm{O}$ correlation.

\subsection{Ground-based measurements}

The $\mathrm{CH}_{4}$ comparisons show a statistically significant positive bias of 5 to $11 \%$ between MIPAS v4.61 and FTIR lowermiddle stratosphere partial columns, and a standard deviation of 4 to $7.5 \%$, when the high variability period (winterspring) for high latitude stations is not taken into account. For $\mathrm{N}_{2} \mathrm{O}$ comparisons, no statistically significant bias is seen between MIPAS v4.61 and FTIR lower-middle stratosphere partial columns, and the standard deviation is between of 2.5 to $6.8 \%$, when the high variability period (winter-spring) for high latitude stations is not taken into account. When the winter-spring period is included in the comparisons for the high latitude stations, standard deviations of 9 and $15 \%$, for $\mathrm{N}_{2} \mathrm{O}$ and $\mathrm{CH}_{4}$ respectively are observed, probably due to collocation and horizontal smoothing errors.

\subsection{Balloon measurements}

The comparisons of MIPAS with balloon data of various types (remote sensing in emission or absorption, in situ) demonstrate the presence of remaining "oscillations". Reasonable agreement is however observed in the mid stratosphere between MIPAS and balloon $\mathrm{CH}_{4}$ and $\mathrm{N}_{2} \mathrm{O}$. The MIPAS values in the very lower stratosphere present a positive bias with respect to balloon measurements. 
Table 6. Summary of comparisons between MIPAS and correlative measurements for $\mathrm{CH}_{4}$. The relative differences are calculated as (MIPAS-Correlative)/Correlative in \%.

\begin{tabular}{lll}
\hline Experiment & Pressure range & $\begin{array}{l}\text { Extrema of relative } \\
\text { differences and average }\end{array}$ \\
\hline MIPAS-B & $400-20$ & $\begin{array}{l}-15.3 \text { to } 23.2 \%(-+3.7 \%) \\
-7.5 \text { to } 3.3 \%(-0.1 \%)\end{array}$ \\
BONBON & $20-3$ & -1.0 to $17.0 \%(-+7.0 \%)$ \\
SPIRALE (winter) & $200-25 \mathrm{hPa}$ & -36.0 to $-5.0 \%(--23.0 \%)$ \\
SPIRALE (fall) & $200-30 \mathrm{hPa}$ & -10.2 to $2.9 \%(\sim-0.1 \%)$ \\
LPMA & $400-70$ & -37.0 to $19.0 \%(\sim-10.7 \%)$ \\
& $20-3$ & -20.2 to $22.4 \%(\sim+2.0 \%)$ \\
MIPAS-STR & $100-50$ & $-14.0 \%$ to $7.0 \%(\sim-7.0 \%)$ \\
FTIR & $300-100$ & -7.0 to $2.01 \%(\sim+7.0 \%)$ \\
HALOE & $2-224$ & -3.8 to $+14.9 \%(\sim+7.0 \%)$ \\
\hline
\end{tabular}

\subsection{Aircraft measurements}

The general agreement is better at mid and high latitude than in the tropical region where a high deviation is observed by ASUR between 24 and $28 \mathrm{~km}$. The $\mathrm{CH}_{4}$ and $\mathrm{N}_{2} \mathrm{O}$ MIPAS v4.61 profiles present "oscillations" which are not observed in aircraft profiles in this UT/LS region, leading to relative differences which can reach $\sim 30 \%$ in this UT/LS altitude range, a region which is difficult for limb measurements from space. Around the $100 \mathrm{hPa}$ level, MIPAS presents a positive bias with respect to correlative measurements as already noticed for other comparisons in the UT/LS.

\subsection{Satellite measurements}

In the pressure range $2-140 \mathrm{hPa}$, MIPAS $\mathrm{CH}_{4}$ profiles show a positive bias of 10 to $20 \%$ compared to HALOE, but the problem with these latter data has already been diagnosed by comparison with other instruments like ACE. Comparisons at high latitudes look similar for both hemispheres, whereas comparisons at mid-latitudes (also the only comparisons in fall) look slightly different. Comparisons for winter, spring and summer look similar for both hemispheres.

\section{5 $\mathrm{CH}_{4} / \mathrm{N}_{2} \mathrm{O}$ correlation as an internal consistency check}

Generally, the MIPAS $\mathrm{N}_{2} \mathrm{O}$ and $\mathrm{CH}_{4}$ values extend up to about 0.4 and 2.5 ppmv, respectively, which exceed the tropospheric climatological values of 0.32 and 1.8 ppmv. The mid-latitude and Arctic correlations are reasonably compact, whereas the tropical correlations exhibit a somewhat larger scatter. Apart from the highest altitudes (low $\mathrm{N}_{2} \mathrm{O}$ and $\mathrm{CH}_{4}$
Table 7. Summary of comparisons between MIPAS and correlative measurements for $\mathrm{N}_{2} \mathrm{O}$. The relative differences are calculated as (MIPAS-Correlative)/Correlative in \%.

\begin{tabular}{lll}
\hline Experiment & Pressure range & $\begin{array}{l}\text { Extrema of relative } \\
\text { differences and average }\end{array}$ \\
\hline IBEX & $200-20$ & -90.0 to $-10.0 \%(\sim-25.0 \%)$ \\
& $20-4$ & -60.0 to $+10.0 \%(\sim-15.0 \%)$ \\
MIPAS-B & $400-20$ & -15.7 to $26.3 \%(\sim+2.2 \%)$ \\
& $20-3$ & -36.7 to $+7.6 \%(\sim-9.3 \%)$ \\
BONBON & $200-25 \mathrm{hPa}$ & -14.0 to $15.0 \%(--1.0 \%)$ \\
SPIRALE (winter) & $200-30 \mathrm{hPa}$ & -85.0 to $-18.0 \%(--47.0 \%)$ \\
SPIRALE (fall) & $200-7$ & -111.9 to $26.3(\sim-24.4 \%)$ \\
LPMA & $400-20$ & $-19.0 \%$ to $23.0 \%(\sim-0.5 \%)$ \\
& $20-3$ & -95.0 to $8.0 \%(\sim-15.0 \%)$ \\
MIPAS-STR & $100-50$ & -40.0 to $+17.0 \%(\sim-7.0 \%)$ \\
FAFIRE-A & $300-100$ & -17.0 to $+17.0 \%(\sim+1.0 \%)$ \\
& $150-50$ & +20.0 to $+40.0 \%(\sim+16.0 \%)$ \\
& $150-25$ & -33.0 to $39.0 \%(\sim+3.0 \%)$ \\
ASUR & $25-2$ & -75.0 to $59.0 \%(\sim-1.0 \%)$ \\
& $140-2 \mathrm{hPa}$ & -10.0 to $+8.8 \%(\sim+4.0 \%)$
\end{tabular}

values) the Michelsen polynomials are generally below the MIPAS polynomials, which hints at a small positive bias $(\sim 10 \%)$ in the MIPAS $\mathrm{CH}_{4}$.

\subsection{Overall assessment}

Even if a very significant effort from the validation scientists and balloon or aircraft operation teams has been made to achieve good space and time coincidence with MIPAS, the number of such correlative data is only allowing a limited statistical analysis of the full vertical profiles of $\mathrm{CH}_{4}$ and $\mathrm{N}_{2} \mathrm{O}$.

The large variety of correlative techniques considered in this validation effort allows the following conclusion with respect to the quality MIPAS Envisat data for $\mathrm{CH}_{4}$ and $\mathrm{N}_{2} \mathrm{O}$, which overall have the major advantage of being global and homogeneous.

A quantitative summary of overall comparison between MIPAS and correlative measurements is presented in Tables 6 and 7 for $\mathrm{CH}_{4}$ and $\mathrm{N}_{2} \mathrm{O}$ respectively. Care must be taken when deriving averages because of the different weight to be assigned to individual correlative measurements (some cases are pertaining to complicated geophysical conditions, to possible space/time mismatch, or known problems with correlative data).

In the middle stratosphere, no significant bias is observed between MIPAS and correlative measurements, and MIPAS is providing a very consistent and global picture of the 
distribution of $\mathrm{CH}_{4}$ and $\mathrm{N}_{2} \mathrm{O}$ in this region. This is expected to be true also in the upper stratosphere, an altitude range for which correlative measurements are notably scarce. In average, the MIPAS $\mathrm{CH}_{4}$ values show a small positive bias in the lower stratosphere of about 5\%. A similar situation is observed for $\mathrm{N}_{2} \mathrm{O}$ with a positive bias of $4 \%$. The MIPAS data version 4.61 still exhibits unphysical oscillations in individual $\mathrm{CH}_{4}$ and $\mathrm{N}_{2} \mathrm{O}$ profiles caused by the processing algorithm. As a consequence, $\mathrm{CH}_{4}$ and $\mathrm{N}_{2} \mathrm{O}$ values are sometimes uncorrelated; these specific pairs of values are recognized as outliers in the $\mathrm{CH}_{4} / \mathrm{N}_{2} \mathrm{O}$ correlation plots. Taking these problems into account the MIPAS $\mathrm{CH}_{4}$ and $\mathrm{N}_{2} \mathrm{O}$ data are behaving as expected from the error estimation analysis (see Sect. 2.2).

In order to investigate the causes of the unphysical oscillations in the $\mathrm{CH}_{4}$ and $\mathrm{N}_{2} \mathrm{O}$ profiles retrieved with the ESA offline processor, IFAC performed several tests using MIPAS scan \#16 (lat. 46.4 N) of orbit \#2975 (24 September 2002), for which a correlative measurement by MIPAS balloon measurement is available. Retrievals using different occupation matrices (choice of microwindows as a function of tangent height) were performed. The results indicate that the $\mathrm{N}_{2} \mathrm{O}$ oscillations are reduced when more microwindows were used.

Other tests have been performed using a temperature profile characterised by a better vertical resolution, but the oscillations are not significantly affected. The impact of the water vapour profile has been investigated by performing a retrieval using the $\mathrm{H}_{2} \mathrm{O}$ profile derived from the coincident MIPAS balloon measurements. The impact on the $\mathrm{CH}_{4}$ and $\mathrm{N}_{2} \mathrm{O}$ profile is negligible.

However, some of these oscillations have been recently explained as due to non-filtered clouds. Indeed we have verified that in some cases performing retrieval after the removal of the lowest measurement, and hence on a restricted altitude range, reduces significantly the oscillations in the retrieved profile. However, this does not work for all oscillating scans. The other possible causes already described remain.

Additional tests have to be repeated for other scans for which other correlative measurements are available. The fact that $\mathrm{N}_{2} \mathrm{O}$ and $\mathrm{CH}_{4}$ oscillations are correlated could indicate the presence of a common systematic error. However, a single cause of the observed differences between MIPAS and correlative measurements could not be found.

Acknowledgements. Acknowledgements are due to the HALOE group at Hampton University, especially to J. M. Russell III and at NASA LaRC, and to E. Thompson for providing the data and information on these data. All the balloon teams are very grateful to CNES and SSC as well as ESA and DLR for their support during the balloon campaigns.

Edited by: P. Hartogh

\section{References}

Abrams, M. C., Chang, A. Y., Gunson, M. R., Abbas, M. M., Goldman, A., Irion, F. W., Michelsen, H. A., Newchurch, M. J., Rinsland, C. P., Stiller, G. P., and Zander, R.: On the assessment and uncertainty of atmospheric trace gas burden measurements with high resolution infrared solar occultation spectra from space by the ATMOS experiment, Geophys. Res. Lett., 23(17), 23372340, 1996.

Bernath, P. F., McElroy, C. T., Abrams, M. C., Boone, C. D., Butler, M., Camy-Peyret, C., Carleer, M., Clerbaux, C., Coheur, P. F., Colin, R., DeCola, P., DeMazière, M., Drummond, J. R., Dufour, G., Evans, W. F. J., Fast, H., Fussen, D., Gilbert, K., Jennings, D. E., Llewellyn, E.J., Lowe, R. P., Mahieu, E., McConnell, J. C., McHugh, C., McLeod, S. D., Michaud, R., Midwinter, C., Nassar, R., Nichitiu, F., Nowlan, C., Rinsland, C. P., Rochon, Y. J., Rowlands, N., Semeniuk, K., Simon, P., Skelton, R., Sloan, J. J., Soucy, M.-A., Strong, K., Tremblay, P., Turnbull, D., Walker, K. A., Walkty, I., Wardle, D. A.,. Wehrle, V., Zander, R., and Zou, J.: Atmospheric Chemistry Experiment (ACE): Mission overview, Geophys. Res. Lett., 32, L15S01, doi:10.1029/2005GL022386, 2005.

Bianchini G., Boscaleri, A., Mencaraglia, F., Pascale, E., and Castelli, E.: Correlative Measurements of Selected Molecules over the Mediterranean, Region, Proceedings of ENVISAT valdationWorkshop, Frascati, 9-13 December 2002, ESA SP-531, August 2003.

Bianchini G., Cortesi, U., Palchetti, and Pascale, L. E.: SAFIREA: optimised instrument, configuration and new assessment of spectroscopic performances, Appl. Opt., 43, 2962-2977, 2004.

Boone, C. D., Nassar, R., Walker, K. A., Rochon, Y., McLeod, S. D., and Bernath, P. F.: Retrievals for the atmospheric chemistry experiment Fourier-transform spectrometer, Appl. Opt., 44(33), 7218-7231, 2005.

Bremer, H., von König, M., Kleinböhl, A., Küllmann, H., Bramstedt, K., Burrows, J.P., Eichmann, K.-U., Weber, F., Goede, A. P. H.: Ozone depletion observed by the Airborne Submillimeter Radiometer (ASUR) during the Arctic winter 1999/2000, J. Geophys. Res., 107(D20), 8277, doi:10.1029/2001JD000546, 2002.

Calisesi, Y., Soebijanta, V. T., and van Oss, R.: Regridding of remote soundings: Formulation and application to ozone profile comparison, J. Geophys. Res., 110, D23306, doi:10.1029/2005JD006122, 2005.

Camy-Peyret, C.: Balloon-borne Fourier transform spectroscopy for measurements of atmospheric trace gases, Spectrochim. Acta, 51A, 1143-1152, 1995.

De Mazière, M., Vigouroux, C., Bernath, P. F., Baron, P., Blumenstock, T., Boone, C., Brogniez, C., Catoire, V., Coffey, M., Duchatelet, P., Griffith, D., Hannigan, J., Kasai, Y., Kramer, I., Jones, N., Mahieu, E., Manney, G. L., Piccolo, C., Randall, C., Robert, C., Senten, C., Strong, K., Taylor, J., Tétard, C., Walker, K. A., and Wood, S.: Validation of ACE-FTS v2.2 methane profiles from the upper troposphere to the lower mesosphere, Atmos. Chem. Phys., 8, 2421-2435, 2008, http://www.atmos-chem-phys.net/8/2421/2008/.

Dessler, A. and Kim, H.: Determination of the amount of water vapor entering the stratosphere based on Halogen Occultation Experiment (HALOE) data, J. Geophys. Res., 104(D23), $30605-$ $30607,1999$.

Dudhia, A., Jay, V. L., and Rodgers, C. D.: Microwindow selection 
for high-spectral-resolution sounders, Appl. Opt., 41(18), 36653673, 2002.

Dufour, G., Payan, S., Lefèvre, F., Eremenko M., Butz A., Jeseck, P., Té, Y., Pfeilsticker, K., and Camy-Peyret, C.: 4-D comparison method to study the $\mathrm{NO}_{\mathrm{y}}$ partitioning in summer polar stratosphere - Influence of aerosol burden, Atmos. Chem. Phys., 5, 919-926, 2005,

http://www.atmos-chem-phys.net/5/919/2005/.

Engel, A., Schiller, C., Schmidt, U., Borchers, R., Ovarlez, H., Ovarlez, J.: The total hydrogen budget in the Arctic winter stratosphere during the European Arctic Stratospheric Ozone Experiment, J. Geophys. Res., 101(D9), 14 495-14 504, 1996.

Engel, A., Schmidt, U., McKenna, D., and Fischer, H.: Stratospheric Trends of CFC-12 Over the Past Two Decades: Recent Observational Evidence of Declining Growth Rates, Geophys. Res. Lett., 25(17), 3319-3322, 1998.

Fisher, H. and Oelhaf, H.: Remote sensing of vertical profiles of atmospheric trace constituents with MIPAS limb emission spectrometers, Appl. Opt., 35, 2787-2796, 1996.

Fischer, H., Birk, M., Blom, C., Carli, B., Carlotti, M., von Clarmann, T., Delbouille, L., Dudhia, A., Ehhalt, D., Endemann, M., Flaud, J. M., Gessner, R., Kleinert, A., Koopman, R., Langen, J., López-Puertas, M., Mosner, P., Nett, H., Oelhaf, H., Perron, G., Remedios, J., Ridolfi, M., Stiller, G., and Zander, R.: MIPAS: an instrument for atmospheric and climate research, Atmos. Chem. Phys., 8, 2151-2188, 2008,

http://www.atmos-chem-phys.net/8/2151/2008/.

Friedl-Vallon F., Maucher, G., Seefeldner, M., Trieschmann, O., Kleinert, A., Lengel, A., Keim, C., Oelhaf, H., Fischer, H.: Design and characterization of the balloon-borne Michelson Interferometer for Passive Atmospheric Sounding (MIPAS-B2), Appl. Opt., 43, 3335-3355, 2004.

Frisk, U., Hagström, M., Ala-Laurinaho, J., Andersson, S., Berges, J.-C., Chabaud, J.-P., Dahlgren, M., Emrich, A., Florén, H.G., Florin, G., Fredrixon, M., Gaier, T., Haas, R., Hirvonen, T., Hjalmarsson, Å., Jakobsson, B., Jukkala, P., Kildal, P. S., Kollberg, E., Lassing, J., Lecacheux, A., Lehikoinen, P., Lehto, A., Mallat, J., Marty, C., Michet, D., Narbonne, J., Nexon, M., Olberg, M., Olofsson, A. O. H., Olofsson, G., Origné, A., Petersson, M., Piironen, P., Pons, R., Pouliquen, D., Ristorcelli, I., Rosolen, C., Rouaix, G., Räisänen, A. V., Serra, G., Sjöberg, F., Stenmark, L., Torchinsky, S., Tuovinen, J., Ullberg, Vinterhav, C., E. , Wadefalk, N. , Zirath, H. , Zimmermann, P., and Zimmermann, R.: The ODIN satellite - I. Radiometer design and test, Astron. Astrophys., 402, L27-L34, 2003.

Hase, F.: Inversion von Spurengasprofilen aus hochaufgelösten bodengebundenen FTIR-Messungen in absorption, Dissertation, FZK Report $N^{\circ}$ 6512, Forschungzentrum Karlsruhe, Germany, 2000.

Hase, F., Hannigan, J., Coffey, M. T., Goldman, A., Jones, N., Rinsland, C. P., and Wood, S. P.: Intercomparison of Retrieval Codes Used for the Analysis of High-Resolution, Ground-Based FTIR Measurements, J. Quant. Spectrosc. Radiat. Transfer, 87, 25-52, 2004.

Hauchecorne, A., Godin, S., Marchand, M., Heese, M., and Souprayen, C.: Quantification of the transport of chemical constituents from the polar vortex to midlatitudes in the lower stratosphere using the high-resolution advection model MIMOSA and effective diffusivity, J. Geophys. Res., 107(D20), 8289, doi:10.1029/2001JD000491, 2002.

Höpfner, M., Stiller, G. P., Kuntz, M., von Clarmann, T., Echle, G., Funke, B. Glatthor, N., Hase, F., Kemnitzer, H., and Zorn, S.: The Karlsruhe optimized and precise radiative transfer algorithm, Part II: Interface to retrieval applications, Proceedings of SPIE, 3501, 186-195, 1998.

Höpfner, M., Oelhaf, H., Wetzel, G., Friedl-Vallon, F., Kleinert, A., Lengel, A., Maucher,G. Nordmeyer, H., Glatthor, N., Stiller, G., von Clarmann, T., and Fischer, H.: Evidence of scattering of tropospheric radiation by PSCs in mid-IR limb emission spectra: MIPAS-B observations and KOPRA simulations, Geophys. Res. Lett., 29(8), 1278, doi:10.1029/2001GL014443, 2002.

Huret, N., Pirre, M., Hauchecorne, A., Robert, C., and Catoire, V.: On the vertical structure of the stratosphere at midlatitudes during the first stage of the polar vortex formation and in the polar region in the presence of a large mesospheric descent, J. Geophys. Res., 111, D06111, doi:10.1029/2005JD006102, 2006.

Keim, C., Blom, C. E., von der Gathen, P., Gulde, T., Höpfner, M., Liu, G. Y., Oulanovski, A., Piesch, C., Ravegnani, F., Sartorius, C., Schlager, H., and Volk, C. M.: Validation of MIPASENVISAT by correlative measurements of MIPAS-STR., Proc. ACVE-2 meeting, 3-7 May 2004, Frascati, Italy, ESA SP-562, 2004.

Kiefer, M., von Clarmann, T., Grabowski, U., De Laurentis, M., Mantovani, R., Milz, M., and Ridolfi, M.: Characterization of MIPAS elevation pointing, Atmos. Chem. Phys., 7, 1615-1628, 2007, http://www.atmos-chem-phys.net/7/1615/2007/.

Kleinert, A., Aubertin, G., Perron, G., Birk, M., Wagner, G., Hase, F., Nett, H., and Poulin, R.: MIPAS Level 1B algorithms overview: operational processing and characterization, Atmos. Chem. Phys., 7, 1395-1406, 2007,

http://www.atmos-chem-phys.net/7/1395/2007/.

Kuttippurath, J.: Study of stratospheric composition using airborne submillimeter radiometry and a chemical transport model, Ph.D Thesis, INSB: 3-8325-11069-9, Logos-Verlag, Berlin, 2005.

Lambert, A., Read, W. G., Livesey, N. J., Santee, M. L., Manney, G. 1., Froidevaux, L., Wu, D.L., Schwartz, M. J., Pumphrey, H. C., Jimenez, C., Nedoluha, G. E., Cofield, R. E., Cuddy, D. T., Daffer, W. H., Drouin, B. J., Fuller, R. A., Jarnot, R. F., Knosp, B. W., Pickett, H. M., Snyder, V., Stek, P. C., Thurstans, R.P., Wagner, P. A., Waters, J., W., Jucks, K. W., Toon, G. C., Stachnik, R.A., Bernath, P. F., Walker, K. A., Urban, J., Murtagh, D., Elkins, J. W., and Atlas, E.: Validation of the Aura Microwave Limb Sounder middle atmosphere water vapor and nitrous oxide measurements, J. Geophys. Res., 112, D24S36, doi:10.1029/2007JD008724, 2007.

Mees, J., Crewell, S., Nett, H., de Lange, G., van de Stadt, H., Kuipers, J. J., and Panhuyzen, R. A.: ASUR-an airborne SIS receiver for atmospheric measurements of tracegases at 625 to 760 GHz, IEEE Trans. Microwave Theory Tech., 43, 2543-2548, 1995.

Michelsen, H. A., Manney, G. L., Gunson, R., and Zander, R.: Correlations of stratospheric abundances of $\mathrm{NO}_{y}, \mathrm{O}_{3}, \mathrm{~N}_{2} \mathrm{O}$ and $\mathrm{CH}_{4}$ derived from ATMOS measurements, J. Geophys. Res., 103(28), 359, 1998.

Michelsen, H. A., Manney, G. L., Gunson, M. R., Rinsland, C. P., and Zander R.: Correlations of stratospheric abundances of $\mathrm{CH}_{4}$ 
and $\mathrm{N}_{2} \mathrm{O}$ derived from ATMOS measurements, Geophys. Res. Lett., 25, 2777-2780, 1998.

Moreau G., Robert, C., Catoire, V., Chartier, M., Camy-Peyret, C., Huret, N., Pirre, M., Pomathiod, L., and Chalumeau, G.: SPIRALE: A multispecies in situ balloon-borne experiment with six tunable diode laser spectrometers, Appl. Opt., 44(28), 59725989, 2005.

Murtagh, D., Frisk, U., Merino, F., Ridal, M., Jonsson, A., Stegman, J., Witt, G., Eriksson, P., Jimenez, C., Mégie, G., de La Noëë, J., Ricaud, P., Baron, P., Pardo, J.-R., Hauchecorne, A., Llewellyn, E. J., Degenstein, D. A., GattingerR. L., Lloyd, N. D., Evans, W. F. J., McDade, L. C., Haley, C., Sioris, C., von Savigny, C., Solheim, B. H., McConnell, J. C., Strong, K. Richardson, E. H., Leppelmeier, G. W., Kyrölä, E., Auvinen, H., and Oikarinen, L.: An overview of the Odin atmospheric mission, Can. J. Phys., 80, 309-319, 2002.

Nett, H., Perron, G., Sanchez, M., Burgess, A., and Mossner, P.: MIPAS inflight calibration and processor validation, ENVISAT Calibration Review, Proc. of the European Workshop, ESTEC, Noordwijk, The Nederlands, 9-13 September 2002.

Park, J. H., Russell III, J. M., Gordley, L. L., Drayson, S. R., Benner, D. C., McInerney, J. M., Gunson, M. R., Toon, G. C., Sen, B., Blavier, J.-F., Webster, C. R., Zipf, E. C., Erdman, P., Schmidt, U., and Schiller, C.: Validation of Halogen Occultation Experiment $\mathrm{CH}_{4}$ measurements from the UARS, J. Geophys. Res., 101(D6), 10 183-10 203, 1996.

Payan, S., Camy-Peyret, C., Jeseck, P., Hawat, T., Durry, G., and Lefèvre, F.: First direct simultaneous $\mathrm{HCl}$ and $\mathrm{ClONO}_{2}$ profile measurements in the Artic vortex, Geophys. Res. Letters, 25(14), 2663-2666, 1998.

Payan, S., Camy-Peyret, C., Jeseck, P., Hawat, T., Pirre, M., and Renard, J.-B.: Diurnal and nocturnal distribution of stratospheric $\mathrm{NO}_{2}$ from solar and stellar occultation measurements in the Arctic vortex: Comparison with models and ILAS satellite measurements, J. Geophys. Res., 104(D17), 21 585-21 593, 1999.

Piccolo, C. and Dudhia, A.: Precision validation of MIPAS-Envisat products, Atmos. Chem. Phys., 7, 1915-1923, 2007,

http://www.atmos-chem-phys.net/7/1915/2007/.

Piesch, C., Gulde, T., Sartorius, C., Friedl-Vallon, F., Seefeldner, M., and Wölfel M.: Design of a MIPAS instrument for high altitude aircraft, Proc. of the $2^{\text {nd }}$ Internat. Airborne Remote Sensing Conference and Exhibition, ERIM, Ann Harbor, MI, Vol. II, 199208, 5845, 1996.

Pougatchev, N. S. and Rinsland, C. P.: Spectroscopic study of the seasonal variation of carbon monoxide vertical distribution above Kitt Peak, J. Geophys. Res., 100(D1), 1409-1416, 1995.

Pougatchev, N. S., Connor, B. J., and Rinsland, C. P.: Infrared measurements of the ozone vertical distribution above Kitt Peak, J. Geophys. Res., 100(D8), 16 689-16 697, 1995.

Raspollini, P., Belotti, C., Burgess, A., Carli, B., Carlotti, M., Ceccherini, S., Dinelli, B. M., Dudhia, A., Flaud, J.-M., Funke, B., Höpfner, M., López-Puertas, M., Payne, V., Piccolo, C., Remedios, J. J., Ridolfi, M., and Spang, R.: MIPAS level 2 operational analysis, Atmos. Chem. Phys., 6, 5605-5630, 2006, http://www.atmos-chem-phys.net/6/5605/2006/.

Rinsland, C. P. , Connor, B. J., Logan, J. A., Pougatchev, N. S., Murcray, F. J., Stephen M., Mahieu, E., and Demoulin, P.: Northern and Southern Hemisphere ground-based infrared spectroscopic measurements of tropospheric carbon monoxide and ethane, J.
Geophys. Res., 103(D21), 28 197-28 218, 1998.

Rodgers, C. D.: Retrieval of Atmospheric Temperature and Composition from Remote Measurements of Thermal Radiation, Rev. Geophys., 14(4), 609-624, 1976.

Rodgers, C. D. and Connor, B. J.: Intercomparison of remote sounding instruments, J. Geophys. Res., 108(D3), 4116, doi:10.1029/2002JD002299, 2003.

Rohs, S., Schiller, C., Riese, M., Engel, A., Schmidt, U., Wetter, T., Levin, I., Nakazawa, T., and Aoki, S.: Longterm changes of methane and hydrogen in the stratosphere in the period 1978-2003 and their impact on the abundance of stratospheric water vapor, J. Geophys. Res., 111, D14315, doi:10.1029/2005JD006877, 2006.

Rothman, L. S.,.Barbe, A., Benner, C. D., Brown, L. R., CamyPeyret, C., Carleer, M.R., Chance, K., Clerbaux, C., Dana, V., Devi, V. M., Fayt, A., Flaud, J.-M., Gamache, R. R., Goldman, A., Jacquemart, D., Jucks, K. W., Lafferty, W. J., Mandin, J.-Y., Massie, S. T., Nemtchinov, V., Newnham, D. A., Perrin, A., Rinsland, C. P., Schroeder, J., Smith, K. M., Smith, M. A. H., Tang, K., Toth, R. A., Vander Auwera, J., Varanasi, P., and Yoshino, K.: The HITRAN molecular spectroscopic database : Edition of 2000 including updates through 2001, J. Quant. Spectrosc. Radiat. Transfer, 82, 5-44, doi:10.1016/S0022-4073(03)00146-8, 2003.

Rothman, L. S., Jacquemart, D., Barbe, A., Benner, D. C., Birk, M., Brown Jr., L. R., Chackerian, C., Chance, K., Coudert, L. H., Carleer, M. R., Dana, V., Devi, V. M., Flaud, J.-M., Gamache, R. R., Goldman, A., Hartmann, J.-M., Jucks, K. W., Maki, A. G., Mandin, J.-Y., Massie, S. T., Orphal, J., Perrin, A., Rinsland, C. P., Smith, M. A. H., Tennyson, J., Tolchenov, R. N., Toth, R. A., Vander Auwera, J., Varanasi, P., and Wagner, G.: The HITRAN 2004 Molecular Spectroscopic Database, J. Quant. Spectrosc. Radiat. Transfer, 96, 139-204, doi:10.1016/j.jqsrt.2004.10.008, 2005.

Stiller, G. P., von Clarmann, T., Funke, B., Glatthor, N., Hase, F., Höpfner, F., and Linden, A.: Sensitivity of trace gas abundances retrievals from infrared limb emission spectra to simplifying approximations in radiative transfer modelling, J. Quant. Spectrosc. Radiat. Transfer, 72, 249-280, 2002.

Strong, K., Wolff, M. A., Kerzenmacher, T. E., Walker, K. A., Bernath, P. F., Blumenstock, T., Boone, C., Catoire, V., Coffey, M., De Mazière, M., Demoulin, P., Duchatelet, P., Dupuy, E., Hannigan, J., Höpfner, M., Glatthor, N., Griffith, D. W. T., Jin, J. J., Jones, N., Jucks, K., Kuellmann, H., Kuttippurath, J., Lambert, A., Mahieu, E., McConnell, J. C., Mellqvist, J., Mikuteit, S., Murtagh, D. P., Notholt, J., Piccolo, C., Raspollini, P., Ridolfi, M., Robert, C., Schneider, M., Schrems, O., Semeniuk, K., Senten, C., Stiller, G. P., Strandberg, A., Taylor, J., Tëtard, C., Toohey, M., Urban, J., Warneke, T., and Wood, S.: Validation of ACE-FTS $\mathrm{N}_{2} \mathrm{O}$ measurements, Atmos. Chem. Phys., 8, 47594786, 2008, http://www.atmos-chem-phys.net/8/4759/2008/.

Urban, J., Lautié, N., Le Flochmoën, E., Jiménez, C., Eriksson, P., de La Noë, J., Dupuy, E., El Amraoui, L., Frisk, U., Jégou, F., Murtagh, D., Olberg, M., Ricaud, P., Camy-Peyret, C., Dufour, G., Payan, S., Huret, N., Pirre, M., Robinson, A.D., Harris, P., BremerH., Kleinböhl, A., Küllmann, K., Künzi, K., Kuttippurath, J., Nakajima, H., Sasano, Y., Sugita, T., Yokota, T., Piccolo, C., Raspollini, P., and Ridolfi, M.: Odin/SMR limb observations 
of stratospheric trace gases: Validation of $\mathrm{N}_{2} \mathrm{O}$, J. Geophys. Res., 110, D09301, doi:10.1029/2004JD005394, 2005.

Vigouroux, C., De Maziére, M., Errera, Q., Chabrillat, S., Mahieu, E., Duchatelet, P., Wood, S., Smale, D., Mikuteit, S., Blumenstock, T., Hase, F., and Jones, N.: Comparisons between groundbased FTIR and MIPAS $\mathrm{N}_{2} \mathrm{O}$ and $\mathrm{HNO}_{3}$ profiles before and after assimilation in BASCOE, Atmos. Chem. Phys., 7, 377-396, 2007 , http://www.atmos-chem-phys.net/7/377/2007/.

von Clarmann, T., Ceccherini, S., Doicu, A., Dudhia, A., Funke, S., Grabowski, U., Hilgers, S., Jay, V., Linden, A., MartínTorres, F.-J., López-Puertas, M., Payne, V., Reburn, J., Ridolfi, M., Schreier, F., Schwarz, G., Siddans, R., and Steck, T.: A blind test retrieval experiment for infrared limb emission spectrometry, J. Geophys. Res., 108, 4746, 2003.

von Clarmann, T.: Validation of remotely sensed profiles of atmospheric state variables: strategies and terminology, Atmos. Chem. Phys., 6, 4311-4320, 2006,

http://www.atmos-chem-phys.net/6/4311/2006/. von König, M., Bremer, H., Eyring, V., Goede, A., Hetzheim, H., Kleipool, Q., Kuellmann, H., and Künzi, K.: An airborne submm radiometer for the observation of stratospheric trace gases, in: Microwave Radiometry and Remote Sensing of the Earth's Surface and Atmosphere, edited by: Pampaloni, P. and Paloscia, S., VSP Utrecht, 2000.

Wetzel, G., Oelhaf, H., Friedl-Vallon, F., Kleinert, A., Lengel, A., Maucher, G., Nordmeyer, H., Ruhnke, R., Nakajima, H., Sasano, Y., Sugita, T., and Yokota, T.: Intercomparison and validation of ILAS-II version 1.4 target parameters with MIPAS-B measurements, J. Geophys. Res., 111, D11S06, doi:10.1029/2005JD006287, 2006.

Wetzel, G., Sugita, T., Nakajima, H., Tanaka, T., Yokota, T., FriedlVallon, F., Kleinert, A., Maucher, G., and Oelhaf, H.: Technical Note: Intercomparison of ILAS-II version 2 and 1.4 trace species with MIPAS-B measurements, Atmos. Chem. Phys., 8, 11191126, 2008, http://www.atmos-chem-phys.net/8/1119/2008/.

Wursteisen P.: The validation of ENVISAT Chemistry instruments by use of stratospheric balloon and aircraft, Proceedings of ENVISAT validation Workshop, Frascati, 9-13 December 2002, ESA SP-531, August 2003. 